\title{
A MULTI-LEVEL OPTIMIZATION TECHNIQUE FOR ELECTRICITY CONSUMPTION MANAGEMENT AND PRICING IN RESIDENTIAL NEIGHBORHOODS
}

\author{
by \\ Ramyar Rashed Mohassel
}

Master of Science, Electrical Engineering, Tarbiat Modares University, Tehran, Iran, 2007

Bachelor of Science, Electrical Engineering, University of Tehran, Tehran, Iran, 2003

\author{
A dissertation \\ presented to Ryerson University \\ in partial fulfillment of the requirements for the degree of \\ Doctor of Philosophy \\ in the Program of \\ Electrical and Computer Engineering
}

Toronto, Ontario, Canada, 2017

(C) Ramyar Rashed Mohassel 2017 


\section{AUTHOR'S DECLARATION FOR ELECTRONIC SUBMISSION OF A DISSERTATION}

I hereby declare that I am the sole author of this dissertation. This is a true copy of the dissertation, including any required final revisions, as accepted by my examiners.

I authorize Ryerson University to lend this dissertation to other institutions or individuals for the purpose of scholarly research.

I further authorize Ryerson University to reproduce this dissertation by photocopying or by other means, in total or in part, at the request of other institutions or individuals for the purpose of scholarly research.

I understand that my dissertation may be made electronically available to the public. 


\title{
A MULTI-LEVEL OPTIMIZATION TECHNIQUE FOR ELECTRICITY CONSUMPTION MANAGEMENT AND PRICING IN RESIDENTIAL NEIGHBORHOODS
}

\author{
Ramyar Rashed Mohassel \\ Doctor of Philosophy in Electrical and Computer Engineering \\ Ryerson University, 2017
}

\begin{abstract}
With the introduction of new technologies, concepts and approaches in power transmission, distribution and utilization such as Smart Grids (SG), Advanced Metering Infrastructures (AMI), Distributed Energy Resources (DER) and Demand Side Management (DSM), new capabilities have emerged that enable efficient use and management of power consumption. These capabilities are applicable at micro level in households and building complexes as well as at macro level for utility providers in form of resource and revenue management initiatives. On the other hand, integration of Information Technology (IT) and instrumentation has brought Building Management Systems (BMS) to our homes and has made it possible for the ordinary users to take advantage of more complex and sophisticated energy and cost management features as an integral part of their BMS.

The idea of combining capabilities and advantages offered by SG, AMI, DER, DSM and BMS is the backbone of this thesis and has resulted in developing a unique, two-level optimization method for effective deployment of DSM at households and residential neighborhoods. The work consists of an optimization algorithm for households to maximize utilization of DER as the lower level of the envisioned two-level optimization technique while using a customized Game Theoretic optimization for optimizing revenue of utility providers for residential neighborhood as the upper level. This work will also introduce a power management unit, called Load
\end{abstract}


Moderation Center (LMC), to host the developed optimization algorithms as an integrated part of BMS. LMC, upon successful completion, will be able to automatically plan consumption, effectively utilize available sources including grid, renewable energies and storages, and eliminate the need for residences to manually program their BMS for different market scenarios. 


\section{ACKNOWLEDGMENTS}

I would like to express my sincere appreciation to my supervisor Dr. Kaamran Raahemifar for his continuous support and constant presence beside me. He has not been just an academic supervisor but a noble, down to earth, kind and considerate brother who helped me in my personal, professional and academic lives.

A very special thanks goes to my co-supervisor, Dr. Farah Mohammadi, who paved my way for pursuing my interest as my $\mathrm{PhD}$ thesis. Without her patience, guidance and understanding, completion of this task was not possible.

I have to express my deepest gratitude to my parents who were my motivation and driving force throughout my life. I see their presence in every single achievement I had in my life.

I would like to express my gratitude for my sister's extended helping hand and support.

Last but not least, a very special thanks to my wife and her family who encouraged and supported me throughout my $\mathrm{PhD}$.

To conclude, this work would have not been possible without all the support from my friends, lab mates and Ryerson staff and specifically Avishek Banerjee who was instrumental in this project; wish them all the best in their future endeavors. 


\section{TABLE OF CONTENTS}

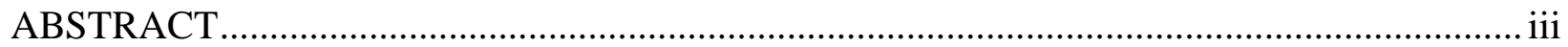

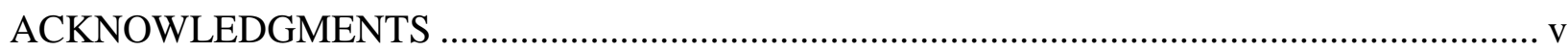

TABLE OF CONTENTS .......................................................................................... vi

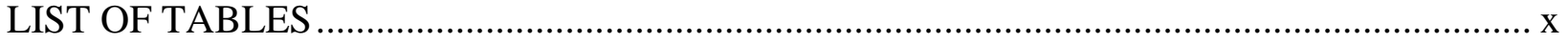

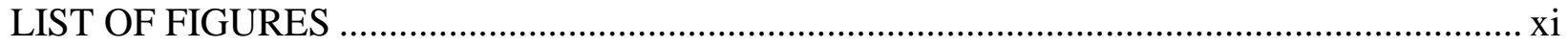

LIST OF ABBREVIATIONS/ACRONYMS ................................................................... xiii

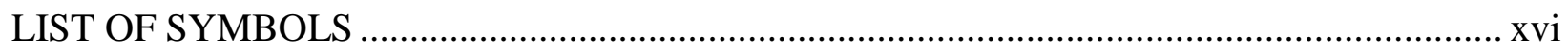

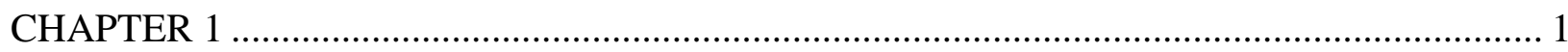

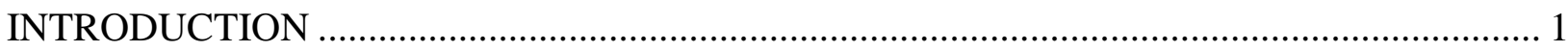

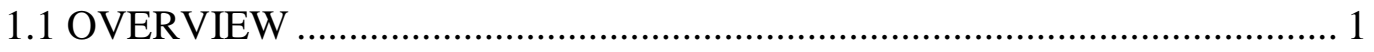

1.2 OUTCOME ..................................................................................... 3

1.3 CONTRIBUTIONS ........................................................................ 5

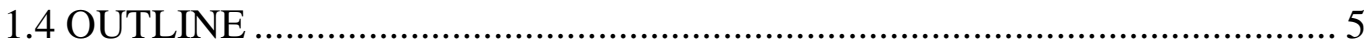

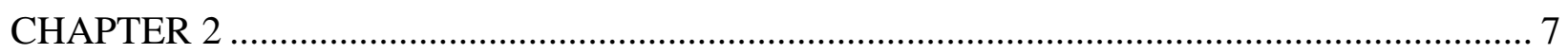

RESEARCH OBJECTIVES AND APPROACH ........................................................ 7

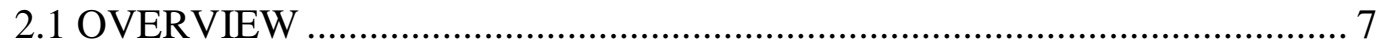

2.2 PROBLEM FORMULATION ........................................................... 8

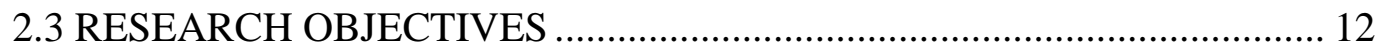

2.4 RESEARCH METHODOLOGY ............................................................ 13

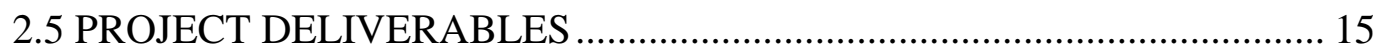

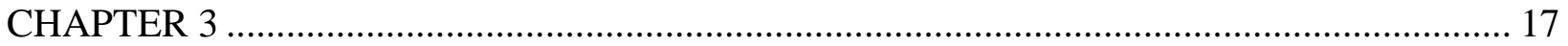

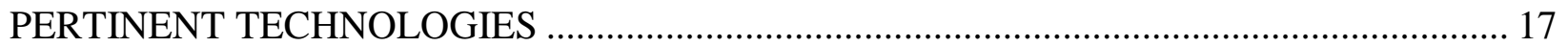

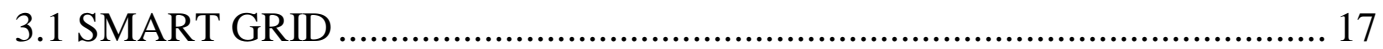

$\mathrm{vi}$ 


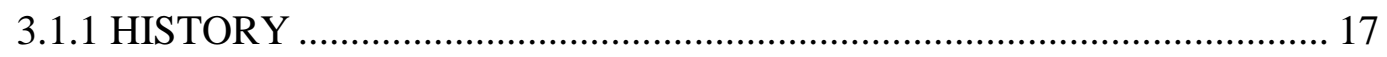

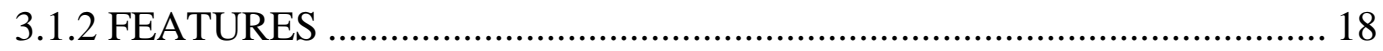

3.1.3 SUB-SYSTEMS _............................................................................. 22

3.2 ADVANCED METERING INFRASTRUCTURE .................................... 25

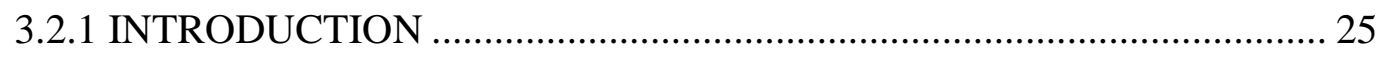

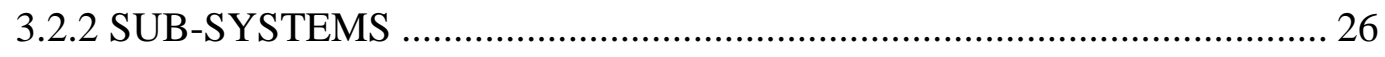

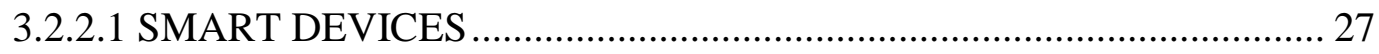

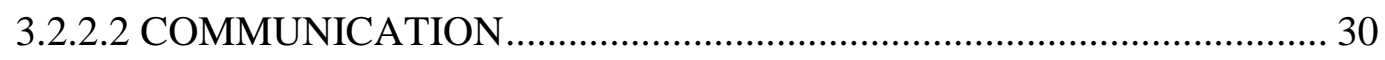

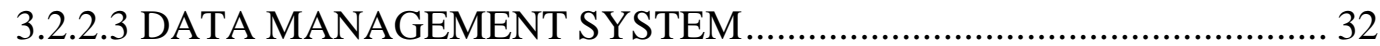

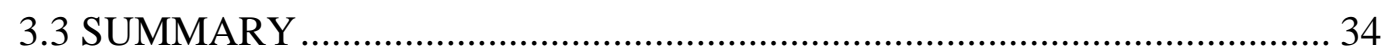

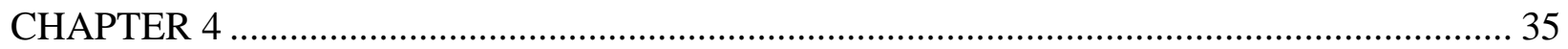

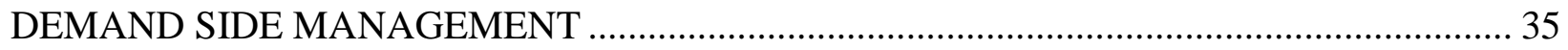

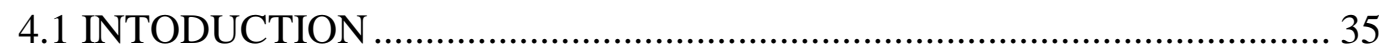

4.2 DSM BACKGROUND, OBJECTIVES AND BOTTLENECKS ................. 36

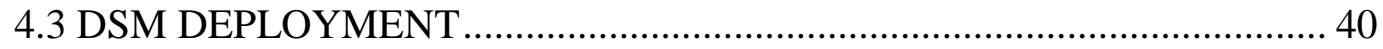

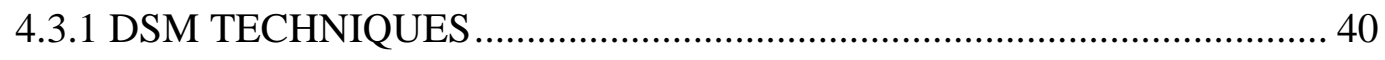

4.3.2 DSM APPROACHES AND IMPLEMENTATION ................................. 42

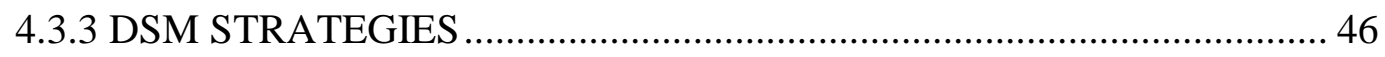

4.4 DISTRIBUTION SYSTEM AUTOMATION (DSA) .................................. 47

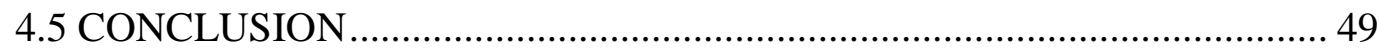

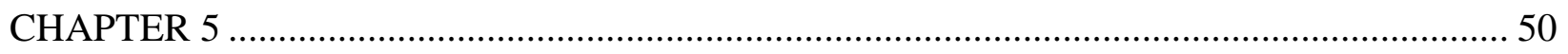

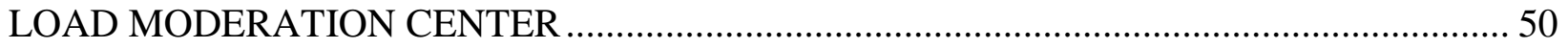

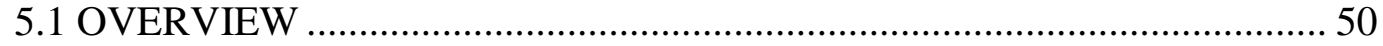

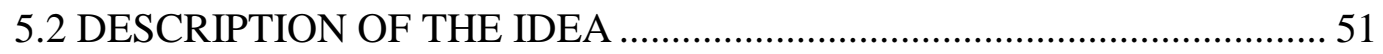

vii 


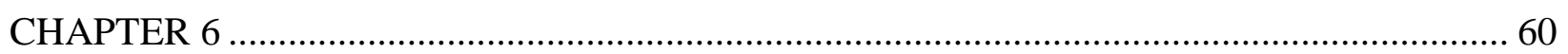

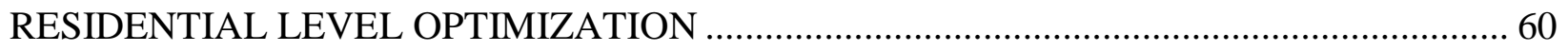

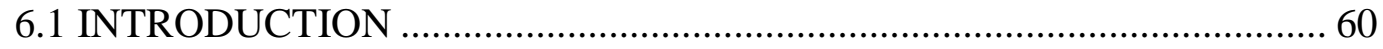

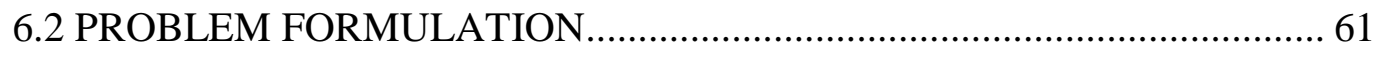

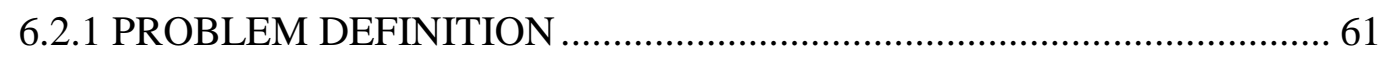

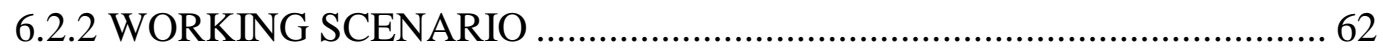

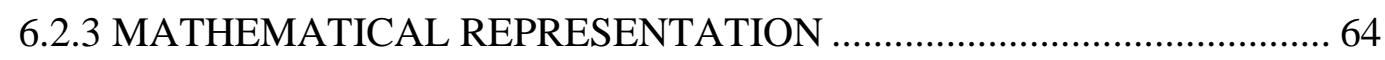

6.3 OPTIMIZATION METHODS AND SIMULATION CASES....................... 67

6.3.1 MATHEMATICAL ANALYSIS OF THE EQUATION_............................ 67

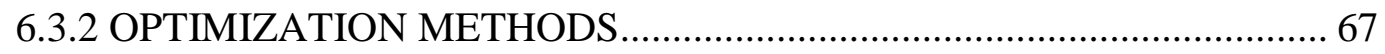

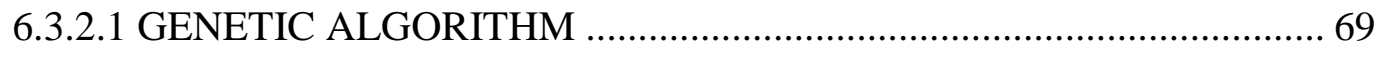

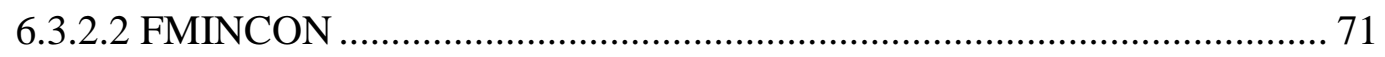

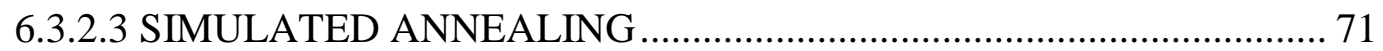

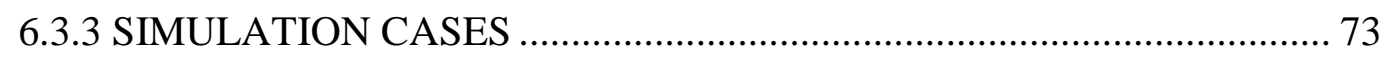

6.4 SIMULATION RESULTS AND COMPARISON ....................................... 77

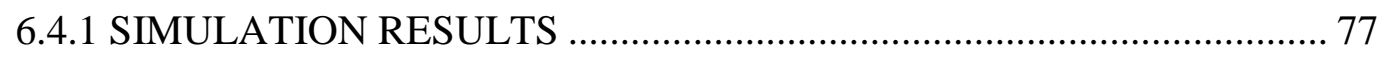

6.4.2 COMPARABLE WORKS IN THE LITERATURE ................................. 79

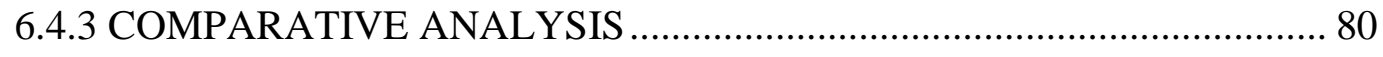

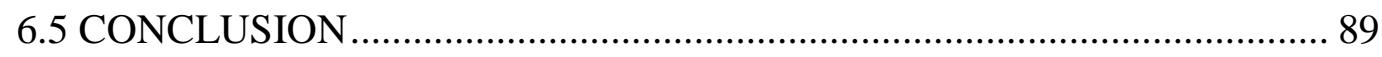

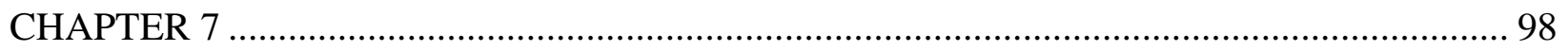

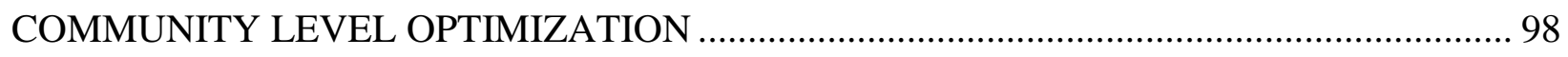

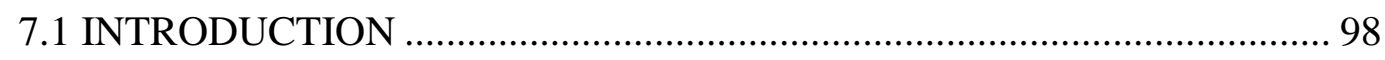




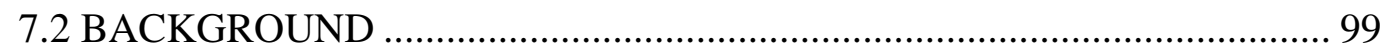

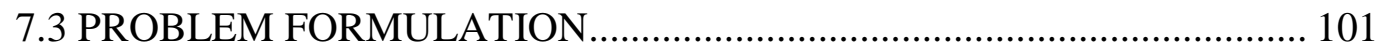

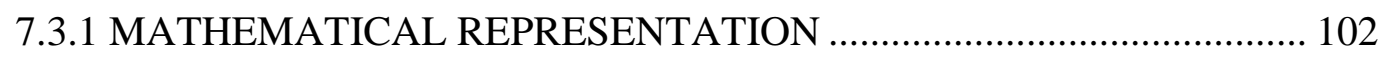

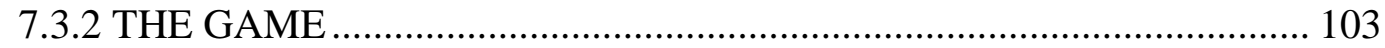

7.4 SIMULATION CASES AND RESULTS …………….......................... 106

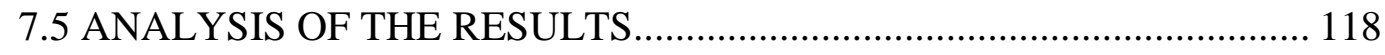

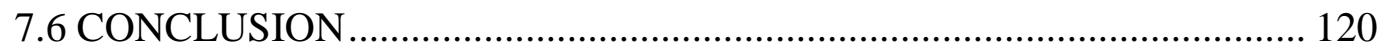

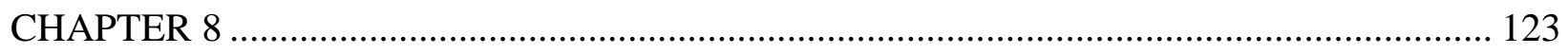

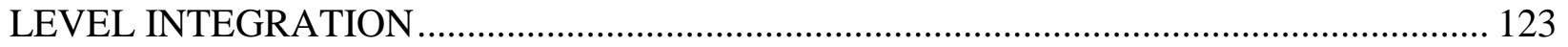

8.1 OVERVIEW …………………………………............................... 123

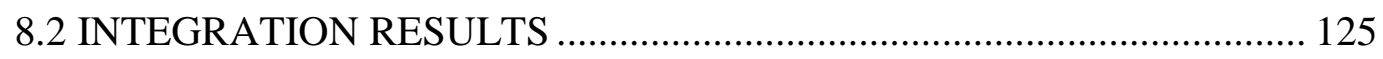

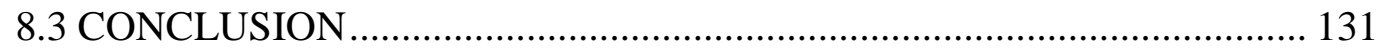

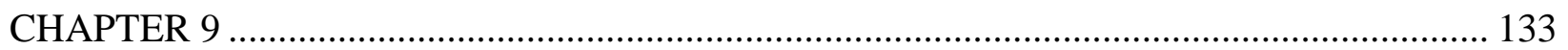

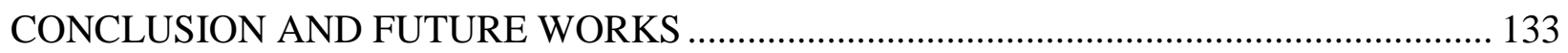

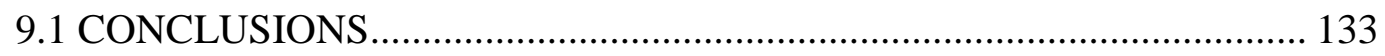

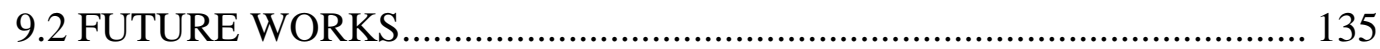

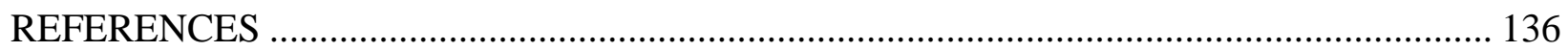




\section{LIST OF TABLES}

Table 4.1: Examples of DSM Techniques and Their Impact on Load Shape 47

Table 6.1: Household Level Optimization Simulation Results Based on GA Method 78

Table 6.2: Household Level Optimization Simulation Results Based on Fmin Method 78

Table 6.3: Household Level Optimization Simulation Results Based on SA Method 78

Table 6.4: Comparison of GA and SA Results for Case 1 Under New Condition 91

Table 6.5: Comparison of GA and SA Results for Case 2 Under New Condition 92

Table 6.6: Comparison of GA and SA Results for Case 3 Under New Condition 92

Table 6.7: Comparison of GA and SA Results for Case 4 Under New Condition 92

Table 6.8: Comparison of GA and SA Results for Case 5 Under New Condition 92

Table 6.9: Comparison of GA and SA Results for Case 6 Under New Condition 92

Table 7.1: Hourly Demand Rates Based on Toronto's ToU Pricing 106

Table 7.2: Demand-Supply-Price for Case 1 107

Table 7.3: Demand-Supply-Price for Case 2

Table 7.4: Demand-Supply-Price for Case $3 \quad 109$

Table 7.5: Demand-Supply-Price for Case 4

Table 7.6: Demand-Supply-Price for Case 5 112

Table 7.7: Demand-Supply-Price for Case 6

Table 7.8: Demand-Supply-Price for Case 7 114

Table 7.9: Demand-Supply-Price for Case 8

Table 7.10: Minimum, Maximum and Optimum Values of Objective Function per Case 120

Table 8.1: Simulation Results of the Integrated Optimization Approach Case 1

Table 8.2: Simulation Results of the Integrated Optimization Approach Case 2 


\section{LIST OF FIGURES}

Fig. 3.1: Smart Grid Sub-System Sequence Overview 23

Fig. 3.2: Schematic of AMI $\quad 25$

Fig. 3.3: Overview of AMI 26

Fig. 3.4: AMI Communication Network Overview 31

Fig. 4.1: DSM Deployment Procedure 45

Fig. 4.2: Simplified Form of Load-Shape Changes 46

Fig. 5.1: Overview and Connections of Proposed LMC 52

Fig. 6.1: An Overview of Household Level Problem Formulation 62

Fig. 6.2: Comparative Overview of the Results by GA Method for Cases 1,3 and $5 \quad 81$

Fig. 6.3: Comparative Overview of the Results by GA Method for Cases 2, 4 and $6 \quad 82$

Fig. 6.4: Comparative Overview of the Results by Fmincon Method for Cases 1, 3 and 583

Fig. 6.5: Comparative Overview of the Results by Fmincon Method for Cases 2, 4 and 684

Fig. 6.6: Comparative Overview of the Results by SA Method for Cases 1, 3 and $5 \quad 85$

Fig. 6.7: Comparative Overview of the Results by SA Method for Cases 2, 4 and $6 \quad 86$

Fig. 6.8: Comparative Overview of the Results for DER1 Using Different Methods 87

Fig. 6.9: Comparative Overview of the Results for DER2 Using Different Methods $\quad 88$

Fig. 6.10: Comparative Overview of the Results for DER3 Using Different Methods 88

Fig. 6.11: Comparative Overview of the Results for DER4 Using Different Methods 89

Fig. 6.12: Comparative Overview of the Results for Grid Using Different Methods 89

Fig. 6.13: Comparative Overview of Second Simulation, GA Method, Cases 1, 3, $5 \quad 93$

Fig. 6.14: Comparative Overview of Second Simulation, GA Method, Cases 2, 4, $6 \quad 94$ 
Fig. 6.15: Comparative Overview of Second Simulation, SA Method, Cases 1, 3, $5 \quad 95$

Fig. 6.16: Comparative Overview of Second Simulation, SA Method, Cases 2, 4, $6 \quad 96$

$\begin{array}{ll}\text { Fig. 7.1: Equilibrium Points for Case } 1 & 108\end{array}$

Fig. 7.2: Equilibrium Points for Case 2 109

Fig. 7.3: Equilibrium Points for Case 3 110

Fig. 7.4: Equilibrium Points for Case $4 \quad 111$

Fig. 7.5: Equilibrium Points for Case 5 112

Fig. 7.6: Equilibrium Points for Case $6 \quad 113$

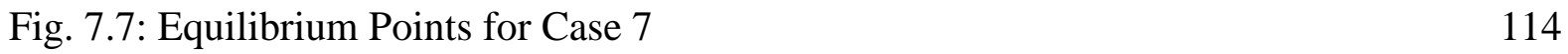

Fig. 7.8: Equilibrium Points for Case 8 115

Fig. 7.9: Summer Vs. Winter results (1) 116

Fig. 7.10: Summer Vs. Winter results (2) 117

Fig. 8.1: Interaction between Two Levels of Optimization 124 


\section{LIST OF ABBREVIATIONS/ACRONYMS}

AAM

ADO

ADP

AMI

AMR

ASI

ATO

BMS

BPL

BPL

CAN

DAC

DER

DR

DSA

DSM

EDRP

EMS

EV

GA

GT
Advanced Asset Management

Advanced Distribution Operations

Adaptive Dynamic Programming

Advanced Metering Infrastructure

Automatic Meter Reading

Asynchronous Serial Interface

Advanced Transmission Operations

Building Management System

Broadband over Power Line

Broadband PLC

Control Area Network

Distribution Automation and Control

Distributed Energy Resources

Demand Response

Distribution System Automation

Demand Side Management

Emergency Demand Response Program

Energy Management System

Electric Vehicle

Genetic Algorithm

Game Theory 


\begin{tabular}{|c|c|}
\hline GTO & Game Theoretic Optimization \\
\hline HAN & Home Area Network \\
\hline IaaS & Infrastructure as a Service \\
\hline IHD & In-Home Displays \\
\hline IT & Information Technology \\
\hline KW & Kilo Watts \\
\hline $\mathrm{KWh}$ & Kilo Watt Hour \\
\hline LEED & Leadership in Energy and Environmental Design \\
\hline $\mathrm{LM}$ & Load Management \\
\hline LMC & Load Moderation Center \\
\hline LP & Linear Programming \\
\hline LRP & Load Response Program \\
\hline LS & Load Signature \\
\hline LSM & Load Signature Moderation \\
\hline LTE & Long Term Evolution \\
\hline MD & Maximum Demand \\
\hline MDMS & Meter Data Management Systems \\
\hline MW & Mega Watts \\
\hline OWA & Ordered Weighted Aggregation \\
\hline PLC & Power Line Communications \\
\hline PoE & Power over Ethernet \\
\hline PQ & Power Quality \\
\hline
\end{tabular}




$\begin{array}{ll}\text { PV } & \text { Photo Voltaic } \\ \text { RE } & \text { Renewable Energy } \\ \text { SA } & \text { Simulated Annealing } \\ \text { SCADA } & \text { Supervisory Control and Data Acquisition } \\ \text { SG } & \text { Smart Grid } \\ \text { SM } & \text { Smart Meter } \\ \text { ToU } & \text { Time Of Use }\end{array}$




\section{LIST OF SYMBOLS}

$\begin{array}{ll}P_{p} & \text { Preferred price at which household is willing to buy from the grid } \\ P_{e} & \text { Equilibrium market price at which the energy trade will occur } \\ \alpha_{i} & \text { The weight factor assigned to the DER } i \\ \alpha_{j+1} & \text { The weight factor assigned to the grid } \\ X_{i} & \text { Required optimized amount of contribution from source } i \text { to supply } \\ & \text { the household demand } \\ X_{j+1} & \text { Required optimized amount of contribution from the grid to supply } \\ & \text { the household demand } \\ M_{h} & \text { Number of communities } \\ P_{h} & \text { Trading price for the } h^{\text {th }} \text { time slot } \\ d_{h} & \text { Community demand for the } h^{\text {th }} \text { time slot } \\ E_{h} & \text { Amount the Grid can supply during the } h^{\text {th }} \text { time slot } \\ C_{h} & \text { Cost of electricity generation for the } h^{\text {th }} \text { time slot } \\ P^{*} & \text { Equilibrium price for trading electricity } \\ Q^{*} & \text { Micro (10 }\end{array}$




\section{CHAPTER 1}

\section{INTRODUCTION}

\subsection{OVERVIEW}

The emerging challenges and concerns in the energy market of the $21^{\text {st }}$ century have made the changes in electrical systems inevitable. These changes include altering and advancing the conventional ways of generation, transmission and distribution of power. However, the newly developed technologies brought new challenges with themselves. Some major challenges to power industry are [1]:

- Effective utilization of Distributed Energy Resources (DER)

- Improvement of delivered power quality

- Environmental concerns over conventional and centralized methods of power generation

- Privacy of consumer's information

- Security of the system against external cyber or physical attacks

- Economics of power systems

- Needs for better control schemes for complex systems

- Effective involvement of consumers in consumption management

- Increase in power demand

One main challenge is to develop control schemes that are able to address numerous uncertainties due to load distribution and integration of new sources of energy, as well as integration of electrical storage systems into the grid [2]. Challenges such as improved power quality or economics of power systems have been the concern of utility providers and engineers for many years; however, security threats and privacy of information are the emerging challenges 
resulted from incorporation of new technologies. Utilization of DER is gaining attention as Renewable Energy (RE) plays an important role in sustainability of the system. RE is abundant, naturally restorable and has minimum environmental impacts. A number of different technologies have been developed to convert RE resources, such as wind and solar, into usable electricity. Although DER are part of the solution, they are not easy to use since their inherently sporadic nature, which produces irregular power, adds to the complexity of the grids and thus their control systems. Europe and North America modernized their energy generation and distribution systems and switched to Smart Grid (SG) to address some of these challenges. The last decades of the $20^{\text {th }}$ century experienced an increase in electric demand due to the introduction of new consumers, such as entertainment industry, and dependency on electricity as the main source of heat and ventilation. Furthermore, there were significant fluctuations in the rate of energy consumption. With increased demand at peak times, generation plants were required to prevent from voltage drops and decline in power quality more frequently. On the other hand, the consumption rates were lower at night time causing an unbalanced consumption that left the plants' production capacity idle. Therefore, to promote a more even consumption pattern, the electricity industry tried to encourage its consumers to manage their consumption through offered incentives by changing its approach to Demand Side Management (DSM). The improvements in Information Technology (IT) and communication industries along with introduction of smart sensors eliminated the restriction of precise consumption measurement for each consumer and allowed adaptive billing mechanisms to financially motivate consumers to shift their consumption to off-peak times. Improvement in RE, combined with environmental 
concerns led to integration of these technologies into electrical systems to form decentralized generation. Electrical storage systems were also developed to address power management issues [3]. These developments were the beginning of the flourishing of a new concept known as SG.

Smart Grids modernized the traditional concept and functionality of electrical grids by using Information Technology to obtain network components' data from power producers and consumers, and use them properly to maximize the efficiency and reliability of the system. There is no clear or fully agreed boundary and definition for intelligence of a Smart Grid, as there are a number of factors involved in designing such a system. However, it is unanimous that for an efficient SG design, interaction among three fields of communication, control and optimization is essential. The development of SG requires new design and analysis tools. In particular, there is a need for new models and algorithms to characterize the emerging SG in terms of communication and control, heterogeneous nature of the SG and signal processing at various levels (i.e., household, community, city and country).

The intention of this $\mathrm{PhD}$ thesis is to investigate and utilize a novel way of load management and consumption moderation at both community and household levels while maximizing utilization of RE and alleviating consumers' privacy concerns.

\subsection{OUTCOME}

The main outcome of this $\mathrm{PhD}$ thesis is to address two challenges of SG:

- Load handling and demand adjustment: the total load connected to the grid is not a fixed amount and changes significantly based on many factors. Consumption habits, weather and climate changes or natural phenomena can alter the network load considerably. Instant changes in consumption can cause stability issues for the grid. Providers currently 
use standby generators to address such increase in demand. This method is not economical. SG can help tackle this challenge in two ways: by adjusting the demand on consumer's side through DSM initiatives; or by automatically adjusting household consumption through changing set points or altering appliance working schedule. This work tends to introduce approaches based on DSM definition for load management at consumer end. This consumption management will be carried out at two levels: residential households and residential community level.

- Flexibility and sustainability: Considering the increase in demand, cost, safety and scarcity of conventional sources such as fossil fuel and nuclear energy, environmental concerns and advancement in technology, the best approach for having a sustainable energy grid is to incorporate renewable energy sources. Renewable or green energies include solar, wind and geothermal electricity. The technological advancements in these fields along with advanced storage systems have made utilization of DER a must in new generation of grids. Demand Response (DR) schemes or power demand regulating efforts depend largely on DER utilization. Due to technical issues associated with each system, the SG should have the flexibility to incorporate these technologies with least possible glitch. RE resources have associated variability, uncertainty, and unpredictability that result in short term intermittency causing power fluctuations and medium to long term intermittency causing energy supply interruptions, all of which contribute to nondispatchability. To incorporate DER, service providers should tackle a number of problems to overcome the aforementioned nondispatchability. This thesis aims to realize the utilization of DER at household level, easing the burden on service providers. Incorporation of DER at residential units is easier as far less uncertainty and controllability issues are involved, maximum transmitted and used power is in the range of Kilo Watts (KW) rather than Mega Watts (MW), maintenance and troubleshooting is much easier without affecting supply to a large area, and smaller thus cheaper storage and auxiliary systems are needed for regulating them. 


\subsection{CONTRIBUTIONS}

This work focuses on load management in SGs through DSM initiatives while addressing two other main concerns in SGs: maximized utilization of RE and DER, as well as ensuring market clearing through competitive pricing. The contributions of this work in particular are:

1. Introduction and utilization of Load Moderation Center (LMC) for load management at residential buildings

2. Maximizing utilization of DER through LMC decision making mechanism based on known optimization techniques

3. Application of Game Theoretic Optimization (GTO) techniques at community level for optimal allocation of grid capacity to demanding households based on generation and price conditions as part of DSM scheme.

As a consequence of the implemented strategy, it is expected that privacy of users' information will be protected by masking load signatures through utilization of LMC which makes load profiling impossible at metering points.

\subsection{OUTLINE}

This chapter provided an overview of power industry in modern era, and the challenges and areas of improvement this proposed research intends to cover. The rest of this dissertation is organized as follows:

Chapter 2 explains the problem formulation, research objectives and deliverables as well as methodology.

In chapter 3 highlights of the pertinent concepts and technologies will be provided.

Chapters 4 and 5 provide detailed information on DSM and LMC, respectively, including literature review, current practice and challenges as well as their role in this work. 
The load management and DER utilization optimization along with this work's contribution at end user level will be presented in detail in chapter 6 .

In chapter 7, the competitive equilibrium price calculation and this work's contribution at community level will be presented in detail.

Chapter 8 entails the work on integration of the methods presented in chapters 6 and 7 to create a uniform optimization scheme.

The final chapter, chapter 9, presents conclusion of the work and suggestions for future work in this domain. 
Ryerson University $\quad$ Chapter 2: RESEARCH OBJECTIVES \& APPROACH 2017

\section{CHAPTER 2}

\section{RESEARCH OBJECTIVES AND APPROACH}

\subsection{OVERVIEW}

Energy conservation and demand adjustment are two main sought-after objectives in recent research projects. These two factors, along with the cost optimization resulted from asset management, efficient utilization of equipment and reduced maintenance costs, are the main sources of financial benefits for end users. As it will be explained in the forthcoming chapters, separate works have been done by different entities that are roughly similar to some aspects of the work proposed in this thesis. From energy saving aspect, the study by SensorSuite Company [4] showed 25\% saving in monthly utility bills for a 200-unit apartment building by means of monitoring and controlling boilers and air conditioning units in portfolio of 15 buildings. This was accomplished through a combination of peak demand controlling and throttling the boiler units to reduce energy consumption without affecting the tenants' comfort level. In a similar study, Navigant Consulting Ltd. [5] showed that sub-metering in multi-residential buildings reduced the average electricity consumption by $34 \%$ for non-electrically heated buildings, and by $27 \%$ for electrically heated buildings. In another work, National Science and Technology Council (NSTC) showed that $60 \%$ to $80 \%$ of the consumed energy in commercial buildings was used by tenants within their offices [6]. There are few technologies and techniques that can reduce this amount of consumption without requiring changes in the network and hence major costs. 
The numbers mentioned above justify any research or product development carried out with the goal of reducing and regulating energy consumption in buildings. The benefits of the proposed idea are not limited to energy conservation and cost optimization. As explained before, there is a correlation between SG and SM, therefore, the security of network and privacy of information are critical for both customers and utility providers. The proposed two-level optimization scheme can also enhance the security of such data collecting networks or specifically AMI by empowering privacy of consumer's information through load signature moderation. Thus, security is another functionality of the proposed system and safeguarding consumer's data is another motivation behind this work.

A further application for the proposed system is in green energy field. The product is capable of effective utilization of renewable energies such as solar and wind as well as incorporating electrical storages including batteries and electric vehicles. This system will facilitate the usage of DER at residential buildings; home owners or owners of buildings with a small number of units can also take advantage of this work as it will provide an affordable solution for them. This can increase the prevalence of DER usage by general public and promote utilization of clean energy.

\subsection{PROBLEM FORMULATION}

Developed countries started to take advantage of SG years ago due to numerous factors including technological advancement in DER, storages, communication systems and instrumentation as well as concerns regarding energy conservation and environment. SG is dependent on the data collected from loads at customer's end. This data is mainly collected and transmitted to the 
utility end using SM and through AMI. The functionality and success of SG is therefore very much dependent on establishment and functionality of AMI and SMs. AMI has Home Area Network (HAN) at its lower level. HANs are to connect SMs, other smart devices within the home premises, energy storage and generation (solar, wind, etc.) equipment, electric vehicles as well as In-Home Displays (IHD) and controllers together. Growing demand for energy and energy conservation plans urged condominium, multi-residential buildings as well as other property owners to look for ways to reduce consumption and costs. BMS or Energy Management Systems (EMS) are capable of fulfilling this task in residential and commercial/industrial complexes through managing building utility plants and network of smart devices, e.g. light, carbon monoxide or occupancy sensors. Programs such as Leadership in Energy and Environmental Design (LEED) or Energy Star are part of the efforts to create more energy efficient and green buildings.

DSM or Demand Response (DR) is another effort to regulate consumption by consumers and at their end. Federal Energy Regulatory Commission defines DR as changes in the electric consumption pattern of end users over time in response to changes in the price of electricity, or to incentive payments designed to encourage lower electricity usage at times of high wholesale market prices, or when system reliability is threatened [7]. DR can have different forms; changing the time of use, modifying consumption pattern or reducing the number of loads, all done by consumers and voluntarily. DR is meant to decrease electricity consumption or shift it from peak to off-peak periods; therefore, it is largely dependent on the habits and behavior of occupants in one household. Occupants must act based on the received price signal from utility 
provider, or intentionally based on the incentives provided by utility company or government. In SG, the price signal can be instantaneous as the decisions are made based on near real-time data collected by SM. Considering the numerous parameters and players involved in DR, it is clear that an automated mechanism should assist residents in the process of decision making to best manage consumption or their loads.

On the other hand, DER are vital in successful implementation of DR. DER include all available sources of energy that unlike conventional centralized plants, can work independent from each other in different locations, with minimum or no destructive effect on their surrounding environment. As these power sources are not constant and available at all times due to their dependency on external conditions such as weather, their effective and in time utilization can replace power supplied by grid at different times. Recent technological improvements in the area of DER made DR more realistic. A tool that is able to incorporate DER and schedule usage based on household demand and grid status is therefore of high importance. Once again, as various parameters are involved in utilization of DER, a mechanism is needed to assist residents in proper and punctual utilization of their available DER.

BMS uses sensors and smart devices that are placed strategically inside the building to measure and collect the required data for analysis. Similarly, AMI uses SMs to collect real-time consumption data of the loads. The frequency by which the data is collected varies based on the type of data. Critical information, such as state of a boiler, needs to be collected with higher frequency, while the outside temperature can be collected with longer intervals. All collected data shall be transmitted and stored at utility provider end for further analysis and decision 
making. The security of these data is of high importance as by analyzing this data, it is possible to perform "consumer profiling" with an alarming high accuracy. With the help of computeraided algorithms, one is able to extract the unique signatures of individual appliances from the collected data with higher time intervals and therefore, less detailed information. Even without having detailed signatures of appliances or previous training, it is possible to identify usage patterns from AMI data, using available general statistical schemes [8]. Having this much detailed information is one of the objectives of SG that facilitates DR, distributed generation management, grid optimization, efficient billing and peak saver programs. However, this can backfire when used without the consent of the owner (consumer) or authorities as well as unauthorized usage by third parties. It is possible to protect consumers from such consumer profiling through contemplated utilization of DER; however, this process should be done with the help of computer-aided optimization techniques.

Based on what was explained in this chapter, it is now possible to summarize and formulate the problem this thesis addresses.

It is desired to have a system that deploys DSM initiatives by incorporating DER in residential units. Due to nondispatchability of DER, and since SG as the platform that allows for DSM and DER utilization depends on AMI and SMs for real-time data collection, an assistive tool or a mechanism is needed to help the occupants of residential units with such approach and provide them with the required hardware and software to carry out such scheme.

This thesis introduces LMC as the hardware for such plan and will employ optimization techniques as the software embedded in the LMC. This thesis focuses on residential units and 
will perform optimization at two levels of household and community. The details, approach and deliverables of this research work will be outlined hereafter.

\subsection{RESEARCH OBJECTIVES}

Based on the provided problem formulation, the novelties associated with this proposal and the objectives can be summarized as:

A) Allocating power to loads using LMC

B) Integration of existing features of BMS and AMI into one device; energy preservation and DSM, efficient utilization of DER and security of collected and transmitted information

C) Eliminating the risk of load profiling at SM point through utilization of energy storages and LMC

D) Development of proper decision making scheme to be embedded in LMC based on known optimization techniques at residential level

E) Development of a proper decision making scheme based on Game Theoretic Optimization technique at the community level

F) Combining the two levels of optimized decision making process for enhanced DSM deployment

The final product will perform the following primary tasks:

- Energy preservation through automatic demand regulation by noninvasive approaches that do not harm users or affect their comfort

- Efficient and effective utilization of DER based on their availability, grid status and price signal, internal demand of the building and outside condition

- Minimizing the possibility of load profiling by means of load signature moderation 
The contribution of this thesis is to employ GTO to match demand and price at the community level, an approach that has not been widely studied for this application so far. At the residential level, this thesis contributes by incorporating an optimization technique in the introduced LMC as the medium for decision making for optimized allocation of power sources to demanding loads, the process that has not been generally automated for households. Currently, occupants manually allocate power to loads such as washing machines or ventilation systems based on their understanding of Time of Use (ToU) approach.

The approach for realization of each objective has been defined in details in the methodology section.

The long-term objectives of this research program, that can be considered as the future works, are as follows:

A) Expanding the system for industrial building application

B) Incorporation of asset optimization schemes

C) Incorporation of Big Data analysis and Data Analytics tools

D) Integration of more advanced applications (e.g. fire detection and access controls) into the system

E) Load prediction and in advance resource allocation planning

F) Occupant behavior analysis for optimization of system performance (trainable system)

\subsection{RESEARCH METHODOLOGY}

A) Formulating the requirements, expected functionalities and limitations for each of the two levels of decision making 
B) Deriving the objective functions based on the requirements and assumptions while considering the proper constraints for residential level

C) Adopting the best optimization technique, applying the required modifications and improvements to be embedded in LMC for residential level power allocation decision making D) Deriving the objective functions based on the requirements and assumptions while considering the proper constraints for community level

E) Developing the best optimization technique based on game theoretic approach for community level power allocation decision making process

F) Analysis and verification of the results.

The system will be validated under different operating conditions, at both community and residential levels, considering the known effective factors including:

- Weather condition (unavailability of solar or wind powers, etc.)

- Occupants' preferences (demand)

- load and grid uncertainties

- Island mode of operation (disconnected from grid)

- Peak saver condition

The following performance parameters will be examined:

- Comfort of occupants

- Energy preservation

- Performance of optimization schemes

- Effective utilization of DER in the grid

- Supply \& demand balance

- Cost optimization 
- Response time

To do so, simulations will be done using MATLAB at laboratory environment under different working scenarios that mimic real world situations.

\subsection{PROJECT DELIVERABLES}

This thesis, upon completion, delivers the following results:

- At consumer end (residential unit level):

1. A proper objective function and all required constraints that best model the application in hand

2. Best available optimization technique to be applied to the objective function

3. Satisfactory simulation results based on the following criteria:

- Minimizing the cost of electricity from the grid

- Maximizing the share of RE sources in the overall supply trend

- Supplying demanding loads by the storage throughout the day while keeping the storage's stored electricity at optimal level by enforcing proper charging cycles

- Proper response time

- The most simplified approach as the optimization process should be embedded in the LMC hardware and extra cost due to complexity is not desirable

- At the community level:

1. A proper objective function and all required constraints that best model the application in hand

2. A game theoretic optimization process to be applied to the objective function

3. Satisfactory simulation results based on the following criteria: 
- A win-win scenario for consumer and utility provider where the cost for consumer and the benefit for supplier are balanced and optimized

- Proper response time

- Expandable to sub-station or city levels 


\section{CHAPTER 3}

\section{PERTINENT TECHNOLOGIES}

\subsection{SMART GRID}

\subsubsection{HISTORY}

While the first electrical grids date back to the late 1800s, the 1960s were the golden era of power grids in developed countries as distribution networks' penetration rates and their load delivery capacity were high, reliability and quality of delivered power were satisfactory and centralized power generation in fossil, hydro and nuclear plants technically and economically boomed [1].

The last decades of the $20^{\text {th }}$ century experienced an increase in electric demand due to new types of consumers, such as entertainment, or dependency on electricity as the source of heat and ventilation as fossil fuels became more expensive. The aforementioned significantly increased usage and the demand even became very fluctuating. Demand peaks had to be met, and hence they defined the minimal requirements in the chain. Thus, due to the fluctuating demand, minimal grid requirements increased. Another consequence of fluctuating demand is a decrease in generation efficiency due to change in generator utilization programming as well as the drops in voltage and frequency [9]. This increased demand at peak times necessitates building more generation plants to avoid voltage drop and decrease in the quality of delivered power. As new plants were costly and the consumption rates dropped during night time which caused an 
unbalanced consumption and left plants production capacity idle, the electricity industry tried to change its approach to DSM to encourage the consumers to manage their consumption through offered incentives and as a result, a more even consumption distribution happened. The existing grids at that time were limited in terms of instrumentation, consumers and consumption data gathering and monitoring. Therefore, fixed or day/night (peak/off-peak) tariffs were the only applicable options. The $21^{\text {st }}$ century came along with innovations and advancements in different sectors that each contributes to better formation of SG concept. The improvements in IT and communication industries and smart sensors eliminated the restriction of precise consumption measurement for each consumer and allowed adaptive billing mechanisms to financially motivate consumers to shift their consumption to off-peak times. Improvement in RE, combined with environmental concerns led to integration of these technologies into electrical systems to form decentralized generation concept. Electrical storage systems were also developed to address power management issues [1].

All the above has added to the complexity of power grids, and requirements such as reliability, quality, safety, privacy of information and robustness against faults or external attacks necessitate comprehensive and effective control schemes to be configured and developed for this new generation of electrical grids.

\subsubsection{FEATURES}

There is not a clear or fully agreed upon boundary and definition for intelligence of SG, as there are many factors involved in designing such a system. Based on the definition and functionality 
of SG, interaction among three fields of communication, control and optimization is essential for an efficient SG platform.

The main features of SG that serve as the basis for formulating design goals can be categorized as follows $[1,2]$ :

1- Reliability: the desired grid should be capable of providing power uninterruptedly and without the need for human intervention. Therefore, an automated fault detection system or self-diagnostic capability is needed. The system should also be capable of self-healing. Such systems should rapidly monitor, detect and analyze the problem and create proper response to the fault in real-time in order to restore the desired state.

2- Adaptability: this new grid should be able to adapt itself to new conditions and environments. Part of this adaptability could result from flexibility in structure, i.e., allowing two-way communication with smart devices within the grid or capability to utilize ancillary power sources immediately upon sensing the need.

3- Prediction: the system should be able to predict the behavior of the overall network to be able to take necessary actions. This prediction could be done using the data and information collected from smart devices and through known algorithms. Adaptive Dynamic Programming (ADP) is an example of a system with anticipatory characteristics.

4- Load handling and demand adjustment: the total load connected to the grid is not fixed and changes significantly based on many factors. Consumer's consumption habits, weather and climate changes, natural phenomena or even a popular T.V. show can drastically change the network load. The change in consumption could be very rapid and cause system instability. Providers currently use standby generators to address such increase in demand; an approach which is not economical. SG can help in two ways: by adjusting the demand on consumers' side through DSM initiatives, where the pricing signal will result in adjustment in consumption by consumers; or by automatically adjusting the household's consumption through changing set points or altering appliance working schedule. SG can also perform the demand adjustment by providing real-time consumption and generation data, enabling 
operators to predict consumption and its trend to effectively plan for generation either by starting on the generators, using standby generators, or using DER.

5- Potential for incorporation of advanced services: SG creates a versatile infrastructure using communication channels, smart devices and advanced prediction and control mechanisms. To fully exploit this capacity, SG should be able to incorporate the existing or newly emerging services in order to fulfill technical and managerial necessities. These services vary and include initiating actions in case of emergency such as informing the clients or system supervisors of the critical situation, fire monitoring, alarming, complex pricing and customized billing procedures, executive reports or customer-defined load management services.

6- Flexibility and sustainability: considering the increase in demand, available sources, environmental concerns and advancement in technology, the best approach to ensure a sustainable energy grid is to incorporate RE sources. The technological advancements in these fields along with storage systems have made DER a must in the new generation of grids. DR schemes or power demand regulating efforts depend largely on DER utilization. Due to technical issues associated with each system, the SG should have the flexibility to incorporate these technologies with least possible glitch. Simple interconnection and fast utilization of these resources shall be the goal of SG. Current grids are not capable of fully integrating DER. Fluctuations of the generated power at distributed points are creating stability and reliability concerns. Cost, interconnection standards and operational constraints are other aspects that shall be studied further.

7- End to end controllability: The control mechanism of SG should be able to address a wide range of needs due to the complexity resulted from the presence of smart devices, distributed energy resources, energy storage, etc. This system should be able to fulfill the needs of management layer in real-time by analyzing data from end nodes, and incorporating necessary algorithms to define the best scenario for fast and effective response. The control system should be able to manage bidirectional communication and provide intelligent, real- 
time decision making capability in an autonomous manner. This system is also the tool for authorities and service providers to manage, optimize and configure the whole grid.

8- Market enabling: SG provides communication between suppliers and consumers at different levels. The most important communicated data are the real-time price signals. This feature gives consumers more flexibility in planning their consumption based on their budget and requirements, and enables providers to create strategic plans and optimize their assets. This feature alone can revolutionize the energy market and allow for competitive markets at wholesale as well as retail level. This competition will, in return, improve the quality of service, pricing procedures and planning routines.

9- Power and service quality: the power quality needs of residential and industrial consumers have changed in recent decades, and SG should be able to accommodate these changes. Sensitive loads' share is increasing in modern systems; therefore, power quality should have minimum fluctuation at generation, transmission and distribution levels. AMI's SMs are equipped with Power Quality (PQ) monitoring capabilities, enabling more rapid detection, diagnostics and restoration of PQ problems.

10- Cost and asset optimization: SGs are capable of using IT to continuously monitor the capital assets in order to minimize the cost of operation and maintenance. At the other end, consumers are able to plan for their power consumption and appliances working schedule based on ToU pricing.

11- Security: The power grid should be resistant against intrusions aiming at disrupting services or damaging the grid. Considering the extensive usage of SM, the data collected from consumers should be kept private. The grid should tolerate external cyber or physical attacks and be able to recover quickly from any probable manipulation. Communications infrastructure and data storage and transmission devices should also meet security requirements. Power theft detection and prevention could be another aspect of security in SG.

12-Performance: performance of the system is not simply limited to its efficiency in terms of delivering the power to the loads. Various factors are important in determining the performance of the system. System planning, which enables operators to analyze transient, 
short and long term demand and consumption trends for planning power generation or resource allocation, is also an indication of SG performance. Fine-tuning the daily routines of the grid based on the existing circumstances, tools and means to run the routines and configure and modify grid parameters, ability to detect emergencies and responding to them, and restoring the normal operation are also among indicators of system performance [10].

13- Self-healing and restoration: since intelligence is the main characteristic of SG, it is expected that the system has the capability to automatically detect any problem and malfunctioning, analyze it and take the necessary actions to restore the network condition to its original state. This function is important in reliability and security, as well as power quality of the SG. Selfhealing and restoration should be done in real-time. Imagine cascading blackouts; in such cases promptness in detection, analysis and restoration can prevent the system from entering instability. In the event of network failure, the stored data in the system from different locations and components in different times will assist technicians to restore the system in a rather short time compared to days or weeks currently needed.

\subsubsection{SUB-SYSTEMS}

To have a functional, intelligent SG, a sequence of sub-systems should be realized. In this sequence, functionality of each sub-system is instrumental in the system's overall performance, as each layer has to be built on the functionalities of the previous layer. An overview of this sequence is depicted in Fig. 3.1.

Functions of each sub-system could be briefed as follows [9]:

$\underline{\text { Advanced Metering Infrastructure (AMI) }}$

Due to the role of AMI in the problem formulation of this work, this sub-system has been described in details in section 3.2 of this dissertation. 


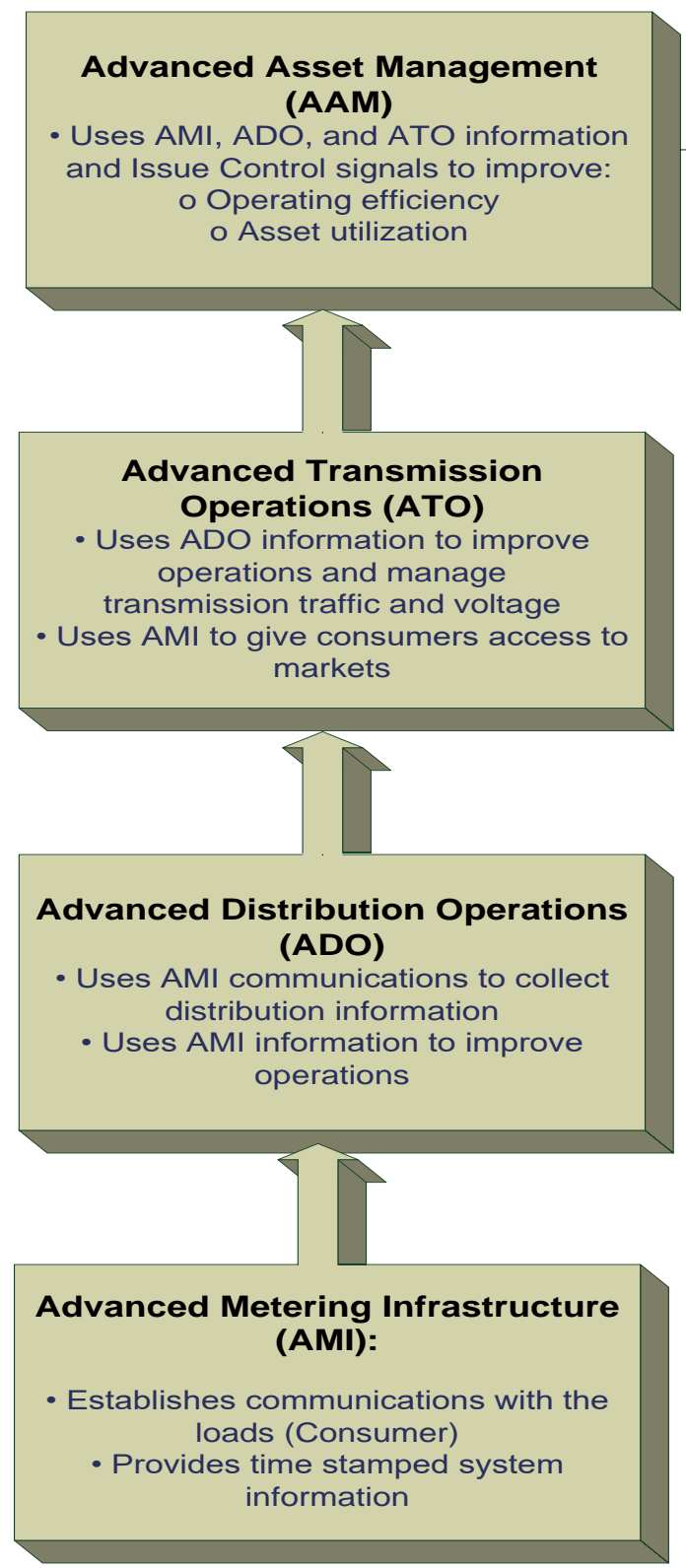

Fig. 3.1: Smart Grid sub-system sequence overview [11]

$\underline{\text { Advanced Distribution Operations (ADO) }}$

- Distribution Management System with advanced sensors including PQ data from AMI meters

- Advanced Outage Management which provides real-time outage information from AMI meters 
- DER operations, using Watt and VAR data from AMI meters

- Distribution automation including Volt/VAR optimization and Fault Location, Isolation, Sectionalization and Restoration (FLISR)

- Distribution Geographic Information System

- Application of AMI communications infrastructure for:

○ Micro-grid operations

○ Hi-speed information processing

- Advanced protection and control

- Advanced grid components for distribution

$\underline{\text { Advanced Transmission Operations (ATO) }}$

- Sub-station automation

- Hi-speed information processing

- Advanced protection and control, including distribution control to improve transmission conditions

- Modeling, simulation and visualization tools

- Advanced regional operational applications

- Electricity Markets

$\underline{\text { Advanced Asset Management (AAM) }}$

- System's operating information

- Asset "health" information

- Operations to optimize asset utilization

- Transmission \& Distribution planning

- Condition-based maintenance

- Engineering design and construction

- Consumer service

- Work and resource management

- Modeling and simulation 


\subsection{ADVANCED METERING INFRASTRUCTURE}

\subsubsection{INTRODUCTION}

AMI cannot be defined in a single sentence since it is not a single technology but a configured infrastructure that integrates a number of technologies to achieve its design goals.

The infrastructure includes SM at consumer end, communication networks at different levels of the infrastructure hierarchy to connect the two ends, Meter Data Management Systems (MDMS) and means to integrate the collected data into software application platforms and interfaces at the utility provider or head end [9].

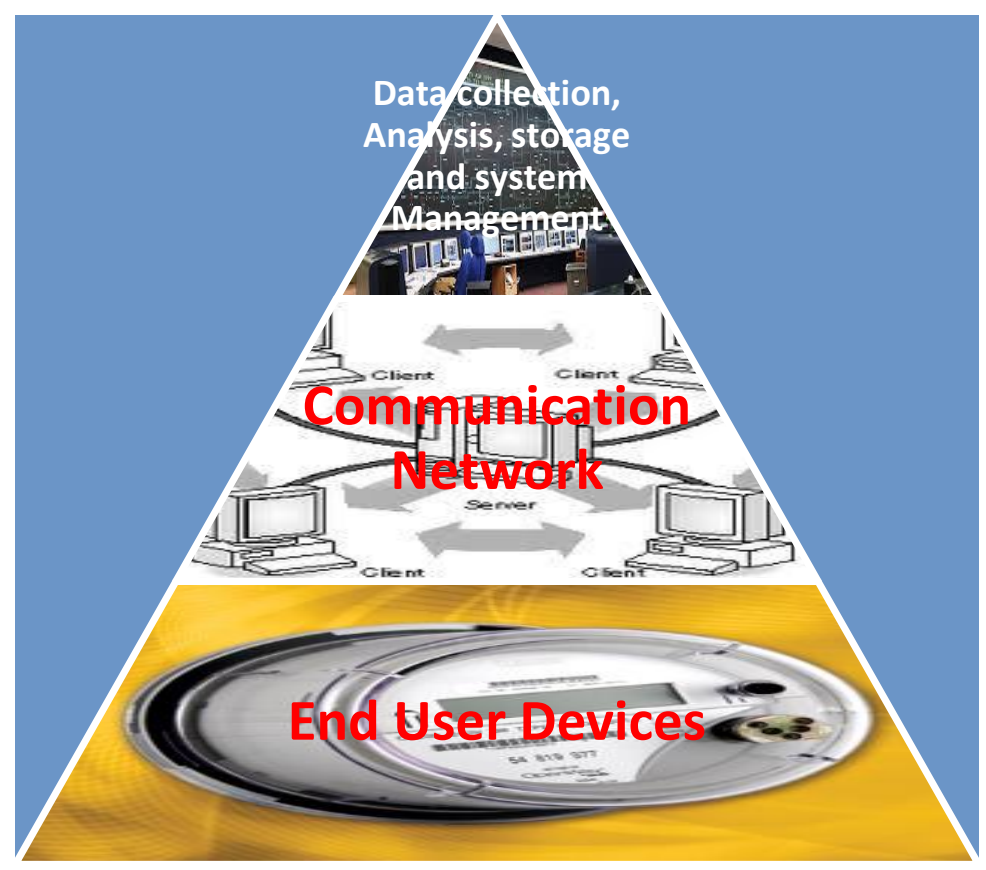

Fig. 3.2: Schematic of AMI

As shown in Fig. 3.2, the customer is equipped with advanced solid state electronic meters that collect time-based data. These meters have the ability to transmit the collected data through commonly available fixed networks, such as Broadband over Power Line (BPL), Power Line Communications (PLC), Fixed Radio Frequency (RF) networks, and public networks (e.g., 
landline, cellular, paging). The metered data are received by the AMI host system and sent to the MDMS. The MDMS manages data storage and analysis to provide the information to the utility service provider in a useful form. AMI enables a two-way communication; therefore, communication or issuance of command or price signals from the utility provider to the meter or load controlling devices are also possible [12].

The interactions among different layers of a typical AMI are shown in Fig. 3.3 [9].

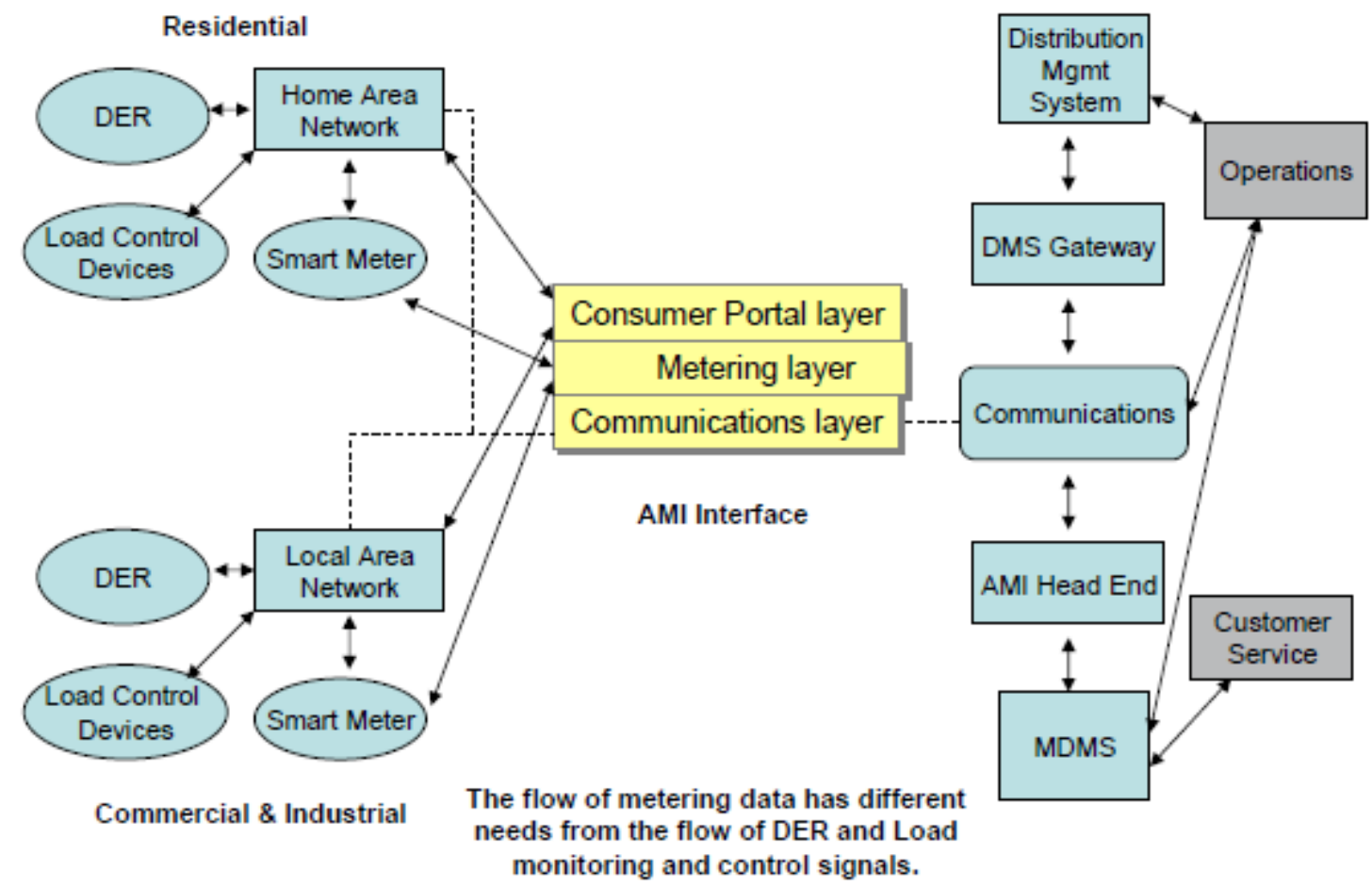

Fig. 3.3: Overview of AMI

\subsubsection{SUB-SYSTEMS}

AMI is not limited to electrical grids; water and gas distribution networks are also part of the AMI. The advantage of electrical grid is that it is capable of providing power to the meters. In gas and water metering networks, the meters are battery powered which impose great constraint 
as metering, communication, display and other functionalities of the meter and infrastructure are power dependent. In electrical grid, the meters and the infrastructure use part of the electric power they measure. This section will explain different layers of the AMI as shown in Fig. 3.2 in more detail.

\subsubsection{SMART DEVICES}

End user devices are comprised of state-of-the-art electronic hardware and software capable of data collection or measurement in desired time intervals and with time stamping. These systems have established communication with remote data centers and are capable of transmittal of such information to various parties in time slots required and set by system administrator. Unlike Automatic Meter Reading (AMR), communication in AMI is bidirectional; therefore, smart devices or load controlling devices are able to accept command signals and act accordingly.

At the consumer level, SMs communicate consumption data to both the user and the service provider. In-Home Displays (IHD) illustrate the smart devices' data for consumers, making them aware of their energy usage. Utility pricing information supplied by the service provider enables load controlling devices (e.g. smart thermostats) to regulate consumption based on pre-set user criteria and directives. Where DER or storages are available, the system can come up with an optimized solution in terms of the share of each source in answering the demand. This capability of the system is the focus of this research.

The utility service provider employs a system at its location that collects and analyzes AMI data to help optimize operations, handle economics associated with consumption and provide consumers with quality service. AMI is the tool to provide immediate feedback on consumer 
power quality issues, system failures, etc., enabling the service provider to rapidly address grid deficiencies. AMI's bidirectional communication platform allows grid automation at the substation and circuit levels. This increased footprint allows system management to pinpoint problems, such as power theft, and react with minimum negative effects or interruptions at consumers' end.

SMs have three distinct categories in the broadest view: electrical, fluid and thermal. There are also a number of sensors or devices that measure factors that affect utility consumption, such as humidity, temperature and light. The sensors could be expanded based on the needs and desire of user or system designer, considering their cost and functionality. SMs have two functions: measurement and communication. Therefore, each meter has two sub-systems: metrology and communication. The metrology varies depending on a number of factors including region, measured phenomenon, needed accuracy, technical requirement, level of data security, application, etc. In communication, multiple factors, including security and encryption, define the suitable method.

Regardless of its type and the quantity it measures, the meter should have the following functionalities [13]:

- Quantitative measurement: the meter should be able to accurately measure the quantity of the medium. Meters use different physical principles, topologies and methods to perform this task.

- Control and calibration: this functionality of meters varies based on their type. However, in general, the meter should be able to compensate small variations in the system.

- Communication: sending stored data and receiving operational commands as well as the ability to receive upgrades of firmware. 
- Power management: in the event of a primary source of energy going down, the system should be able to maintain its functionality.

- Display: customer should be able to see the meter's information since this is the base for billing. This is also needed since demand management at customer end won't be possible without informing the customer of real-time consumption. Displays are mandatory in many cases based on the regulatory requirements. The automated approach proposed in this thesis relieves the consumers from the burden of manual implementation of demand management based on information shown on the display.

- Synchronization: timing synchronization is critical for reliable transmission of data to central hub or other collector systems for data analysis and billing. Timing synchronization is even more critical in case of wireless communication.

The key features of smart electricity meters can be listed as follows:

- Time-based pricing

- Providing consumption data for consumer and utility companies

- Net metering

- Failure and outage notification

- Remote command (turn on / turn off) operations

- Load limiting as penalty or for demand response purposes

- Power quality monitoring including: phase voltage and current, active and reactive power, power factor

- Energy theft detection

- Communications with other intelligent devices in the home

- Improving environmental conditions by reducing emissions through efficient power consumption 


\subsubsection{COMMUNICATION}

Reliable and standard communication is an important part of AMI. The devices should be able to send the collected information to the analyzing computer. Considering the number of users and the number of smart meters at each user end, the communication network requires high operational reliability to transfer the high volume of data. On the other hand, this communication network should be able to transfer operational commands from operation control to individual smart meters, IHDs and load control devices. Therefore, designing or selection of an appropriate communication network is a meticulous process which requires careful consideration of the following key factors [14]:

- Huge amount of data transfer

- Restriction in accessing data

- Confidentiality of sensitive data

- Representing complete information of consumer's consumption

- Showing the status of grid

- Authenticity of data and precision in communication with target device

- Cost effectiveness

- Ability to host modern features beyond AMI

- Future expansion

There are various topologies and architectures for communication in SG. The most practiced architecture is to have data collected from groups of meters in local data concentrators, and then transmit the data using a backhaul channel to the central command, where the servers, data storing and processing facilities as well as management and billing applications reside [14]. To realize this topology, different types of networks are used to form the AMI communication 
infrastructure based on their specifications, such as range and capacity. Fig.3.4 shows the networks and their interconnections in AMI communication infrastructure.

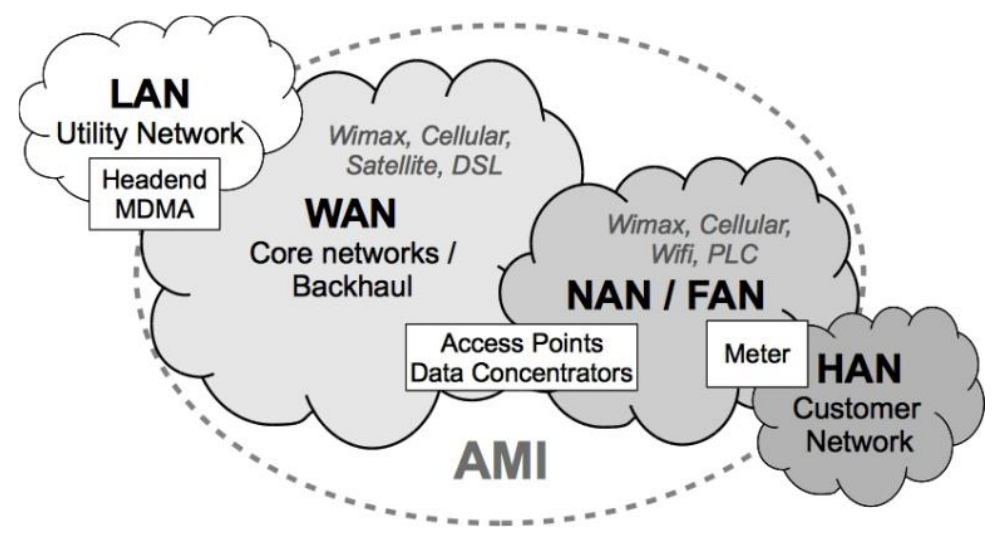

Fig.3.4: AMI communication network overview [7]

As different types of architectures and networks are available for realization of AMI, there are various mediums and communication technologies for this purpose as well. Some of these mediums and technologies are listed below:

- $\quad$ Power Line Carrier (PLC)

- Broadband over power lines (BPL)

- Copper or optical fiber

- Cellular

- WiMax

- Bluetooth

- GPRS

- Internet

- Satellite

- Peer-to-Peer

- Zigbee 
The expected functionality and requirements of each communication layer in AMI should be considered when choosing the proper technology.

\subsubsection{DATA MANAGEMENT SYSTEM}

Before the introduction of SG, utility companies only collected monthly meter readings from their customers which constituted one data point per month, per customer. Introduction and utilization of AMI has significantly increased the volume of data. In the existing AMIs with data collection intervals of 15 minutes, the size of the collected data is huge and in order of terabytes which coined the term "Big Data" [15]. Therefore, special tools are needed to manage and analyze this Big Data. Sources of data in SG, which create the Big Data, are as follows:

- AMI (smart meters): collecting consumption data at a given frequency

- Distribution network automation system: collecting data for real-time control of the system that could be up to 30 samples per second per sensor [16]

- Third-party systems connected to the grid: storages, DER or Electric Vehicle (EV)

- Asset management: communication between central command and smart components in the network including updating firmware

MDMS collects all metered data from AMI systems to create records. The records should be well-sorted and accessible based on the operational needs of users. Different vendors have different definitions for MDMS or design their system based on their specific concept. Therefore, the number or types of additional features or applications in MDMS vary from one vendor to another. Some vendors' system only makes the data available for use by other applications, while other products include additional application suites. Regardless of features or complexity, all MDMS suites should be able to address three demands: improvement and 
optimization of operation of utility grids, improvement and optimization of management of the utility and enabling customer engagement.

Data analytics have become one of the hottest topics in SG. The purpose is to gather all available data from inside and outside of the grid, connect them together using available data analysis and data mining techniques, and extract useful information for decision makings.

From infrastructure and hardware points of view, the following components are necessary for the system [15]:

- Data center infrastructure: the building hosting the system and all related auxiliary systems, i.e., backup power, ventilation, etc.

- Servers: hardware needed for data handling

- Storage system: all hardware needed for storing data and connections with other hardware in the system

- Database system: software needed for data analysis

- Virtualization systems: allow more efficient use of discrete storage and computing resources

Due to the importance of the collected data, utility providers are mainly concerned with the means and facilities to store data. Data centers for this application should be disaster proof with carefully designed back up and contingency plans for different scenarios. The cost associated with such provisions is huge. Virtualization and cloud computing have been suggested as solutions for this problem [17]. Virtualization allows all available resources to be merged together, which can improve efficiency and return on investment but requires additional technology and complexity. Cloud computing allows access to virtual resources in different locations; however, it brings serious concerns over the security of data and can cause problems 
as data are in different locations where different regulations and laws may apply. Cloud computing, nevertheless, reduces the costs of special purpose data centers as it uses the capacity of different service providers globally.

\subsection{SUMMARY}

This chapter has been dedicated to two pertinent infrastructures for deployment of the idea presented in this work. SG is a platform with unique features as well as unique problems. This work tries to use such unique features to answer critical issues in the domain of energy consumption and uses the very same features to overcome the challenges that SG introduces. This work will contribute to the efforts aiming at improving the controllability of SG. Integration of DER has added to the complexity of SG control due to the uncertainties associated with them and their nondispatchability. Utilization of DER at the consumer's end or as close to the end user as possible will therefore alleviate the complexity of control problem.

AMI is a $21^{\text {st }}$ century tool designed to answer challenges in energy distribution system. AMI can perform real-time data acquisition from consumers, transmit the data and return the executive commands to the loads. This valuable tool allows the operators and utility companies to have firsthand information on the status of their network for planning and performance optimization purposes. AMI, through its acquired data, furnishes grid operators with consumption regulation capability, at both consumer's and provider's ends. AMI benefits in electrical distribution grids also include diagnostic and notification tools or cyber or physical attacks detection, which can save millions of dollars in damage prevention and maintenance cost for energy providers and consumers. 


\section{CHAPTER 4}

\section{DEMAND SIDE MANAGEMENT}

\subsection{INTODUCTION}

The term DSM is used for all the activities or programs undertaken by load serving entity or its customers to influence the amount or timing of electricity they use. DSM is the planning, implementing and monitoring of utility activities that are designed to influence customer consumption and as a result, changing the time pattern and magnitude of utility's load. DSM concept was first introduced in the late 1970s and has been traditionally seen as a means of reducing peak electricity demand so that utilities can avoid or delay building additional generation capacity. By reducing the overall load on the grid, DSM has various beneficial effects including mitigating electrical system emergencies, reducing the number of blackouts and increasing system reliability and stability. Other benefits include reducing dependency on expensive fuel, reducing energy prices, and decreasing harmful emissions to the environment. Finally, DSM has a major role in deferring high investments in generation, transmission and distribution networks. Thus, DSM applied to electricity market provides significant economic, reliability and environmental benefits.

Traditional grids enabled DSM programs for industrial consumers and commercial buildings; however, they did not offer such program for residential consumers. The reasons are lack of 
sensors, effective automation tools and efficient communication. Moreover, the advantages of several DR programs are negligibly small when compared with their implementation costs. Thus, in SG, smart meters, low cost sensors, smart loads, and the integration of IT has opened a window for residential energy management programs [18].

\subsection{DSM BACKGROUND, OBJECTIVES AND BOTTLENECKS}

During the 70s and all the way to the 90s the net generating capacity additions in North America decreased dramatically by almost $40 \%$ while the energy utilization increased by more than $50 \%$. To match this increasing demand, new means had to be developed to reduce the peak demand and maintain the proper ratio between generating capacity and demand. Efforts were geared towards two initiatives: 1) to manage customer loads, and 2) to manage the system performance in order to increase the system efficiency and ultimately reduce the system peak energy demand. The initiative of managing customer loads is now known as demand side management and is carried out by Distribution System Automation (DSA).

In the past, the primary objective of most DSM programs was to provide cost-effective energy and resources to help defer the need for new sources of power including generating facilities, power purchases and transmission and distribution capacity additions. However, due to recent changes within the industry, electric utilities are also using DSM to enhance customer service. These changes include regulatory restrictions, public opinion, increasing costs of peak generation, the advent of independent power producers and operators, power market deregulation and free access to transmission systems owned and operated by utilities.

Historical data on DSM deployment in the United States during the 90s [19] reveal that in 1999, 848 electricity providers reported having DSM programs in place. Of those, 459 providers were 
large, and 389 were small utilities; this is a decrease of 124 providers from 1998. Utilities with sales to the end consumers or sales to resellers greater than or equal to $120,000 \mathrm{MWh}$ are considered large. Energy savings for the 459 large utilities increased to 50.6 billion $\mathrm{KWh}^{1}, 1.4$ billion KWh more than energy savings in 1998. Actual peak load reductions for large utilities decreased to $26,455 \mathrm{MW}^{2}$ in 1999 . Potential peak load reductions were 43,570 MW, an increase of 2,140 when compared with the corresponding values in 1998. In 1999, incremental energy savings for large utilities were 3.1 billion $\mathrm{KWh}$, and incremental actual peak load reductions were 2,263 MW.

There are different reasons behind adopting DSM initiatives by utility providers. DSM has been developed to address the following issues [20]:

- Cost reduction: many energy efficiency schemes have been introduced in the context of integrated resource planning aimed at reducing total costs of meeting energy demands

- Environmental and social improvement: DSM could be one of the solutions for reaching the environmental goals by reducing energy use, leading to reduced greenhouse gas emissions

- Reliability and network issues: improving or preventing problems in the electricity network through reducing demand while maintaining system reliability as a short term objective and, in long term, deferring the need for network expansions

- Improved markets: short term responses to electricity market conditions, particularly by reducing load during periods of high market prices caused by reduced generation or network capacity

Different players on different ends of the electricity market have different motivations for pursuing DSM. For utility providers the reduction in energy demand or shifting it means

\footnotetext{
${ }^{1}$ Kilo Watt Hours
}

${ }^{2}$ Mega Watts 
avoiding or delaying building additional generating capacity. This could also be interpreted as withholding increase in energy price, since eventually the end users should pay the cost for such expansions in the infrastructure. For customers, DSM offers the opportunity to reduce their energy bill through efficiency and conservation measures. In case of industrial customers, this would translate to lower production costs and a more competitive product in the market.

Energy dependent business owners such as manufacturing plant or condominium managers are often very interested in DSM, primarily to reduce their own energy consumption and costs. This reduction can directly help their electricity provider maintain a reliable energy supply. Industrial plants are usually able to curtail their overall energy consumption by adopting various measures. Depending on their process, many plants have the flexibility to reschedule their periods of high demand by cutting or reducing their energy hungry equipment or processes and evening out their consumption profile over a longer time period and thus, helping the utility to run at higher efficiency. Building owners and operators are also capable of using energy and building management system to moderate their consumption. Recent developments in smart building technologies allow home owners to employ different techniques to further reduce or manage their consumptions throughout the day. Cost and energy efficient light fixtures, smart thermostats, new ventilation control systems, smart plugs and building materials as well as customization of solar panels for direct utilization of solar power at homes are just some examples of these technologies.

Society also benefits from deployment of DSM. Reduced or shifted energy usage can directly translate into less air pollution and carbon emission, and lower the potential environmental threats associated with global warming. DSM programs are a promising solution for the utilities 38 
and government agencies increasing concerns regarding global warming and carbon emissions. Moreover, a properly designed DSM program can actually track the program impacts and measure the amount of carbon reduced or saved based on program activities.

Based on the aforementioned points, a properly designed and successfully implemented DSM program should fulfill the following objectives:

- Reduce customer peak and overall energy demand

- Improve reliability of the grid

- Energy efficiency

- Managing electricity costs

- Energy conservation through both behavioral and operational changes

- Load management

- Fuel switching

- Incorporation of DER

- Enabling load shifting or load shedding at peak times

By the same token, the benefits of achieving the aforementioned objectives for DSM are:

- Reduction in customer's energy bills

- Reduction in the need for new generation, transmission and distribution capacity

- Stimulating economic development

- Creating long term jobs by adopting innovations and new technologies

- Increasing the competitiveness of local enterprises

- Reduction in air pollution and environmental impacts

- Reduced dependency on foreign energy sources

- Reduction in peak power prices for electricity

Despite all the benefits and determination of governments and utility companies for incorporating DSM practices, there are some barriers that prevent optimal utilization of DSM. 
Several market barriers limit customer uptake of DSM measures and reduce the incentive for electrical utilities to invest in DSM programs. Barriers affecting customer uptake include lack of information and knowledge about energy efficiency and financial considerations such as affordability, competing investment priorities or, access to financing. Together, these barriers lead to real or perceived "transaction costs" that discourage investment even when it is costeffective. Barriers preventing electrical utilities from undertaking DSM programs include lack of sufficient financial incentive because of deregulation and restructuring, hidden subsidies for other options and, lack of expertise and infrastructure to deliver DSM programs. These barriers can be removed through appropriate government policy and regulation, and by careful design of DSM programs.

\subsection{DSM DEPLOYMENT}

\subsubsection{DSM TECHNIQUES}

There are two major DSM techniques used by utility providers [21, 22]:

- Energy conservation and efficiency programs that aim for saving energy

- Demand Response (DR) or Load Response Programs (LRP) that aim for shifting and rescheduling energy consumption

A third group of programs exist as well:

- Strategic load growth programs that aim to increase energy use during some periods. These programs encourage utilization of cost-effective electrical equipment or technologies that operate primarily during periods of low electricity demand.

Although these programs are implemented at the end user side, they all require a deliberate intervention in the market by the electricity provider to change the configuration or magnitude of the load shape. 


\section{Energy Conservation and Efficiency programs}

In terms of power generation capacity, the energy saved within the grid is actually the additional generated power! Conservation and efficiency measures are the best alternative energy sources. There are various opportunities and techniques available for efficient energy consumption at residential or industrial buildings. These technologies include: efficient lighting systems, variable speed drives for electric motors, solar systems, power factor correction, maximum demand control, energy efficient equipment, improved refrigeration processes, modernized compressed air systems, and replacing old production methods with new processes.

\section{Load Response Programs (LRPs)}

LRPs are the actions undertaken in response to short term requirements of electricity providers and wholesale market. In other words, LRPs refer to switching off or rescheduling of nonessential and non-critical loads by the end users in response to utilities' request. This can lead to saving the grid from exceeding its peak rating. There are a variety of equipment and applications that can be switched on or off at particular times to reduce electricity demand from the network. Depending on the market drivers, LRPs could be classified in two broad categories:

- Reliability-based programs: these programs are also called "contingency" or Emergency Demand Response Programs (EDRP) and will be triggered in response to system emergencies. Whenever there is an urgent need for power supply, a critical shortage due to less generation or more demand, or any other system constraints, contingency programs should be initiated.

- Market based programs: these programs are based on market price signals for electricity. This category includes programs that use ToU rates, real-time prices, interruptible rates and two-part tariffs. These rates are intended to reduce consumer bills through the 
application of time-differentiated rates. The participating consumers that curtail their loads at critical times or during high prices may also enjoy some extra financial incentive because of their help in maintaining system reliability. Depending on the type of load control, these programs can be implemented either by utility providers or by consumer.

\subsubsection{DSM APPROACHES AND IMPLEMENTATION}

DSM programs can be implemented using different approaches including [22]:

1. General information program to inform customers about available energy efficiency options

2. Site-specific information program that provides information about specific DSM measures appropriate for a particular enterprise or home

3. Financing programs, including loan, rebate, and shared-savings programs, to assist customers with paying for DSM measures

4. Turnkey programs that provide complete services to design, finance and install a package of efficiency measures

5. Alternative rate program including ToU rates and load shifting rates. These programs generally do not save energy; however, they can provide effective ways for shifting loads to off-peak periods

6. Bidding program in which a utility solicits bids from customers and energy service companies to promote energy savings in the utility's service area

7. Market transformation program that seeks to change the market for a particular technology or service so that the efficient technology is in widespread use without continued utility intervention

The answers to the following questions will help DSM engineers define a suitable program for implementation:

- Should the program target peak loads or encourage a general reduction in electricity consumption?

- Is a "market transformation" program needed or the objective is to reduce demand in a particular sector or area? 
- Should the program target the existing stock or new equipment?

- Are the targeted consumers from low income communities or from higher income communities who can easily afford to participate?

The duration of the DSM program is an important factor in design phase. The program should be long enough to ensure complete market transformation or to achieve other program goals. It should also continue long enough to ensure that improvements in efficiency continue after the program is over.

Once the approach has been defined, the process of planning and implementing DSM program should follow the following steps [23]:

\section{$\underline{\text { Step 1: Load Research }}$}

This stage will identify customer's base, tariff and load profile on an hourly basis as well as the sectors contributing to the load shape. This step will also identify the tariff classes in the utility, current recovery from different sectors and current subsidy offered to different sectors.

\section{Step 2: DSM Program Planning}

Based on the results of step 1, DSM engineers will define the load shape objectives for the existing situation. Various load shape objectives such as Peak Clipping, Valley Filling, Load Shifting and Load Building are possible. These will be explained more in section 6.3.3.

\section{Step 3: DSM Program Design}

This step will identify the applications that can be potentially used to reduce peak demand, specifically in sectors with higher subsidies. This step will also carry out a detailed cost-benefit analysis for the end users and the utilities, including analysis on societal as well as environmental benefits. 
Step 4: Implementation

Implementation stage will carry out the program for specific end-use applications, promote the program to the target audience through marketing approaches such as advertising, bills and inserts, and focused group meetings as in the case of industrial sector.

Step 5: Monitoring and Evaluation

In this step, the program implementation results will be tracked and compared with the DSM goals set by the utility. A detailed cost-benefit analysis in this case will include identifying the avoided supply costs relative to the total program costs for the utilities as well as benefits to the consumers including reduced bills or incentives to the end users. Based on the results from step 5, feedback to steps 2 and 3 might be necessary to achieve proper results at step 5 .

The five-step process mentioned above is to indicate the deployment process for a DSM program. In practice however, each step involves more in depth analysis and activities. A more comprehensive and practical DSM planning and implementation flowchart has been proposed in [22] and is depicted in Fig. 4.1. 


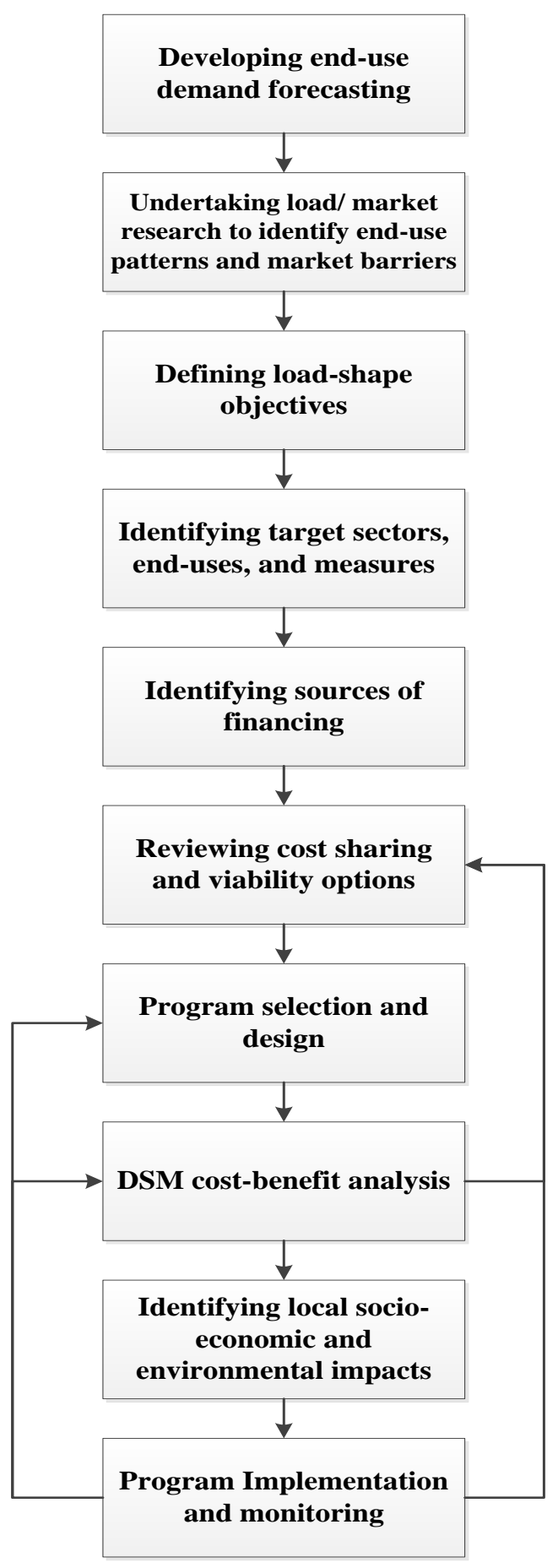

Fig.4.1: DSM deployment procedure 


\subsubsection{DSM STRATEGIES}

As outlined in step 2 of section 4.3.2, based on the results of the load research in the utility, load shape objectives need to be selected for the current situation. There are six load shapes that are generally used as the DSM load-shape strategy. These six shapes (Fig. 4.2) are not mutually exclusive and may frequently be employed in combination.

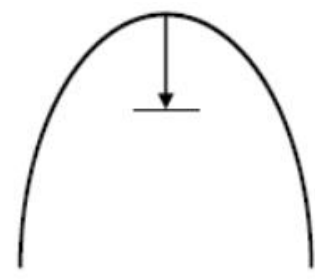

Peak clipping

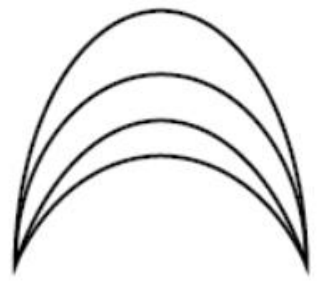

Flexible load shape

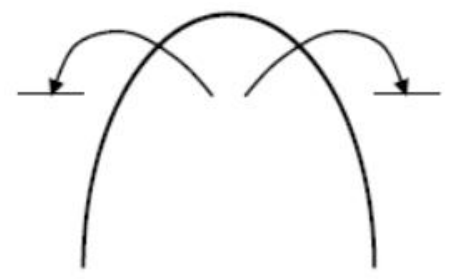

Load shifting

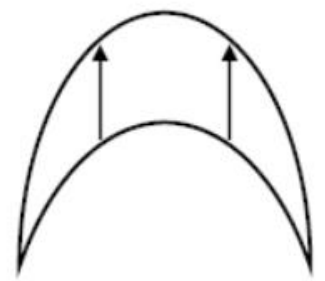

Strategic load growth

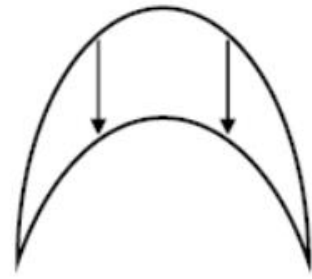

Strategic conservation

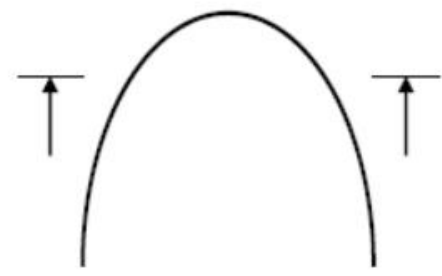

Valley filling

Fig. 4.2: Simplified form of load shape changes [24]

In a simple way, each of the above changes in the load shape can be explained as follows:

- Peak Clipping: reduction in peak demand

- Valley Filling: increased demand at off-peak times

- Load Shifting: shifting demand to off-peak times

- Strategic Conservation: the reduction of utility load, more or less equally, during all or most hours of the day

- Strategic Load Growth: the increase of utility loads 
- Flexible Reliability: interruptible agreements by utility to alter customer energy consumption on an as-needed basis

Table 4.1 provides examples of DSM measures at residential and industrial buildings and their consequence load shape changes.

\begin{tabular}{|c|c|}
\hline Measures & Impact on Load Shape \\
\hline Insulation & Strategic conservation \\
\hline Double glazing windows & Strategic conservation \\
\hline Instantaneous electric water heaters & Load shifting \\
\hline Energy efficient motors & Strategic conservation \\
\hline Gas heaters & Peak clipping \\
\hline Heat storage & Valley filling, Load shifting \\
\hline Photovoltaic systems & Peak clipping, Strategic conservation \\
\hline Cogeneration & Peak clipping \\
\hline
\end{tabular}

Table 4.1: Examples of DSM techniques and their impact on load shape

\subsection{DISTRIBUTION SYSTEM AUTOMATION (DSA)}

Electrical distribution systems are an important part of electrical grid and deliver electricity to the end consumers. In SG, automation of the distribution system allows utilities to implement flexible control of distribution systems which is used to enhance efficiency, reliability and quality of service. Distribution System Automation (DSA) allows dispatchers and engineers to remotely monitor, coordinate and operate distribution system components in a reliable, safe, efficient, and optimal way. DSA is the tool that realizes DSM deployment within the SG through its provided functionalities and features. The main goals of DSA are $[25,26]$ :

- To control energy consumed by loads

- To maximize the efficiency of the distribution network

- To minimize the system losses by performing system reconfiguration

- To maintain high quality service by remote voltage and reactive power control

- To optimize the efficiency of power generating plants 
There are four basic areas that have to be studied in order to properly implement DSA. These areas are: Loads, system voltage, reactive power and system configuration. Some aspects of DSA are as follows:

- Control of customer appliances such as air conditioning and water heaters or Load Management (LM)

- Remote monitoring and control of distribution networks or Supervisory Control and Data Acquisition (SCADA)

- Remote monitoring and control of distribution equipment such as voltage and reactive power control equipment or Distribution Automation and Control (DAC)

- Centralized control and dispatch of generating plants or Energy Management System (EMS)

In order to perform the designed tasks, the following main components should be considered in DSA:

- Load-tap-changing transformer

- Voltage regulators

- Capacitor banks

- Remotely operated disconnected switches

- Remotely operated load switches

- Remotely operated re-closers and circuit breakers

- Fault detectors

- Current and Voltage transformers

- Special residential metering that can transmit load usage to the control center

- Appliance load control switches

The main areas that need to be developed in order to implement DSA are:

- Data collection and system planning

- Operational control and monitoring 
- Communication

- Protection

\subsection{CONCLUSION}

DSM programs play a vital role in mitigating electrical grid emergencies, avoiding blackouts and increasing system reliability. They also reduce dependency on expensive energy imports, avoid high energy prices, provide relief to the power grid and generation plants, and avoid high investments in generation, transmission and distribution network which in turn leads to environmental protection. Thus DSM can provide significant economic, system reliability and environmental benefits. DSM techniques are the cheapest, fastest and cleanest ways to solve parts of challenges faced by SG. DSM programs can be immediately implemented at a fraction of the cost of building new power plants. In this research program a single device is proposed that can bring DSM to the residential home owners while relieving general public from the technical complexities associated with this program. This work, upon completion, will offer a device that can be integrated into the building management systems available in the market or already installed in houses and perform the task of power allocation based on the availability of DER, grid price signal and residents' preferences. This can further increase adaptation of DSM initiatives by ordinary people since the process will be automated. 


\section{CHAPTER 5}

\section{LOAD MODERATION CENTER}

\subsection{OVERVIEW}

Much work has been done in the general area of energy conservation. Most of this work, like other innovations, was first a concept in academia that was brought to industry to create a product. The proposed Load Moderation Center (LMC) aims to bridge the gap among several independent works in the area of energy conservation in SG and BMS. To be specific, the main idea behind the proposed LMC is to integrate energy conservation efforts and security in one package, i.e., BMS, and to take the package to consumers. Energy conservation could be realized through a combination of DR practices, DER utilization and load programing. Security, which in this proposal means the privacy of user's information, will be realized through load profile undetectability by means of load signature moderation. All of the aforementioned factors are interrelated: energy conservation will be possible by DSM and utilization of DER; DER utilization will be efficient if the controller in charge of power allocation makes an intelligent decision of when to use the DER or storages based on their status and capacity at a given time; and load signature masking will be realized by proper utilization of DER and storages. To explain the latter link of the chain in more detail and as an example, LMC can supply a heater by using grid or DER (e.g. battery) or a combination of them. Three scenarios are possible: 
1. A rechargeable battery provides all the needed power for the heater. Later on the battery will recharge gradually. As a result of such scheme, the metered load signature hides the actual consumption of the load in itself.

2. The demand from devices is addressed using a combination of battery and grid. Similar to the first scenario, the battery will be charged later. The metered load signature in this case shows a smoother signature compared to the actual device signature.

3. The battery will be charged in a series of charging periods. Therefore, it won't be possible to detect which period coincides with the actual time of appliance operation.

A number of features are expected for incorporation in LMC:

- Optimization of assets by proper utilization

- Effective utilization of DER

- Load signature moderation and concealing for privacy of user's information

- Peak saver and Demand Side Management

- Noninvasive power management

- Possibility of integrating data and power links

Moreover, there are features that could be developed and integrated in LMC at later stages:

- Ability to predict consumption and plan accordingly in advance

- Trainable based on the stored data and occupants' settings for different scenarios

- Capability of working based on different profiles for different occupants

- Data analytics capability

\subsection{DESCRIPTION OF THE IDEA}

LMC is a hardware that hosts the developed two-level optimization scheme in this work as an embedded software. This device is proposed to improve and integrate the existing technologies and approaches in the fields of BMS, DSM and security in SG to create a product with capability of communication with, and power allocation to, equipment and devices inside a building. 
Simple installation, connection with existing BMS and SM through market dominant wireless and wired technologies of Zigbee and HomePlug, and embedded control schemes to perform the desired tasks are also part of the picture. The overview of such system is depicted in Fig. 5.1.

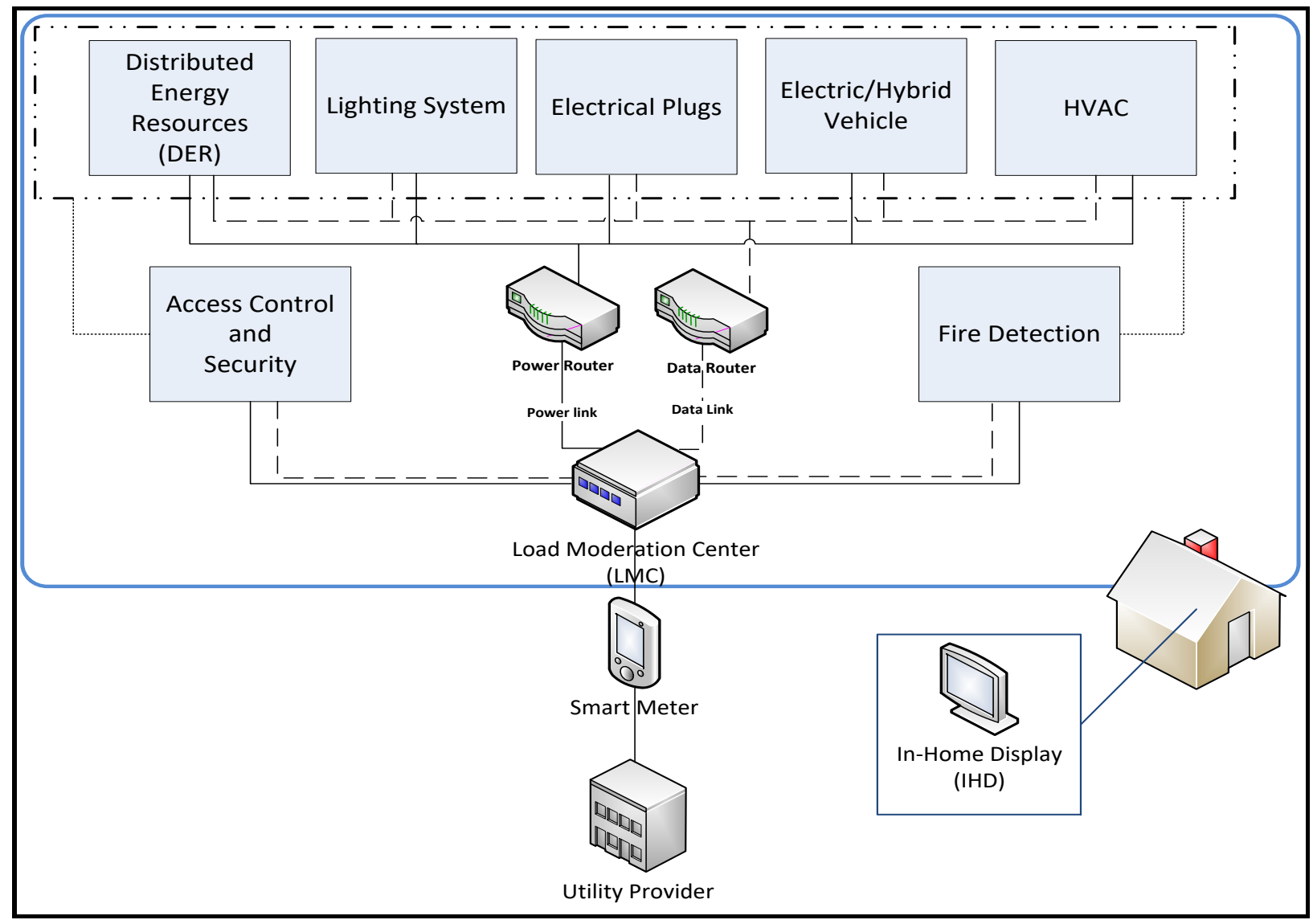

Fig. 5.1: Overview and connections of the proposed LMC

The main target of LMC is residential buildings, condominiums and houses, therefore, it should be able to merge with the existing BMS or have the ability to easily work with them. This necessitates minimum use of proprietary technologies in terms of interfacing and communication. Since wireless technologies such as ZigBee or Z-Wave are gaining attention for home automation and are the best wireless practices in the market, the intention is to adopt them for this purpose. The advantage of Z-Wave is its simplicity. Z-Wave is rather a proprietary 
protocol and one can argue that Z-Wave features are a subset of ZigBee protocol features. The key characteristics of ZigBee can be summarized as below [11]:

- Global operation in the $2.4 \mathrm{GHz}$ frequency band according to IEEE 802.15.4

- Regional operation in the $915 \mathrm{MHz}$ (Americas) and $868 \mathrm{MHz}$ (Europe)

- Frequency agile solution, operating over 16 channels in the $2.4 \mathrm{GHz}$ frequency

- Incorporates power saving mechanisms for all device classes, plus support for batteryless devices

- Discovery mechanism with full application confirmation

- Pairing mechanism with full application confirmation

- Multiple star topology and inter-personal area network communication

- Various transmission options including broadcast

- Security key generation mechanism

- Utilizes the industry standard AES-128 security scheme

- Supports Alliance standards or manufacturer specific innovations

The proposed LMC will have a power link to all power consuming equipment. Upon receiving a request from a load for power allocation or based on a preset working schedule for a device or a setting by occupants which requires supplying a device with power, LMC will allocate the power to the device according to the control algorithms set for it. LMC will determine the required number of sources and the share of each source in supplying the requested load considering a number of factors including the status of each DER, outside and inside conditions, grid status and price signal. LMC will gather all required data for such decision making, either through direct connections with equipment and installed sensors or through SMs, utility or any third party application that could be residing anywhere such as on cloud or in Infrastructure as a Service (IaaS) form. Given that LMC has power links with equipment by means of wires and cables, it is 
possible to configure the system to communicate using power lines. Use of single bus structure for simultaneous transfer of data and power has several advantages for LMC. This technology, referred to in the literature as Power Line Communication (PLC), is being used in the market for many years now. PLC can be divided into narrow and broad bands as well as PLC over AC or DC lines. Broad band PLC over AC lines would be the target for the proposed LMC. In recent years, Power over Ethernet (PoE) has gained dominance in communication sector for telephone systems and cameras. On the power distribution side, Power Line Carrier and Broadband over Power Line, which use power transmission lines to transmit data, have been used in AMI and SG as well. Similarly, for buildings, HomePlug technology allows for transmission of data by means of electrical wiring inside the building.

The control scheme for LMC will play the key role and is where the novelty of this product rests. Control system will be responsible for analyzing all the data and coming up with optimum scenario of power allocation, considering the following requirement:

1. Uninterrupted supply of power to demanding loads

2. Maintaining occupants' comfort (following set points)

3. DSM based on control signals from the grid

4. Maximum utilization of available DER

5. Maintaining undetectability of loads signature

The system will be validated under different operating conditions considering known effective factors including:

1. Weather condition (temperature, humidity, sunshine, wind, etc.)

2. Occupants' behavior

3. Load and grid uncertainties 
4. Island mode of operation (disconnected from grid)

5. Peak saver condition

Upon successful fabrication of LMC hardware, and after the developed optimization algorithm embedded in the device, the following performance parameters should be satisfied by LMC at user's end:

1. Quality of delivered power (voltage and frequency)

2. Reliability and stability of delivered power

3. Occupants' comfort

4. Energy preservation

5. Effective utilization of DER in the grid

6. Supply \& demand balance

7. Cost optimization

8. Response time

9. Security (Privacy of users' information, intrusion, power theft)

\subsection{MOTIVATION, BENEFITS AND APPLICATIONS}

Energy conservation and demand adjustment are two of the main objectives of LMC. These two factors, along with the cost optimization resulted from asset management, efficient utilization of equipment and reduced maintenance costs, are the main sources of financial benefits for LMC users. There are some studies done by different entities that are roughly similar to the proposed work in some aspects. The benefits of the proposed idea are not limited to energy conservation and cost optimization. As explained before, there is a correlation between SG and SM, therefore, the security of network and privacy of information are critical for both customers and utility providers. The proposed idea will enhance the security of data collecting networks, specifically AMI, by boosting the privacy of consumers' information through load signature moderation. 
Thus, security is another functionality of the proposed system and safeguarding consumers' data has been another motivation behind this work.

Another application for the proposed system is in the field of green energy. The product is capable of effective utilization of renewable energies such as solar and wind, as well as incorporating electrical storages including batteries and electric vehicles. This product will facilitate the usage of DER at residential buildings. The product will be affordable for home owners or owners of buildings with small number of units. This can increase the prevalence of DER usage by general public and promote utilization of clean energy.

The short-term and midterm objectives that could be realized by LMC are as follows:

- Intelligent allocation of power sources to loads

- Integration of separate existing features of BMS and AMI into one hardware; energy preservation, DSM and efficient utilization of DER

- Capability of wired and wireless communication with smart sensors within the building

- Enforcement of proper control commands based on the requirements and targets set for the system

Long-term objectives of this research program include:

- Expanding the system for industrial building applications

- Incorporation of asset optimization schemes

- Incorporation of Big Data analysis and Data Analytic tools

- Load prediction and advance resource allocation planning

- Occupant behavior analysis for optimization of system performance (trainable system)

The ultimate goal for LMC is to fulfill the needs and requirements of industrial buildings. The type of equipment used in industrial buildings varies significantly. Some of these devices may 
provide critical services and be quite expensive, hence it is imperative that they be used efficiently and effectively. Asset optimization techniques will assist owners to prolong equipment life span, minimize maintenance costs and create an efficient, uninterrupted working schedule for them. Given the number of sensors, the frequency of data collection and the total amount of data in networked sensors or connected local area networks, it is clear that the order of magnitude of the data could be incredible; the term Big Data refers to this fact. Studying the attributes of Big Data and tools for analyzing and deducing results as well as customizing them for this very application is the motivation behind developing and incorporating data analytic tools in LMC.

As a smart system, LMC should be capable of predicting consumption based on previous records and trends stored in the system, as well as occupants' settings and preferences with regard to inside and outside conditions. It would be possible then to plan in advance for answering the demands using available resources at the time of request from the loads. It is possible to further reduce the energy consumption if the habits and living patterns of building residents are known. As an example, the data on preferred temperature inside a room for different hours and conditions can be collected by the system. This data will be used to form a pattern and based on that, the system will adjust the ventilation system in a way that it delivers the required amount of heat to a room at the time the motion sensors detect that the occupant is in that particular room.

\subsection{CONCLUSION}

Cisco's white paper [27] states that smart buildings worth $\$ 349$ billion. Smart buildings comprise of an intelligent network of electronic devices that monitor and control equipment of different 
types in a building to achieve a number of goals including greater energy efficiency, cost saving, security and comfort for occupants. Canada represents $2.8 \%$ of the global market for smart buildings, which can be translated to approximately $\$ 10$ billion. In the GTA there are over 7000 buildings and it is estimated that approximately $75 \%$ of them still use electrical heating and cooling units. Considering buildings with average number of units ranging from 50 to 200 , a huge cost saving is possible through LMC. The impact of reduced energy consumption in terms of saved money both for building owners and utility providers, the reduced environmental hazard resulted from decrease in need for centralized power generation in fossil or nuclear plants as well as savings due to optimized equipment utilization and asset management are also among the economic impacts of this project. An independent market research is needed to provide accurate numbers [4-6]. Companies active in clean energy field can also benefit from this product. As the system efficiently uses DER to address power demands of consumers, manufacturer of solar panels or electric cars as well as all other companies involved in that sector can be part of the market this system covers. By incorporating these technologies, both sides can take advantage of their expanded market. The added value this technology brings to the buildings will benefit owners and construction firms. Owners and building managers will be more competitive in the property market and buyers will be attracted and more willing to invest in such properties due to the comfort, security, ease of maintenance and problem detection, remote monitoring of rented property and savings that this technology will bring. The movement of the occupants in the building and the performance of the system will not affect each other. The development of such 
technology is not limited to residential buildings. Such technology can benefit different industrial and commercial buildings including hotels, hospitals, airports and sport complexes. 
Ryerson University Chapter 6: RESIDENTIAL LEVEL OPTIMIZATION 2017

\section{CHAPTER 6}

\section{RESIDENTIAL LEVEL OPTIMIZATION}

\subsection{INTRODUCTION}

The energy market of Smart Grid era is a complex system in terms of regulation and control, supply-demand forecasting and planning. Different players, including renewable energy resources, service providers, consumers, environment, governments and socio-economic trends, take part in determining the overall status of the market. Parameters such as DER's uncertainty or human decision factors also add to the complexity of this market. Given this level of sophistication, it is not possible for end users at residential units or offices and industrial buildings to manually adjust their consumption and come up with an optimal utilization scenario for their available sources of energy. In this chapter, the optimization problem will be defined from the end user point of view which is narrowed down to a regular residential or office unit, hereinafter referred to as "household level." This work will provide an optimal solution for end users to maximize their utilization of DER in conjunction with supply from the grid. This does not necessarily minimize the costs for end users since in different scenarios grid might be needed to supply loads at high peak times. LMC, as introduced in chapter 5, will be the key component in realization of the proposed solution, providing two-way communication and control capability among devices, user and service provider. Different optimization techniques and supply scenarios will be investigated in this chapter to verify the feasibility and suitability of the 
proposed solution. This level of optimization will be then combined with optimization at higher levels of supply-demand cycle, namely at community level (or sub-station level), later in this work to provide a unique solution to the demand-supply management problem defined as the primary objective of this work. Upon successful implementation of this approach, utilization of DER will be maximized at household level, the pressure on grid will be reduced during peak times, DSM implementation will be guaranteed and the complexity of controlling centralized DER resources in SGs will be alleviated.

\subsection{PROBLEM FORMULATION}

In this section the optimization problem will be defined. The problem will be formulated as an actual scenario in real world. The objective function will be derived and assumptions associated with the formulated scenario will be made. Finally, the constraints pertinent to the objective function will be stated.

\subsubsection{PROBLEM DEFINITION}

The main goal at this layer of the supply-demand cycle is to maximize utilization of DER to match with the demand request from the household in an interactive way considering the market price set by the utility provider at each instant. The deficit of the required demand will be provided by the grid and a storage system will act as a buffer between the consumer and sources of energy to absorb surplus or provide deficit of household generation/demand through charging and discharging. Such mechanism will be realized by an adaptive optimization function that will reside in the LMC and will define and govern the participation of components connected to it. The layout of such scenario is depicted in Fig. 6.1. 


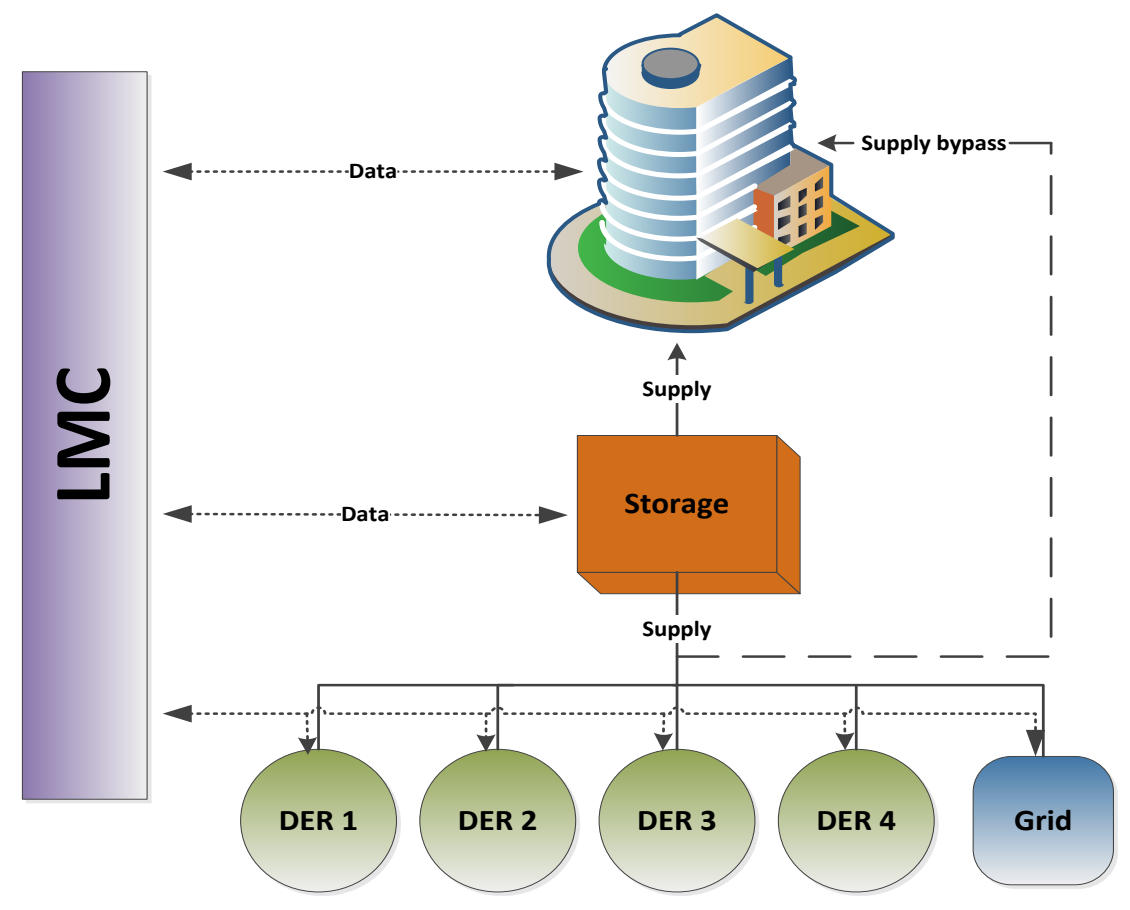

Fig. 6.1: An overview of household level problem formulation

\subsubsection{WORKING SCENARIO}

To formulate the problem, create the objective function, simulate and verify the proposed optimization approach, a working scenario should be built. Let's assume that there are four DER, identified as DER 1 to DER 4, and a central grid in the household energy chain. The house will also have a storage system. DER could be any available source of energy in the locality of the house, including solar PV systems, wind or micro wind turbines, diesel generators, and fully charged electric vehicles that are not in use and can act as a battery. In this chapter, we use the notation DER $i$ to keep the generality of the work.

The storage system is connected to every source as well as the grid. The house will be supplied via the storage system as illustrated in Fig. 6.1. There is a bypass energy path from the sources to 
the house for when the storage system is charging or is off the circuit for any reason. The storage will act as a buffer to supply the deficit of the demand from the house when DER are not generating enough energy, and also to absorb the excess of power generated by the DER when the household demand is low. Grid will kick in when the DER and storage are not capable of supplying the requested demand or when the storage level is below the critical threshold. Grid will also be used when the prices are low and the LMC decides to take advantage of the low price and charge the storage.

The primary objective of the LMC is to meet the demand from the household giving DER the highest priority. LMC should also keep the storage level above a preset threshold, i.e., 20 percent of its capacity. All DER have an hourly maximum and minimum generation which will be communicated to the LMC before each computation. After the household demand is calculated and the market price is fetched from AMI, the storage level will be communicated to the LMC and then the optimization process will be initiated. This process will be reiterative; the system will follow this process at different time slots. The length of the time slot is adjustable in the LMC based on the requirements of the operator. At each iteration point, LMC will run the optimization program for the upcoming slot. Let's assume 3-hour time slot at iteration point $i$, LMC is calculating the values for time $i+3$. This approach allows the grid to program its generation ahead of time and to avoid instability in real-time allocation. The flexibility of time slot allocation enables operators to program the system based on the grid parameters. For example, the time slot length can be set to 12 or 24 hours to give more time to the utility provider for generation planning. The output of the optimization program is a 5 by 1 matrix: DER 1, DER 
2, DER 3, DER 4 and the grid. These values represent the amount of energy each source will contribute to supply the overall demand of the household in that time slot.

\subsubsection{MATHEMATICAL REPRESENTATION}

Ideally, it is desired to mathematically represent the scenario described in 6.2.2 as a function that should be maximized. This maximization is in line with the objective of the work to maximize utilization of DER at a household. Let's consider:

$\operatorname{Max} F=\sum_{i=1}^{j} \alpha_{i} X_{i}-\left(P_{e}-P_{p}\right) \alpha_{j+1} X_{j+1}$

where:

$X_{i}$ is the required optimized amount of contribution from source $i$ to supply the household demand

$X_{j+1}$ is the required optimized amount of contribution from the grid to supply the household demand

$\alpha_{i}$ is the weight factor assigned to the DER $i$ depending on its availability during that time slot

$\alpha_{j+1}$ is the weight factor assigned to the grid

$P_{p}$ is the preferred price at which the household is willing to buy from the grid

$P_{e}$ is the equilibrium market price at which the energy trade will occur

For the working scenario laid out in $6.2 .2, i=4$ and $j=5$. The aassumption is that the household will post its demand. This will be done either by LMC based on its collected data from individual loads inside the building or by the BMS.

LMC will also receive the $P_{e}$ value from the grid through AMI and SM. This is the grid price for supplying electricity to the household at the time of calculation. The frequency of change in price 
signal depends on the characteristic of SG and the existing condition, e.g. currently Toronto is on the ToU system which has three tariffs for off-peak, mid-peak and on-peak times. The approach introduced in this work uses a two-level optimization where $P_{e}$ could also be calculated adaptively based on the circumstances at the time of calculation as well as by utilizing predetermined values as in ToU case. Chapter 7 is dedicated to this subject.

$P_{p}$ is the price desired or preferred by the consumer; the price that the buyer is willing to pay for electricity in larger amount for additional usages or for charging the storage system to be used during peak time. If the market price is greater than the preferred price, then LMC will try to meet the excess demand using the storage. If the demand is still not satisfied, the grid comes into the picture to compensate the deficit and the consumer needs to buy the extra energy from the grid. On the other hand, if the market price is lower than the preferred price, then the LMC will charge the storage for future use or allow for some non-critical loads in the household that have been scheduled to work during the off-peak period, to operate. In this scenario, a threshold level is set for the storage. In this work this threshold level has been set to $20 \%$. LMC has to keep the storage level above this threshold. If the storage falls below this level, LMC will use grid to charge the storage regardless of the price. The storage will also be selected to have additional capacity; the sizing of the storage will be done in a way that storage can sustain household consumption at $70 \%$ to $80 \%$ of its capacity, leaving additional $20 \%$ to $30 \%$ capacity for charging during the time when the market price is lower than the preferred price. In brief, the priority of the LMC is to meet the household demand using the DER. If the demand exceeds the DER production rate, the storage and then the grid will contribute. 
The objective function $F$ has been designed to be maximized in order to provide us with the desired result; maximization of $X_{i}$ is equivalent to maximized utilization of DER. In case of the grid, $X_{j+1}$ or in our scenario $X_{5}$, an additional parameter $\left(P_{e}-P_{p}\right)$ has been added to the grid component. Since the weight of the grid is negative in the objective function, if $P_{e}>P_{p}$, then the grid component has negative effect in the objective function and by maximizing $F, X_{j+l}$ will be minimized which results in less contribution form the grid at high price times. On the other hand, if $P_{e}<P_{p}$, then the opposite will happen and grid contribution will be optimized along with other $X_{i}$. This is in line with the intention of the consumer to buy more electricity from the grid when the price is low for additional usages or for charging the extra capacity of the storage.

Proper constraints pertinent to the scenario laid out in 6.2.2 and 6.2.3 are needed to be added to the objective function in Eq.6.1:

$\alpha_{i}>0$

Lower bound $<X_{i}<$ Upper bound

$\sum_{i}^{j+1} X_{i}=$ Household demand at any iteration

In Eq. 6.2, the lower and upper bounds for each variable $X_{i}$ which represents one source, are determined by the source and communicated to the LMC. LMC will update the table of values and the program fetches these values prior to commencing iteration. A third constraint is in place to ensure the demand of the household is met and to create a cut-off point for optimization program to terminate calculations when the point is reached. 


\subsection{OPTIMIZATION METHODS AND SIMULATION CASES}

In this section, the objective function and its associated constraints in Eq. 6.1 and 6.2 will be discussed, the commonly used optimization techniques based on the mathematical properties of the objective function will be debated and finally, simulation cases that mimic real world working scenarios will be built and explained.

\subsubsection{MATHEMATICAL ANALYSIS OF THE EQUATION}

The objective function presented in Eq.6.1 can be considered both time-variant and timeinvariant depending on the time range: from micro point of view or in a single time slot, Eq.6.1 is time-invariant since the variables do not change with time and remain constant. However, from macro point of view or when considering a day rather than a single time slot, the variables change with time, making Eq.6.1 a time-variant function.

In calculus, analytic geometry and related areas, a linear function is a polynomial of degree one or less, including the zero polynomial. A single variable function can be written in the form of $f(x)=a x+b$, where $\mathrm{a}$ and $\mathrm{b}$ are constants and often, real numbers. The graph of such a function is a non-vertical line where $a$ denotes the slope of the line, and $b$ is the intercept. On the other hand, a function of any finite number of independent variables can be shown in form of $f\left(x_{1}, x_{2} \ldots, x_{n}\right)=$ $a+b_{1} x_{1}+b_{2} x_{2}+\ldots+b_{n} x_{n}$ which forms a hyperplane of dimension $n$. Based on this definition, Eq.6.1 is a polynomial of degree one, therefore, linear and multivariable with five variables.

\subsubsection{OPTIMIZATION METHODS}

In its simplest form, an optimization problem entails maximization or minimization of a function by systematically putting in values from a set of numbers and computing 
the value of the function to find the optimum value. By another definition, optimization includes finding the best available values of an objective function in a defined domain. The generalization of optimization theory and techniques to formulate it comprises a field of applied mathematics that is not the focus of this work. In this section, we intend to use the application of optimization theory and its known techniques to calculate the optimum values for our objective function. Linear programming (LP) is a convex programming technique that deals with a case in which the objective function is linear and the constraints are specified using only linear equalities as well as inequalities. Such a set is called a polyhedron or a polytope if it is bounded. To solve optimization problems, researchers may use iterative approaches that repeat an algorithm and terminate in a finite number of steps, or iterative methods that converge to a solution (for some class of problems), or use heuristic approaches that may provide an approximate solution to the optimization problem. A heuristic method is any algorithm which does not mathematically guarantee to find the solution, but provides near optimal solution for the problem and has been proved to be useful in certain practical situations.

A significant focus of recent research has been on heuristic algorithms applicable to residential and industrial scheduling problems. Heuristic approaches can be efficient by yielding faster solutions and are ideal for implementation as an embedded system and as an integral part of a bigger structure. As a downside, a good but not necessarily an optimal solution to the optimization problem can be found using these techniques [28]. Heuristic methods are problemdependent techniques, therefore, they are usually modified based on the problem at hand to take full advantage of the particularities of the specific problem. However, they usually get trapped in 
a local optimum and thus fail, in general, to obtain the global optimum solution. Metaheuristic approaches, on the other hand, are problem-independent techniques. Therefore, they do not take advantage of any specificity of the problem, and hence can be used as black boxes.

In order to verify the approach proposed in 6.2, three different, yet known optimization methods are used to maximize the objective function in Eq. 6.1. The results of these three methods will be then compared to examine the reliability of the values and to identify the best method to be embedded in the LMC. Parameters such as response time, computation intensity and ease of deployment are important when selecting the method for LMC fabrication.

Six cases have been created for simulation purpose based on the situations that might happen in the actual demand-supply cycle. All six cases have been simulated using the three optimization methods and their results have been compared in section 6.4.

The optimization techniques used in this work are Genetic Algorithm (GA), Fmincon and Simulated Annealing (SA).

\subsubsection{GENETIC ALGORITHM}

Genetic algorithm (GA) is a method for solving both constrained and unconstrained optimization problems based on a natural selection process that mimics biological evolution. Inspired by and named after biological processes of inheritance, mutation, natural selection, and genetic operators such as crossover and mutation, GA is a particular class of evolutionary algorithms. The algorithm continually modifies a population of individual solutions. At each step, the genetic algorithm randomly selects individuals from the current population and uses them as parents to 
produce children for the next generation. With consecutive iteration of the process the population will grow toward an optimal solution [29]. Implementation of GA requires:

- Solution representation

- Solution fitness evaluation and selection scheme

- Reproduction decision (crossover and mutation)

- Replacement scheme

The following is an outline of the standard GA procedures [30]:

1. Randomly generate a starting population

2. Repeat the following until termination criterion is met:

2.1 Evaluate each chromosome using a fitness function

2.2 Select pairs of chromosomes using some scheme based on fitness

2.3 Apply crossover on the selected pairs of chromosomes

2.4 Apply mutation on randomly selected chromosomes

2.5 Replace old population with newly created chromosomes

\section{End}

GA method is a meta-heuristic approach that considers some parts of the solution space rather than the total space in order to reach a global optimum or near-optimum solution. Thus, GA has the advantage of faster response in terms of reaching the global optima. Crossover and mutation operations in GA make the population more diverse and therefore reduce the chance of falling into a local optima trap. The other advantage of GA as a random search optimization method is that it does not require information about the objective function and looks at it as a black box. 
For example, GA does not require an initial point for the specific function to start the optimization process. In brief, GA is the preferred method when a sub-optimal solution in shorter time is acceptable and desired.

\subsubsection{FMINCON}

Fmincon is a function included in MATLAB's Optimization Toolbox which seeks the minimizer of a scalar function of multiple variables, within a region bounded by linear constraints and at an initial estimate. This is generally referred to as constrained nonlinear optimization or nonlinearmultivariable programming. In our case, it is possible to use the Fmincon method and the negative of the objective function in Eq. 6.1 to obtain the required results. When using Fmincon, the optimum point will be strongly dependent on the initial point. This is not a problem for a quadratic equation since in quadratic equations local minimum is the same as global minimum. However, when there are many local minima, in general, Fmincon will converge to a non-global minimum. The advantage, on the other hand, is that Fmincon is a suitable method for constrained, multivariable and smooth functions.

\subsubsection{SIMULATED ANNEALING}

The Simulated Annealing (SA) algorithm was originally inspired from the process of annealing in metal work. Annealing involves heating and cooling a material to alter its physical properties due to the changes in its internal structure. When a solid is slowly cooled so that it is eventually frozen, this change happens at a minimum energy configuration (cost). The SA method used in this work, is a probabilistic technique for approximating the global optimum of a given function. 
Specifically, it is a metaheuristic approach to approximate global optima in a large search space and is often used when the search space is discrete [31].

The following steps briefly describe how SA method works to find the global optima point:

1. First generate a random solution

2. Calculate its cost (energy) using the cost function that has been defined

3. Generate a random neighboring solution

4. Calculate the new solution's cost

5. Compare the two costs:

- If new cost $<$ old cost, then move to the new solution

- If new cost > old cost, then maybe move to the new solution

6. Repeat steps 3 to 5 above until an acceptable solution is found or some maximum number of iterations is reached

Neighboring solution means having only one different element between the old and the new solutions. This simply means switching two elements of the solution randomly and re-calculating the cost. Most of the times, the algorithm will avoid moving to a worse solution; however, this is not always the case. SA sometimes chooses to keep the worse solution. The decision making process is that the algorithm calculates a parameter called the "acceptance probability" and then compares it to a random number. The acceptance probability function takes in the old cost, new cost, and current "temperature" and generates a number between 0 and 1 which determines whether or not to adopt the new solution. The temperature is a function of which iteration SA is on. Once the acceptance probability is calculated, it is compared to a randomly generated number 
between 0 and 1 . If the acceptance probability is larger than the random number, switching to the new solution will happen.

The advantage of SA method for our application is that it is a fast approach because similar to GA method it falls into metaheuristic approaches. SA is also preferred for discrete spaces and provides near-best results which makes it suitable for our case where finding the precise global optimum is less important than finding an acceptable local optimum in a fixed amount of time.

\subsubsection{SIMULATION CASES}

To be able to run the simulations using the objective function, and for each of the three methods described in 6.3.2, it is necessary to narrow down the assumptions. The actual scenarios should be simulated to verify the performance of the proposed approach in different working conditions. Based on the working scenarios outlined in 6.2.2, six cases have been created to best cover the possibilities in real situations. The unit for the values stated as generation, demand and storage capacity could be in any system as the calculations and simulation results are independent of the units. For the sake of simplicity, in this section units are not added to the values; however, KWh would be the best representing unit in our case. The same note is valid for the prices. Canadian Cent was the adopted unit in our assumptions. In this section, Demand denotes the total energy required in the household communicated to LMC in that time slot and DERsum_max denotes the summation of the upper bounds of all DER or the maximum available generation from all sources of energy except the grid. Grid is the upper bound or the maximum energy that is available from the grid at the time slot. To further simplify the cases, the maximum capacity of the storage is considered to be 100 units (KWh) to correspond with the threshold levels of $20 \%$ 
as the minimum amount, $70 \%$ as the nominal required capacity to supply the household and $100 \%$ as the maximum charging capacity to absorb cheap electricity at low price time. The cases are as follows:

Case 1: $P_{\mathrm{p}}<P_{e} \&($ DERsum_max+ storage $)<$ Demand

In case 1 , since the demand exceeds the maximum DER generation capacity plus the available capacity in the storage, utilization of grid becomes essential regardless of the market price. LMC should maintain the storage level at greater than or equal to $20 \%$ of the maximum capacity, so an extra 20 units should be added to the total demand.

- $P_{p}=10$

- $P_{e}=15$

- Demand $=50$

- DERsum_max $=10+10+10+10=40$

- Grid $=50$

- Storage $=0$; storage maximum capacity $=100$, the storage should maintain the minimum level of 20 at all times

Therefore, the total demand to supply is: Demand $=50+20=70$

Case 2: $P_{\mathrm{p}}>P_{e} \&($ DERsum_max+ storage $)<$ Demand

- $P_{p}=15$

- $P_{e}=10$

- Demand $=70$

- DERsum_max $=10+10+10+10=40$ 
- Grid $=50$

- Storage $=10$; storage total capacity $=100$, the storage should maintain the minimum level of 20 at all times

Therefore, the total demand to supply is: Demand $=70-10+20=80$

Case 3: $P_{\mathrm{p}}>P_{e} \&$ (DERsum_max + storage $)>$ Demand \& DERsum_max $<$ Demand

- $P_{\mathrm{p}}=15$

- $P_{e}=10$

- Demand $=70$

- DERsum_max $=10+10+10+10=40$

- Grid $=50$

- Storage $=50$; storage total capacity $=100$, the storage should maintain the minimum level of 20 at all times

Therefore, the total demand to supply is: Demand $=70-(50-20)=40$

Case 4: $P_{\mathrm{p}}>P_{e} \&$ (DERsum_max+ storage) $>$ Demand \& DERsum_max $>$ Demand

- $P_{\mathrm{p}}=15$

- $P_{e}=10$

- Demand $=30$

- DERsum_max $=10+10+10+10=40$

- Grid $=50$

- Storage $=50$; storage total capacity $=100$, the storage should maintain the minimum level of 20 at all times 
Therefore, the total demand to supply is: Demand $=30$.

case 5: $P_{\mathrm{p}}>P_{e} \&($ DERsum_max+ storage $)>$ Demand \& DERsum_max $<$ Demand

- $P_{\mathrm{p}}=15$

- $P_{e}=10$

- Demand $=70$

- DERsum_max $=10+10+10+10=40$

- Grid $=50$

- Storage $=100$; storage total capacity $=100$, the storage should maintain the minimum level of 20 at all times

Therefore, the total demand to supply is: Demand=Demand-(storage- 20$)=-10$

In this case the storage supplies the demand and the DER charge the storage.

Case 6: $P_{\mathrm{p}}<P_{e} \&$ (DERsum_max + storage $)>$ Demand \& DERsum_max $<$ Demand

- $P_{\mathrm{p}}=10$

- $P_{e}=15$

- Demand $=70$

- DERsum_max $=10+10+10+10=40$

- Grid $=50$

- Storage $=50$; storage total capacity $=100$, the storage should maintain the minimum level of 20 at all times

Therefore, the total demand to supply is: Demand $=($ storage_max-storage $)+$ Demand $=100$ $50+70=120$ 


\subsection{SIMULATION RESULTS AND COMPARISON}

The simulations in this work were performed using MATLAB software. MATLAB's optimization toolbox, embedded functions as well as proprietary codes developed for this purpose were used in conjunction. All the assumptions mentioned in sections 6.2 and 6.3 were considered in running the simulations. The maximum and minimum generation capacities for DER and the grids were mentioned for each case separately. These maximum and minimum values were the upper and lower bounds for $X_{i}$. In our simulations, the lower and upper bounds for DER $\left(X_{1}, X_{2}, X_{3}\right.$ and $\left.X_{4}\right)$ were considered fixed at 0 and $10(\mathrm{KWh})$, respectively, while the upper bound for the grid $\left(X_{5}\right)$ was different for each case. The lower bound for the grid was fixed at 0 as well. Another key parameter in the proposed optimization function is the matrix of

weights $\left[\left.\alpha_{i}\right|_{i=1} ^{j+1}\right]$ for each variable $X_{i}$. This matrix has been considered as [5, 2, 1, 1, and 3] in these simulations. To enable the program to receive different values for the upper and lower bounds as well as the weights, respective tables were created in excel format for each item. These tables will be fetched by the program at each iteration in form of calling functions to provide the optimization program with the latest values. In actual working condition, it is the responsibility of LMC to update these tables based on the data communicated from each source to the LMC.

\subsubsection{SIMULATION RESULTS}

The following tables provide the detailed outputs of the proposed optimization process for each case using each of the GA, Fmincon and SA techniques. 


\section{Ryerson University $\quad$ Chapter 6: RESIDENTIAL LEVEL OPTIMIZATION 2017}

\begin{tabular}{|l|c|c|c|c|c|}
\hline \multirow{2}{*}{ GA Method } & DER1 & DER2 & DER3 & DER4 & Grid \\
\hline CASE1 & 10.0000 & 10.0000 & 10.0000 & 9.9972 & 30.0028 \\
\hline CASE2 & 10.0000 & 9.9993 & 9.9843 & 9.9999 & 40.0166 \\
\hline CASE3 & 9.9983 & 9.8461 & 9.5027 & 9.9828 & 0.6701 \\
\hline CASE4 & 9.6647 & 9.1358 & 4.1847 & 7.0147 & 0 \\
\hline CASE5 & 10.0000 & 10.0000 & 10.0000 & 10.0000 & 0 \\
\hline CASE6 & 10.0000 & 10.0000 & 10.0000 & 10.0000 & 80.0001 \\
\hline
\end{tabular}

Table 6.1: Household level optimization simulation results based on the GA method

\begin{tabular}{|l|c|c|c|c|c|}
\hline $\begin{array}{l}\text { Fmincon } \\
\text { Method }\end{array}$ & DER1 & DER2 & DER3 & DER4 & Grid \\
\hline CASE1 & 10 & 10 & 10 & 10 & 30 \\
\hline CASE2 & 10 & 10 & 10 & 10 & 40 \\
\hline CASE3 & 10 & 10 & 10 & 10 & 0 \\
\hline CASE4 & 10 & 10 & 5 & 5 & 0 \\
\hline CASE5 & 10 & 10 & 10 & 10 & 0 \\
\hline CASE6 & 2 & 2 & 2 & 2 & 112 \\
\hline
\end{tabular}

Table 6.2: Household level optimization simulation results based on the Fmincon method

\begin{tabular}{|l|c|c|c|c|c|}
\hline SA Method & DER1 & DER2 & DER3 & DER4 & Grid \\
\hline CASE1 & 9.966 & 9.952 & 9.948 & 9.99 & 30.028 \\
\hline CASE2 & 9.988 & 9.993 & 10 & 9.683 & 40.001 \\
\hline CASE3 & 9.999 & 9.999 & 9.993 & 9.985 & 0.00 \\
\hline CASE4 & 10 & 10 & 5 & 5 & 0 \\
\hline CASE5 & 10 & 10 & 10 & 10 & 0 \\
\hline CASE6 & 9.995 & 9.921 & 9.983 & 9.8597 & 79.992 \\
\hline
\end{tabular}

Table 6.3: Household level optimization simulation results based on the SA method 


\subsubsection{COMPARABLE WORKS IN THE LITERATURE}

There are various works available in the literature on DER utilization in SG platform mainly due to their rapid pace of development. However, these works are more centered around the optimization of consumption at home to overcome the excess costs of a household. This comes at the cost of reduced comfort on part of the residents. Novel mathematical models for major household loads, i.e., fridge, freezer, dishwasher, washer and dryer, stove, water heater, hot tub, and pool pumps as well as other components of a residential energy system including lighting, heating, and air conditioning have been proposed previously [32]. Depending on the end user's choice, different objective functions can be adopted to solve the optimization problem. The work gave an idea about various optimized values but the trade off among the loads, which usually exists in these cases of optimization, has not been addressed. Similarly, the work laid out in [33] used a microgrid with integrated DER, energy storage and controllable, critical and non-critical loads as the case of optimization. The optimization is performed by Reduced Gradient Method in the grid connected mode. Unlike the presented logic in this dissertation, [33] proposes a case where DER optimize their production to optimize the cost. [33] uses a storage similar to our scenario but in a quite different way, therefore, it is not a proper case for comparison of optimized values. We have utilized the idea of market price along with household demand in order to make decision about the timing and amount of storage charging; such inclusion has not been utilized in literatures effectively. As an alternative work, [34] presented a generalized formulation for determining the optimal operation strategy as well as cost optimization while reducing the emissions in microgrids. The model takes into consideration the operation and 
Ryerson University $\quad$ Chapter 6: RESIDENTIAL LEVEL OPTIMIZATION 2017

maintenance costs as well as the reduction in emissions of $\mathrm{NO}_{\mathrm{x}}, \mathrm{SO}_{2}$, and $\mathrm{CO}_{2}$. The work uses Quantum-Inspired Evolutionary Algorithm to find the optimal solution.

The work presented in this dissertation is unique. Majority of previous research works have used DER optimization; in other words they manipulated DER to achieve their goal. In our case however, an objective function has been developed for a residential unit that uses priority levels for DER rather than changing their generation capacity. Our proposed scheme uses a storage stratigicly in conjuction with DER and grid to optimize the cost by otimizing contribution of grid in overall supply of the residential loads.

\subsubsection{COMPARATIVE ANALYSIS}

This section will provide a comparative study of the results from two perspectives. First, all six cases were simulated seperately using each of the three methods. Then, results for the cases under the same method were compared against each other. At the next stage, the results for a single DER, for all 6 cases, obtained from GA, Fmincon and SA methods were compared against each other for better understanding of the methods suitability. Figures 6.2 to 6.7 depict the first perspective. 

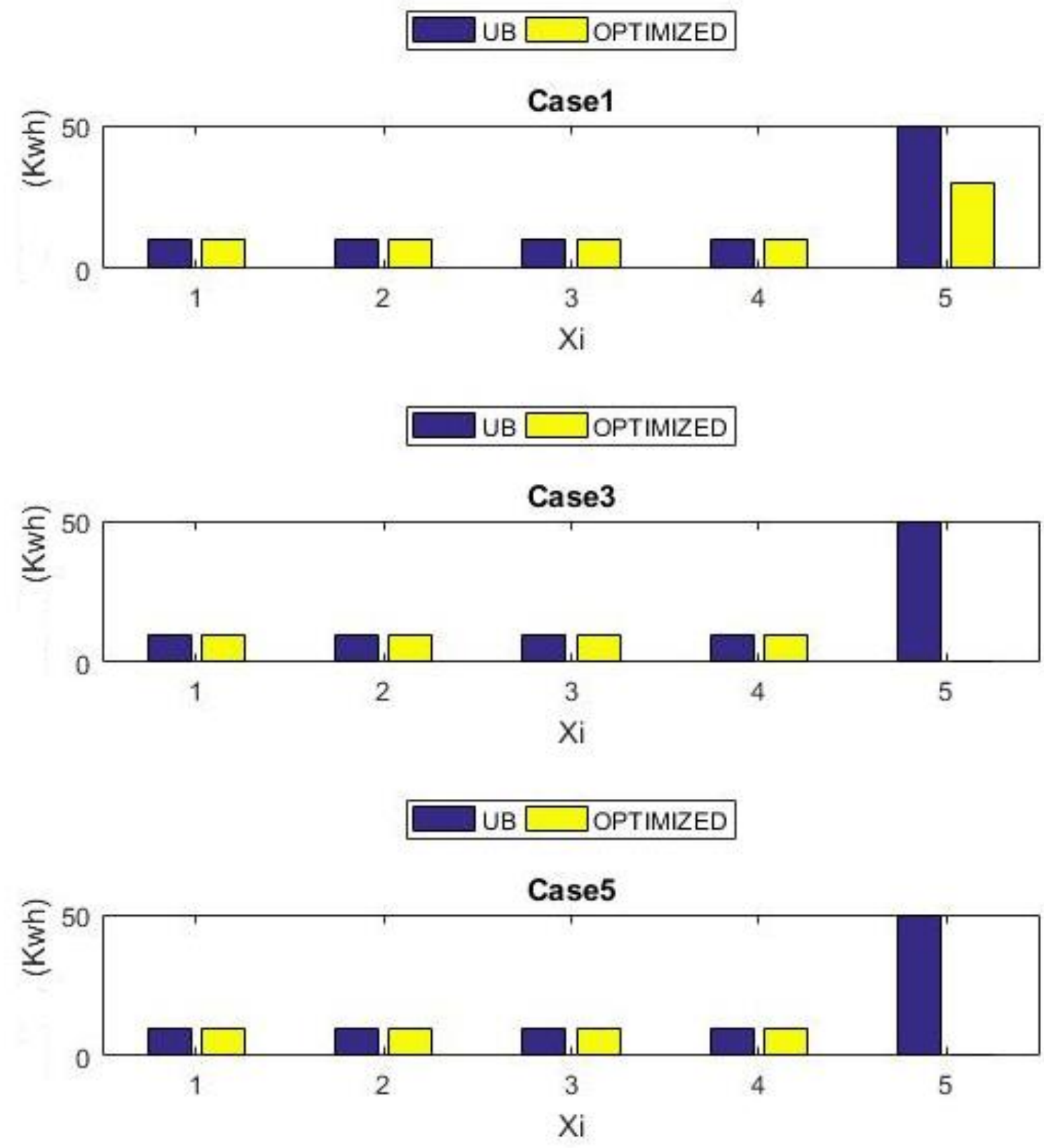

Fig. 6.2: Comparative overview of the results by GA method for cases 1, 3 and 5 

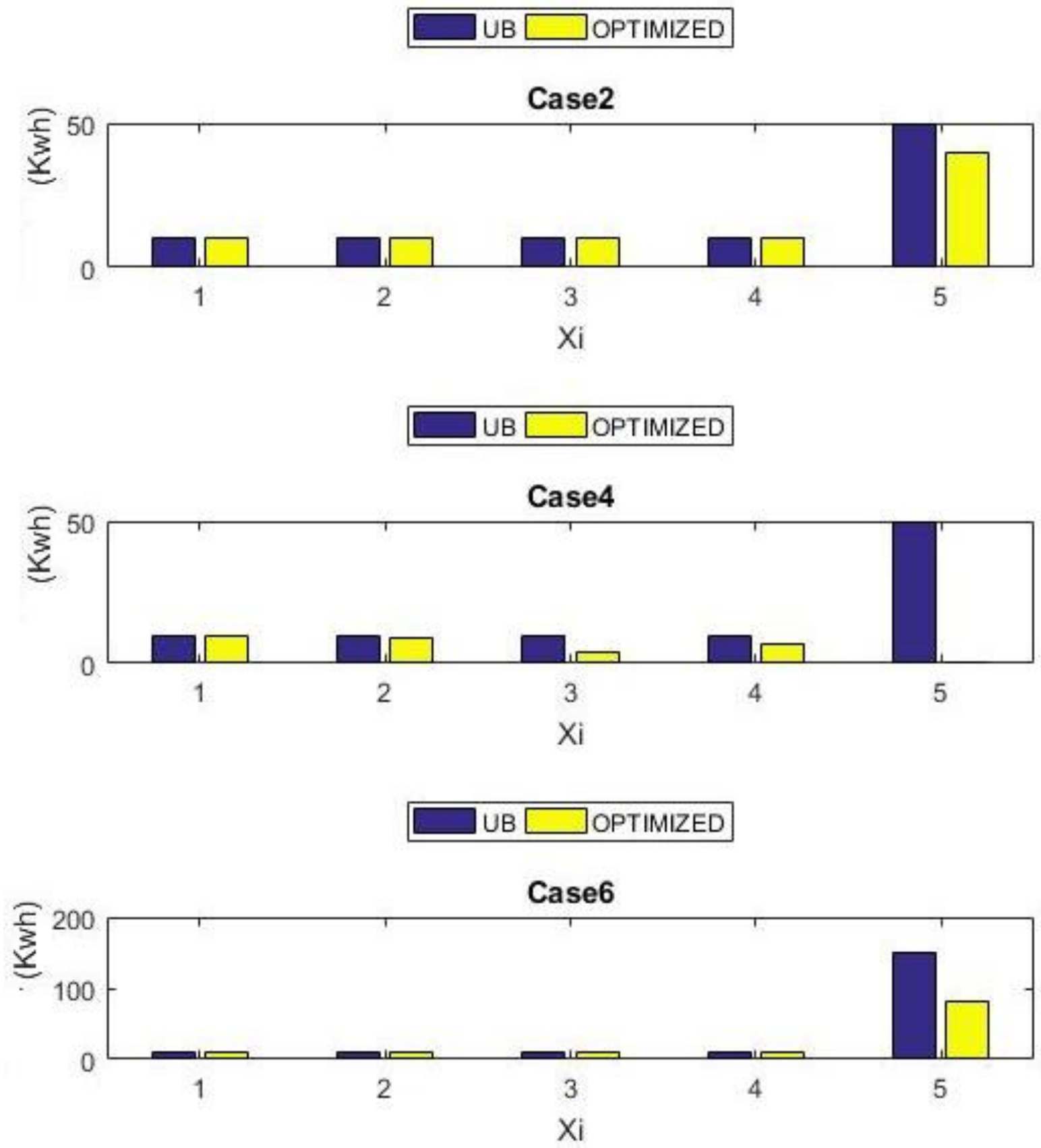

Fig. 6.3: Comparative overview of the results by GA method for cases 2, 4 and 6 

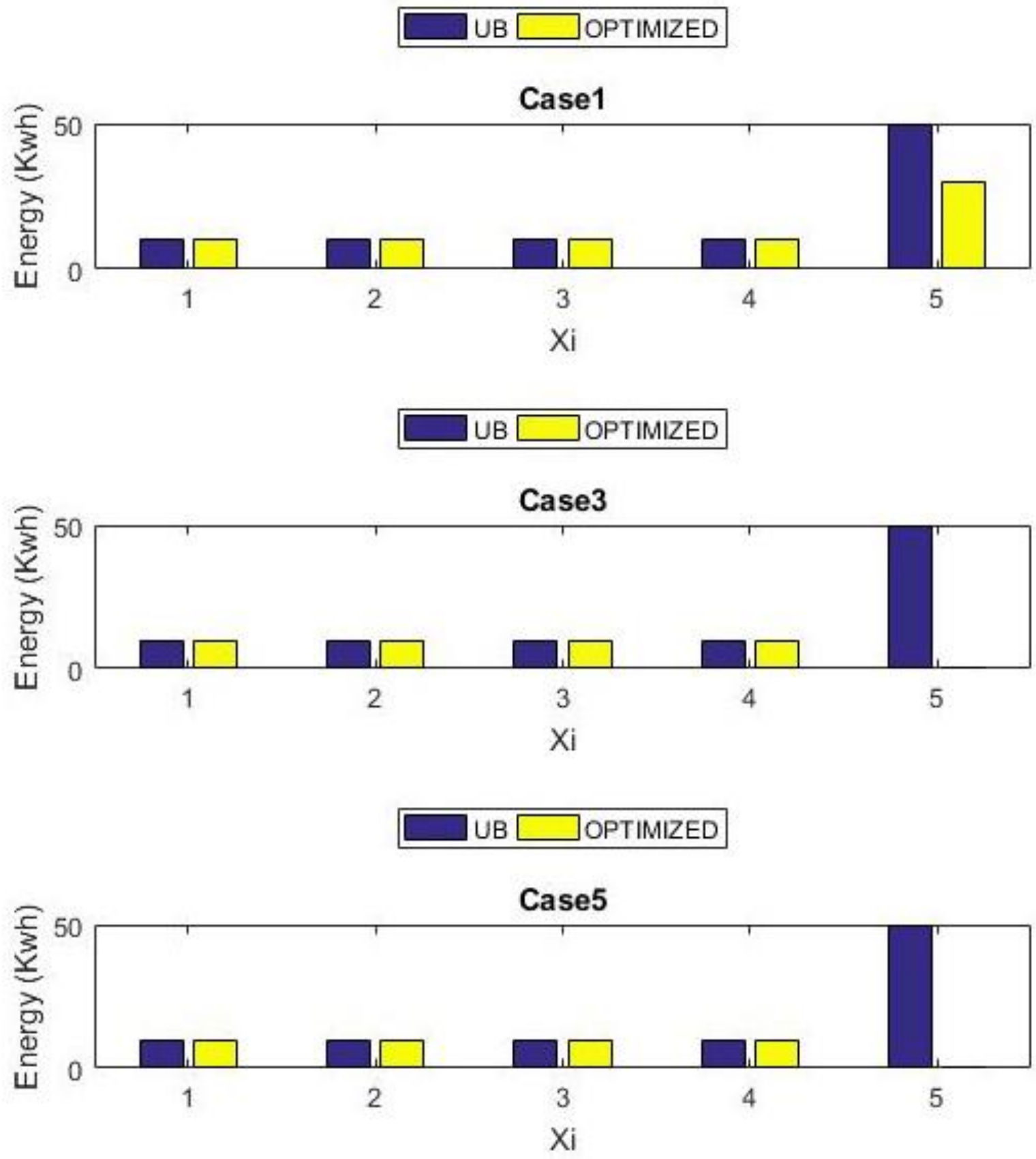

Fig. 6.4: Comparative overview of the results by Fmincon method for cases 1, 3 and 5 

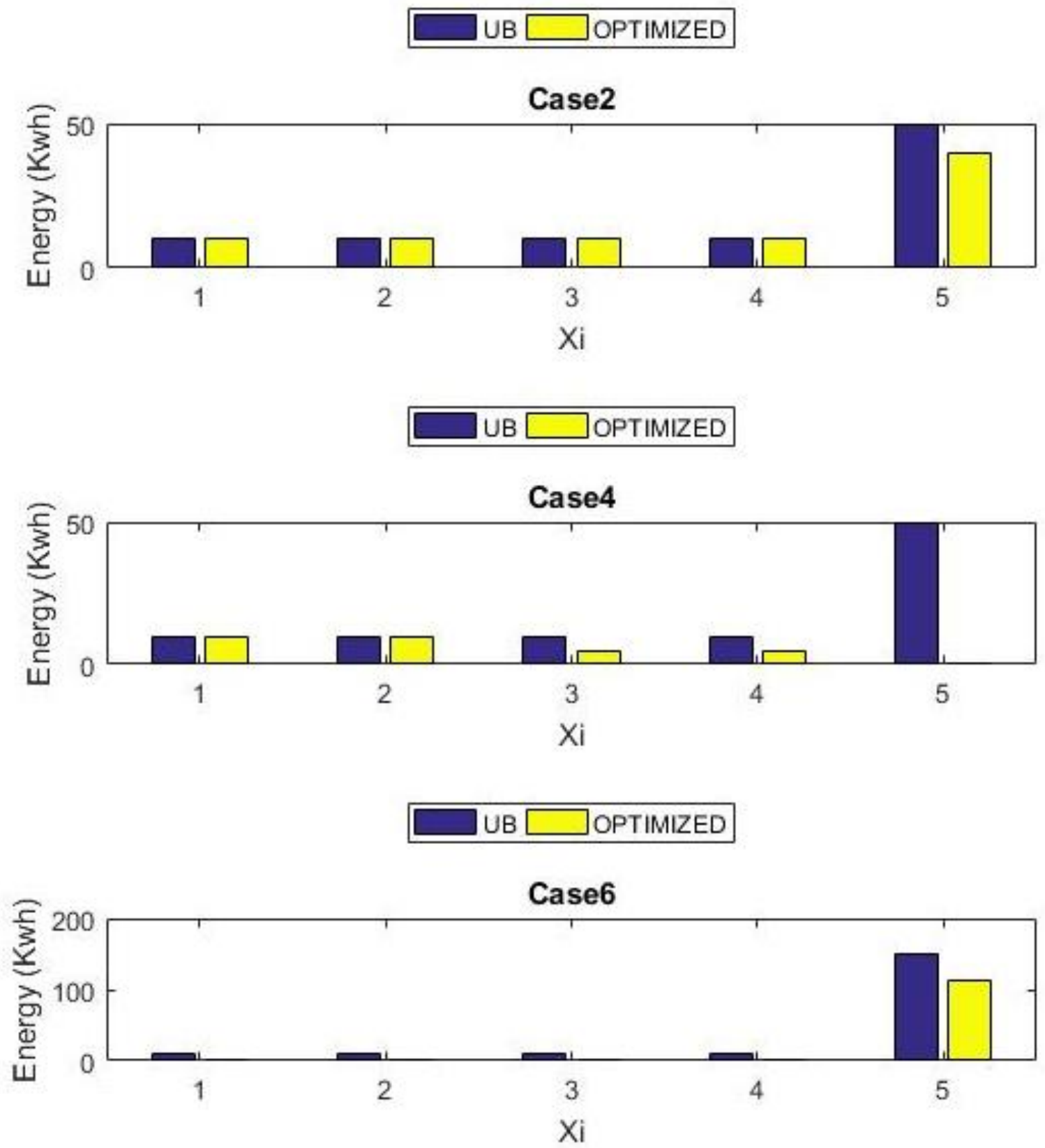

Fig. 6.5: Comparative overview of the results by Fmincon method for cases 2, 4 and 6 

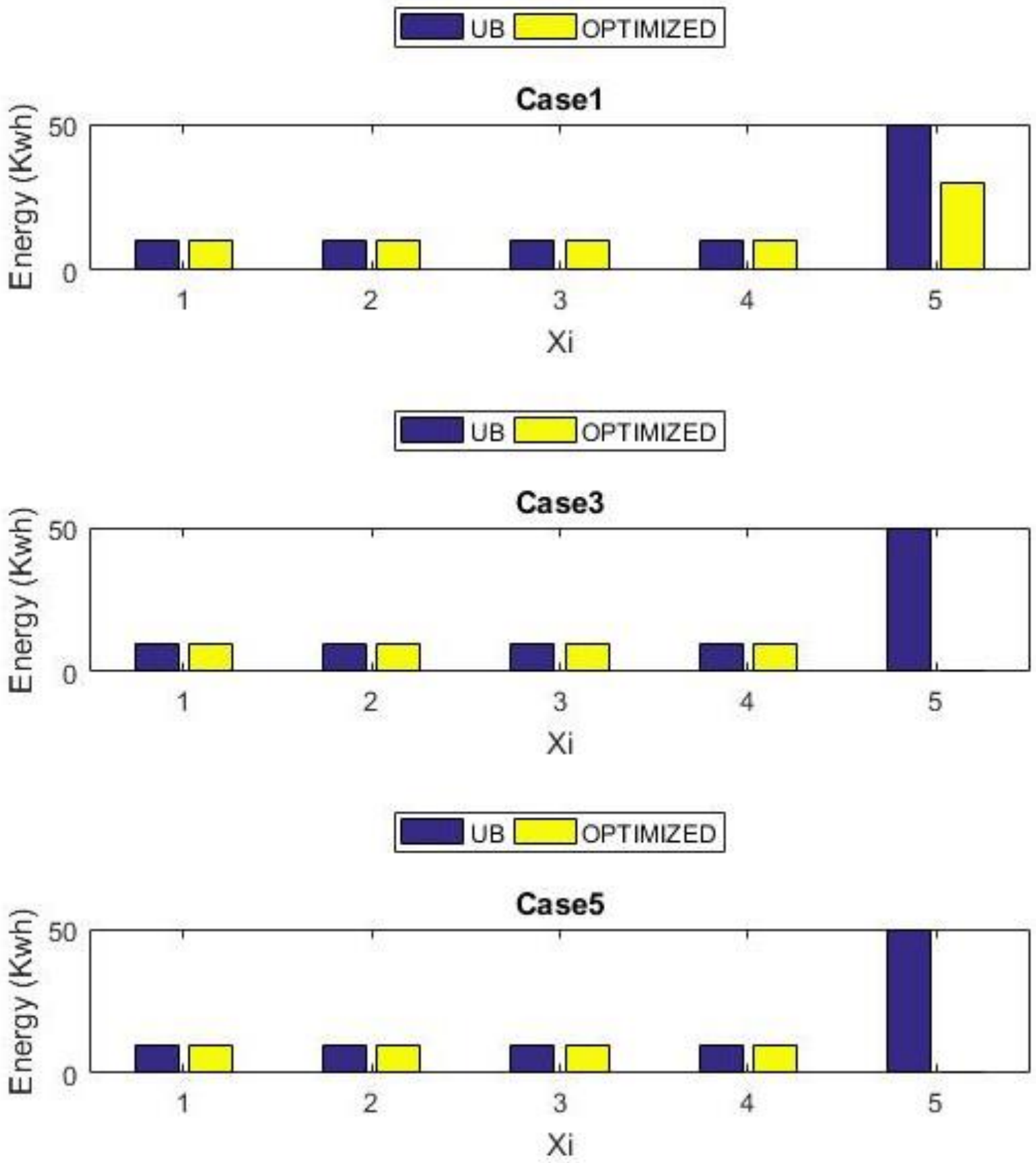

Fig. 6.6: Comparative overview of the results by SA method for cases 1, 3 and 5 

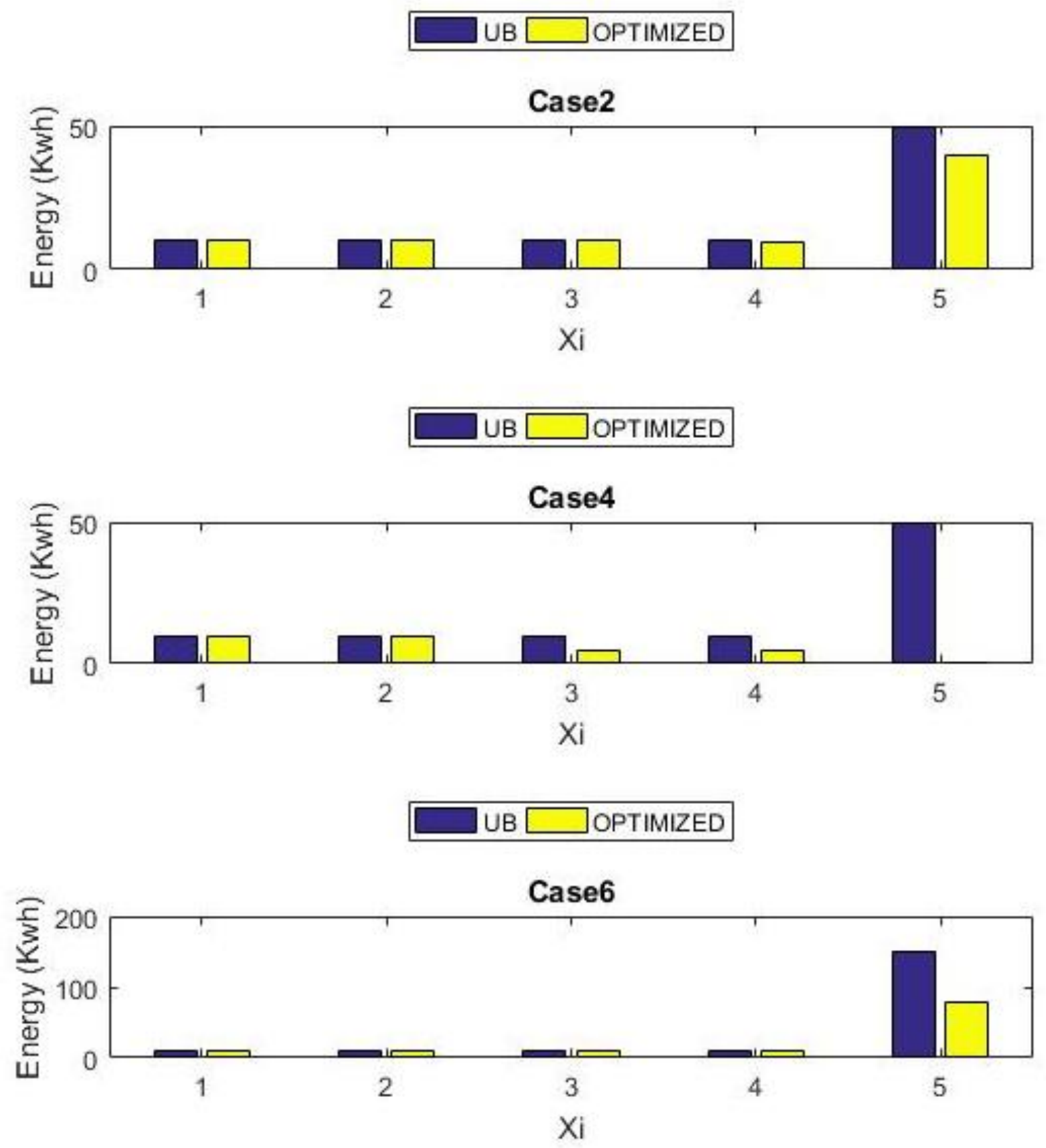

Fig. 6.7: Comparative overview of the results by SA method for cases 2, 4 and 6 
Figures 6.8 to 6.12 illustrate the second comparison perspective. In these pictures, column 1 in the $\mathrm{X}$ axis represents the upper bound while columns 2, 3 and 4 represent the results obtained using GA, Fmincon and SA methods, respectively.
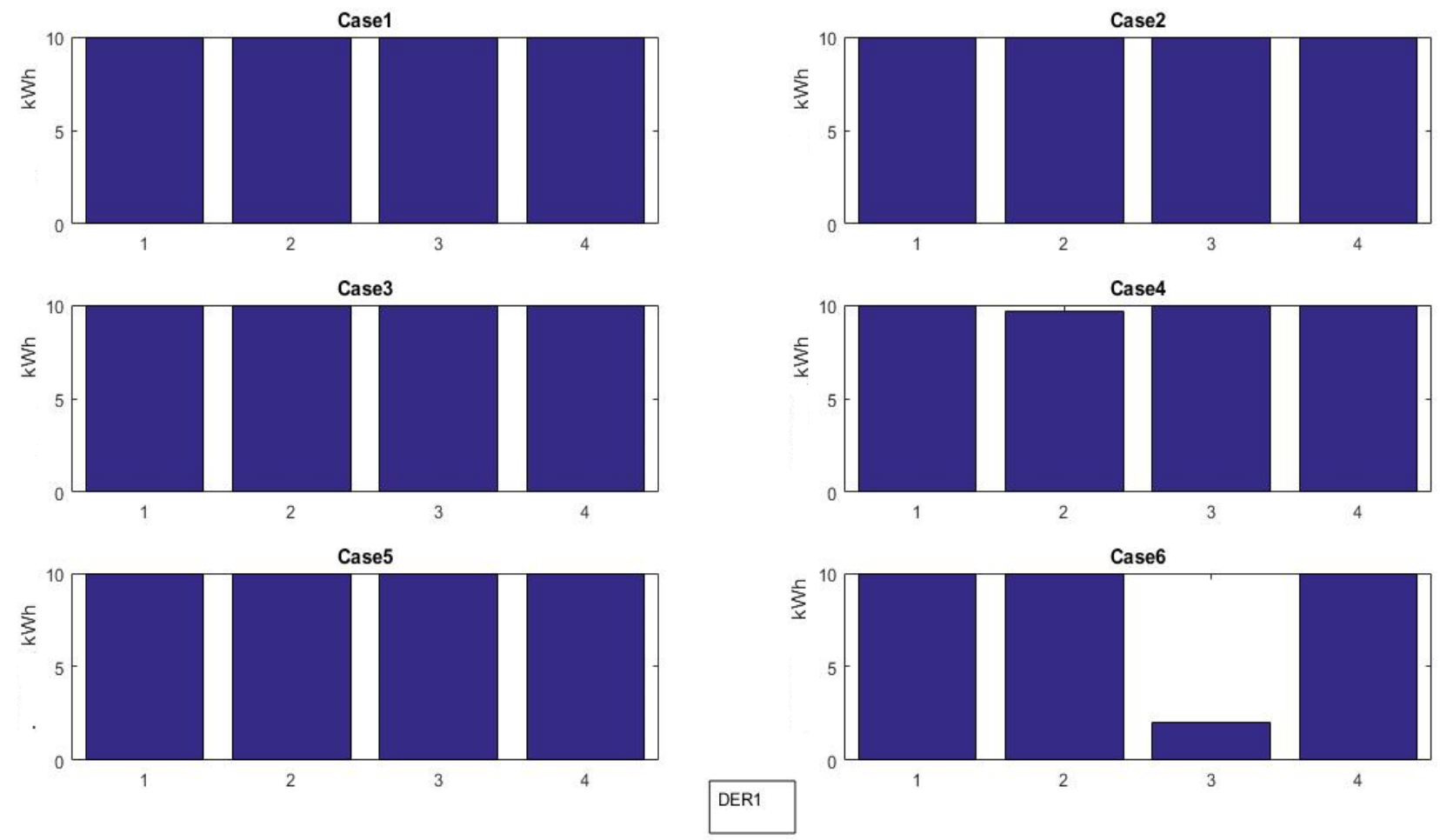

Fig. 6.8: Comparative overview of the results for DER1 using different methods 

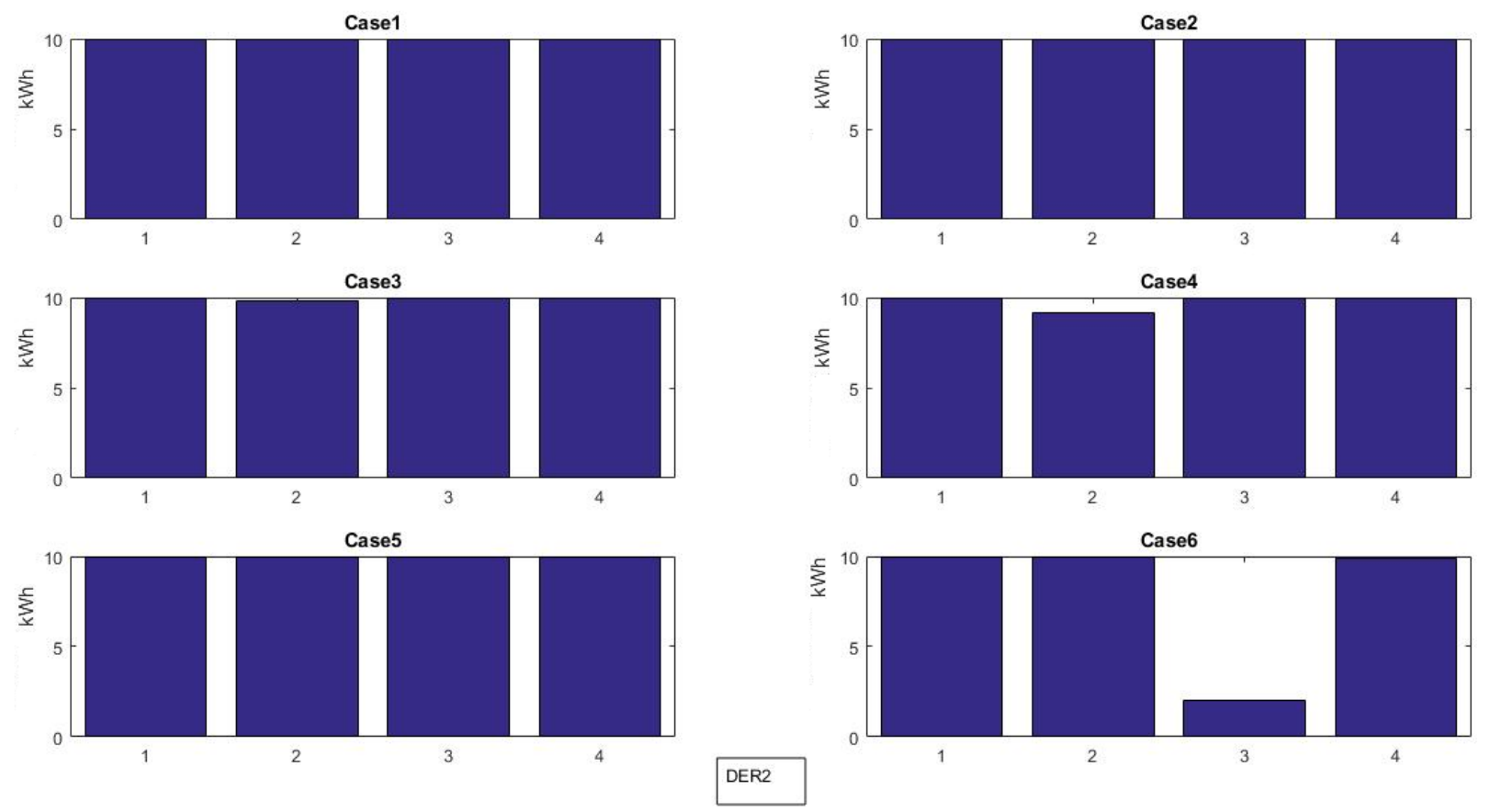

Fig. 6.9: Comparative overview of the results for DER2 using different methods
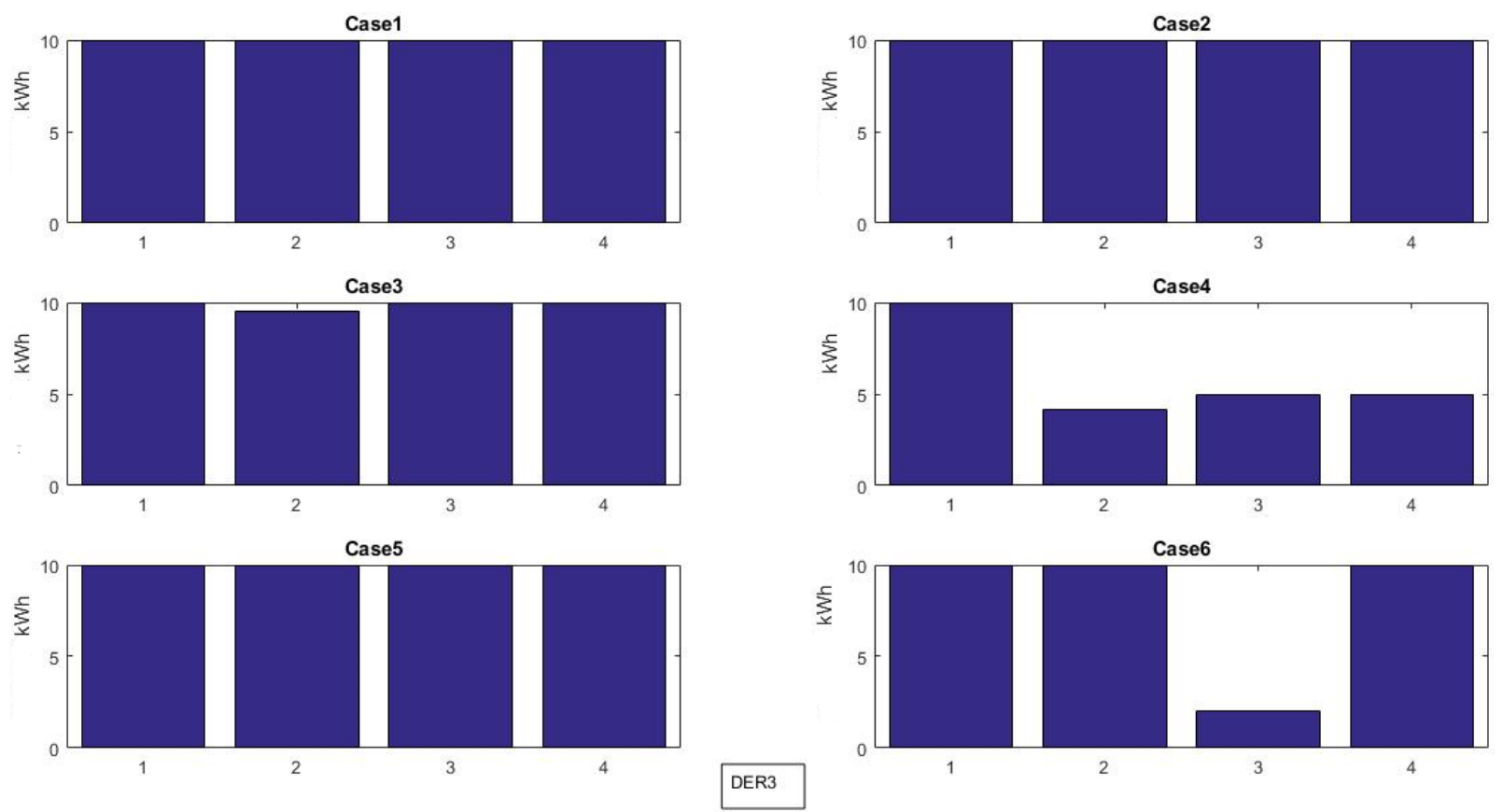

Fig. 6.10: Comparative overview of the results for DER3 using different methods 

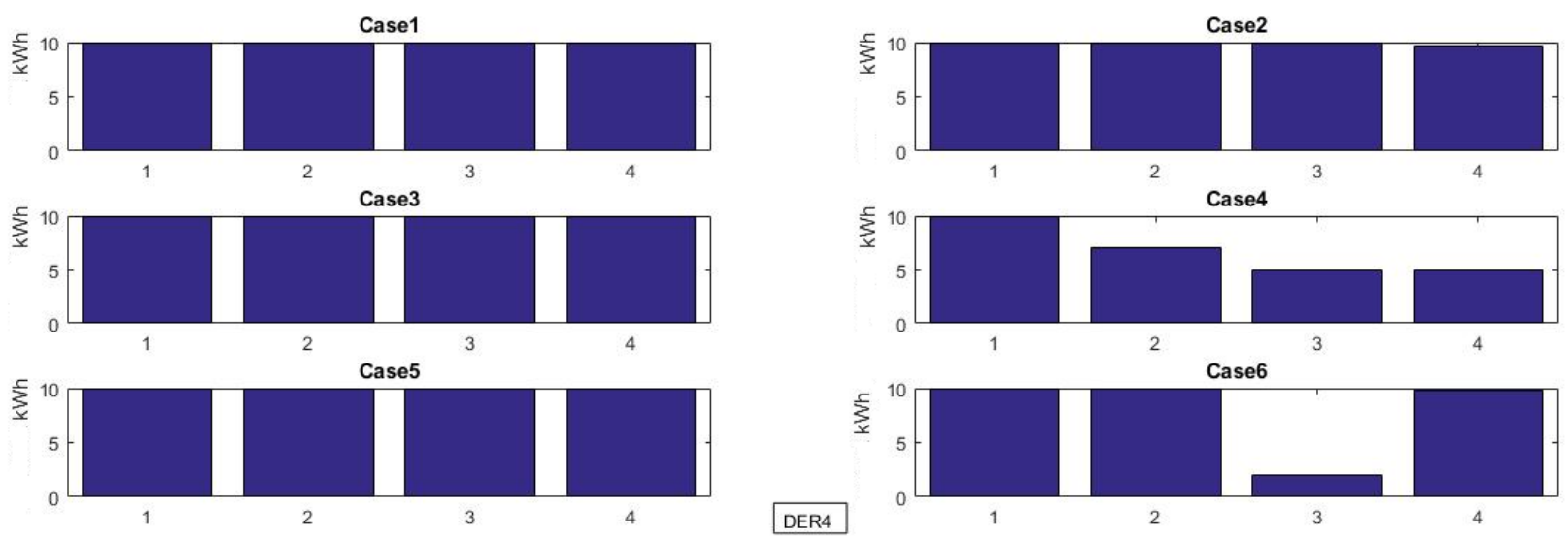

Fig. 6.11: Comparative overview of the results for DER4 using different methods
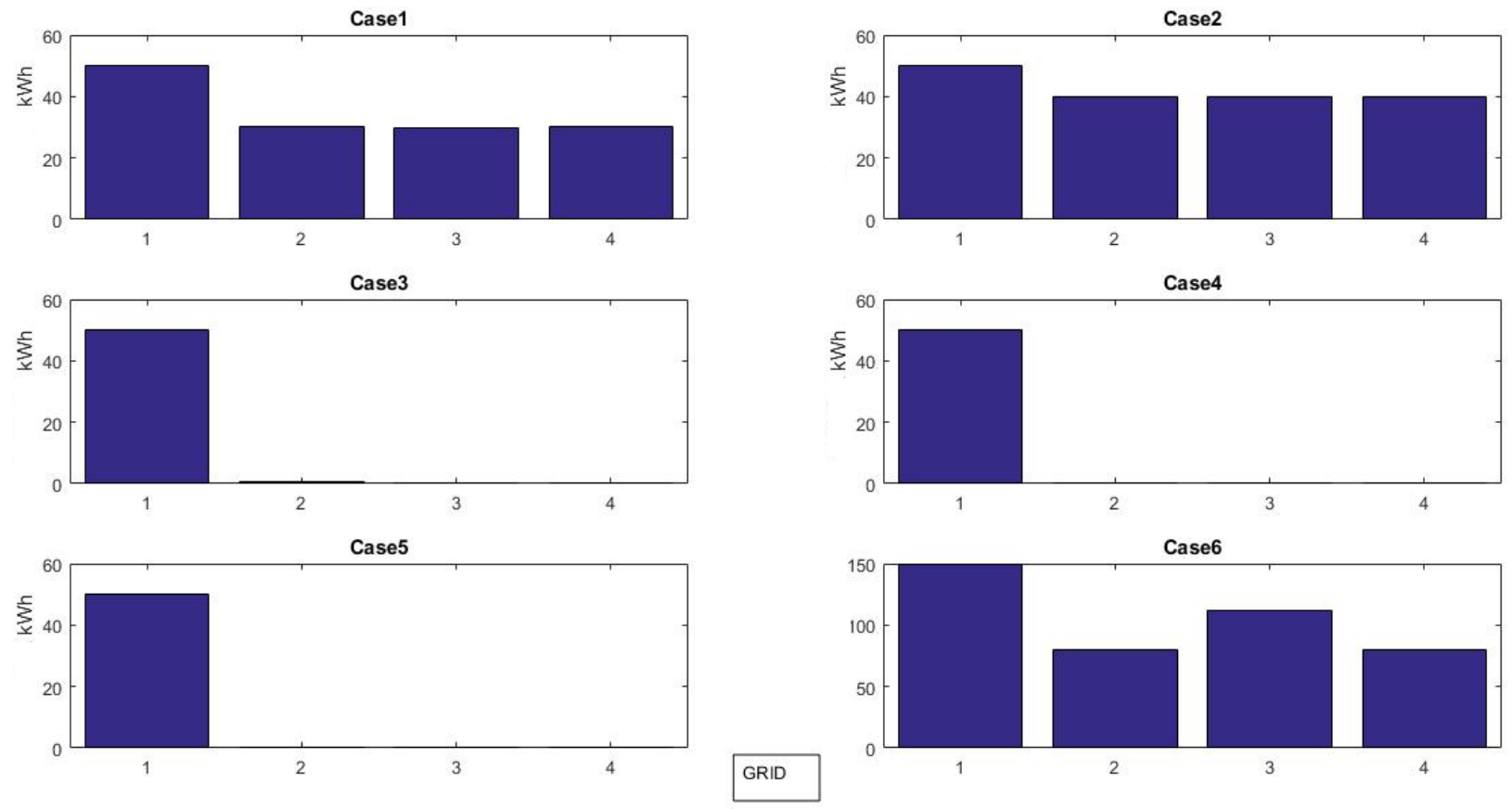

Fig. 6.12: Comparative overview of the results for Grid using different methods

\subsection{CONCLUSION}

Based on the results presented in 6.4.1, all three methods demonstrate excellent coherency in terms of providing optimal values for DER contributions. Based on the comparative analysis of 
simulation results, values from GA and SA methods show better coherency. It is believed that the metaheuristic nature of GA and SA methods is the reason for such similarity, while the different approach used in Fmincon method resulted in slightly different values. The obtained values for DER are as close to the upper bound values set for them as possible; this means that the primary goal of the optimization process, i.e., maximizing utilization of DER, has been achieved. The outputs of the three optimization processes for each case are also consistent with the assumptions and expectations. Grid has been used effectively to supply the energy deficit for critical loads (immediate household demand as well as maintaining the threshold for the storage) at times where market price was higher than the preferred price (case 1). On the other hand, and during low market price periods, grid has been used extensively to charge the storage for usage during peak hours and to give the residents the opportunity to utilize some non-critical appliances (case 6).

It is important to select the preferred method of optimization from the three proposed methods considering the following two main points: 1- the method should be suitable for embedding in the hardware of the LMC and, 2- the method should be linked to the optimization scheme at upper hand, i.e., community level, and to communicate values before each iteration. These two objectives could be summarized in three performance indicators:

- Response time

- Accuracy of results

- Computation intensity 
The comparative study of the results presented in 6.4.3 reveals that GA and SA are better methods in terms of accuracy of the results. However, GA and SA methods should be further investigated from computation load and response time perspectives. Adewole et al. [35] carried out a comprehensive study to compare GA and SA methods using the well-known travelling salesman problem. Based on the results of this study, there is a trade-off between the quality of the solution and run-time for both methods. GA can provide higher quality solutions with larger population; however, the response time will increase exponentially as the population increases. For the SA also run-time increases as the population grows, but not exponentially. Generally, the set of parameters used and their values are crucial factors that affect the solution's quality. This effect is more evident in SA method.

To further investigate the suitability of GA and SA methods for our application, a second round of simulation was performed using GA and SA techniques. The upper bounds of DER as well as the weighting matrix of $X_{i}$ were altered to provide us with a better understanding of the accuracy of the methods. Tables 6.4 to 6.9 and Figures 6.13 to 6.16 illustrate the results from this round of simulation considering the following new assumptions:

$$
\left[\alpha_{1}, \alpha_{2}, \alpha_{3}, \alpha_{4}, \alpha_{5}\right]=[2,4,3,1,-4] \text { and the upper bounds of DER }=[10,8,1,5]
$$

\begin{tabular}{|c|c|c|}
\hline CASE1 & GA & SA \\
\hline DER1 & 9.9978 & 9.8316 \\
\hline DER2 & 7.9989 & 7.9999 \\
\hline DER3 & 0.9942 & 0.9985 \\
\hline DER4 & 4.9995 & 4.9991 \\
\hline Grid & 46.0095 & 46.002 \\
\hline
\end{tabular}

Table 6.4: Comparison of GA and SA results for Case 1 under new condition 
Ryerson University $\quad$ Chapter 6: RESIDENTIAL LEVEL OPTIMIZATION 2017

\begin{tabular}{|c|c|c|}
\hline CASE2 & GA & SA \\
\hline DER1 & 10.0000 & 9.9875 \\
\hline DER2 & 8.0000 & 7.9789 \\
\hline DER3 & 1.0000 & 0.8425 \\
\hline DER4 & 5.0000 & 4.4392 \\
\hline Grid & 50.0000 & 50.0 \\
\hline
\end{tabular}

Table 6.5: Comparison of GA and SA results for Case 2 under new condition

\begin{tabular}{|c|c|c|}
\hline CASE3 & GA & SA \\
\hline DER1 & 9.9999 & 9.9999 \\
\hline DER2 & 7.9989 & 7.9999 \\
\hline DER3 & 0.9999 & 0.9915 \\
\hline DER4 & 4.9983 & 4.9559 \\
\hline Grid & 16.0029 & 16.003 \\
\hline
\end{tabular}

Table 6.6: Comparison of GA and SA results for Case 3 under new condition

\begin{tabular}{|c|c|c|}
\hline CASE4 & GA & SA \\
\hline DER1 & 10.0000 & 10.0000 \\
\hline DER2 & 8.0000 & 8.0000 \\
\hline DER3 & 1.0000 & 1.0000 \\
\hline DER4 & 5.0000 & 5.0000 \\
\hline Grid & 0 & 0 \\
\hline
\end{tabular}

Table 6.7: Comparison of GA and SA results for Case 4 under new condition

\begin{tabular}{|c|c|c|}
\hline CASE5 & GA & SA \\
\hline DER1 & 10.0000 & 10.0000 \\
\hline DER2 & 8.0000 & 8.0000 \\
\hline DER3 & 1.0000 & 1.0000 \\
\hline DER4 & 5.0000 & 5.0000 \\
\hline Grid & 0 & 0 \\
\hline
\end{tabular}

Table 6.8: Comparison of GA and SA results for Case 5 under new condition

\begin{tabular}{|c|c|c|}
\hline CASE6 & GA & SA \\
\hline DER1 & 10.0000 & 9.9948 \\
\hline DER2 & 8.0000 & 7.9503 \\
\hline DER3 & 1.0000 & 0.9896 \\
\hline DER4 & 5.0000 & 4.5590 \\
\hline Grid & 96.0002 & 96.003 \\
\hline
\end{tabular}

Table 6.9: Comparison of GA and SA results for Case 6 under new condition 
Similar to section 6.4 .3 , Figures 6.13 to 6.16 provide a comparative overview of the cases using each of the GA and SA methods.
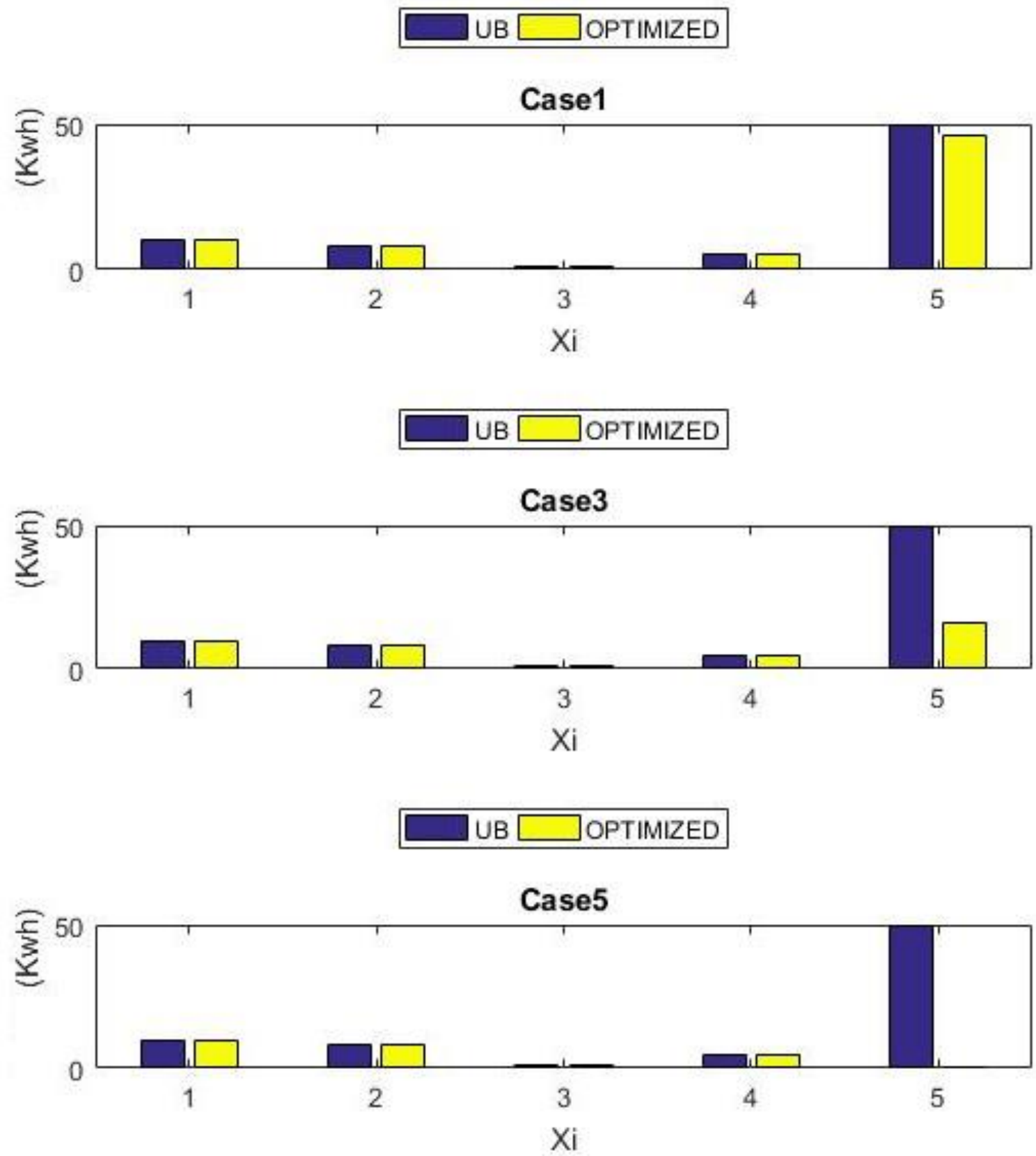

Fig. 6.13: Comparative overview of the second simulation using GA method for cases 1, 3 and 5 

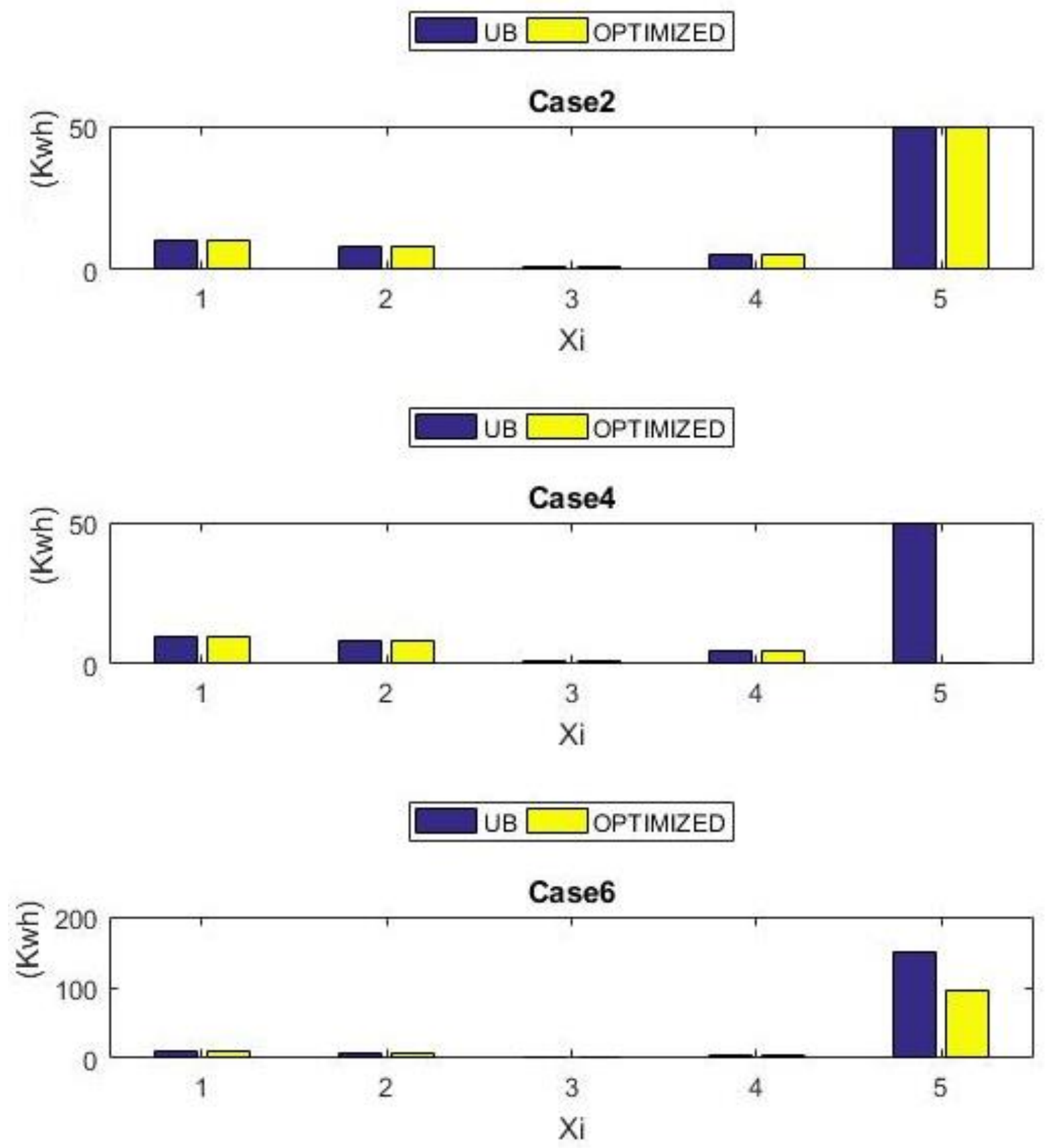

Fig. 6.14: Comparative overview of the second simulation using GA method for cases 2, 4 and 6 

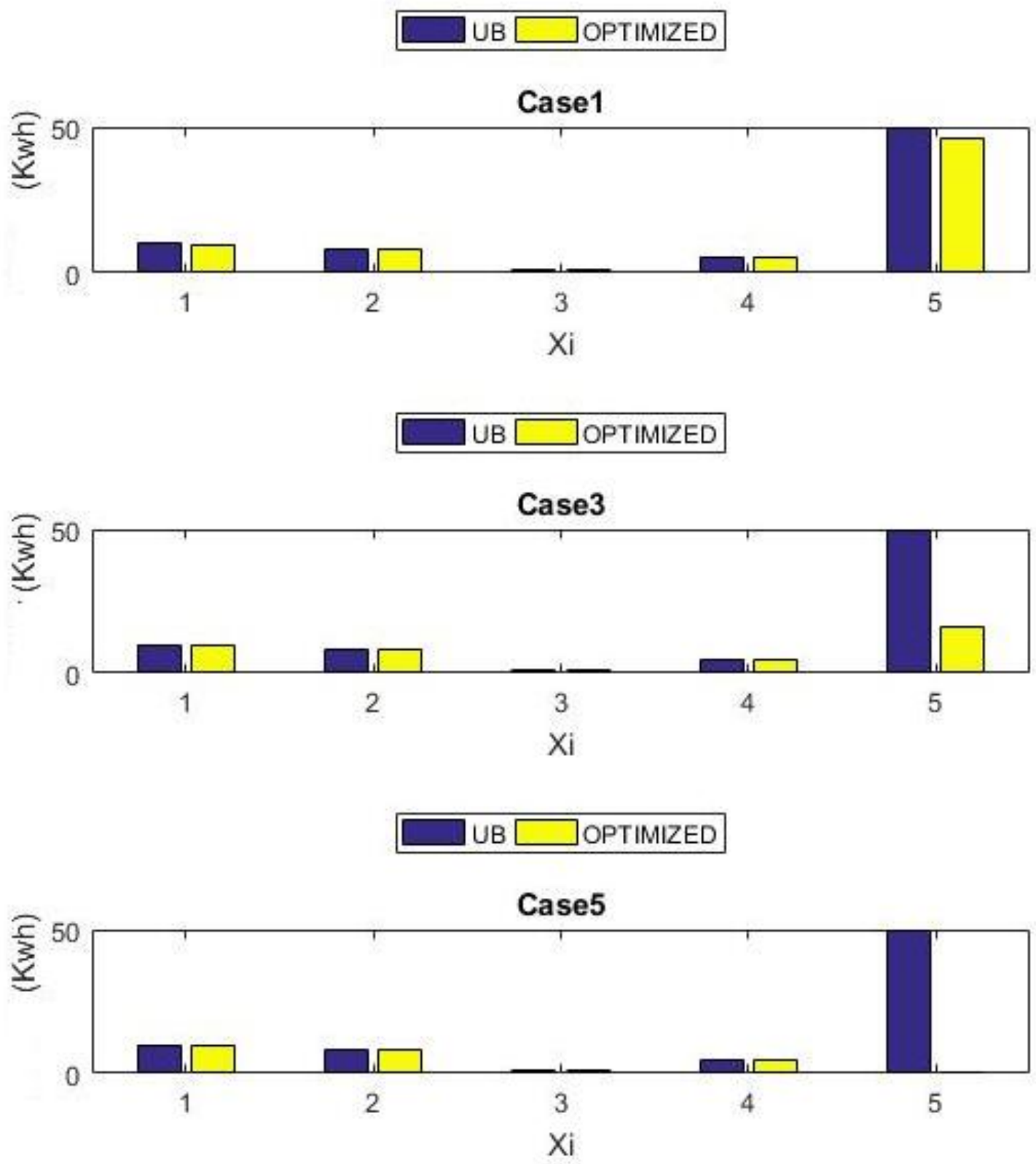

Fig. 6.15: Comparative overview of the second simulation using SA method for cases 1, 3 and 5 

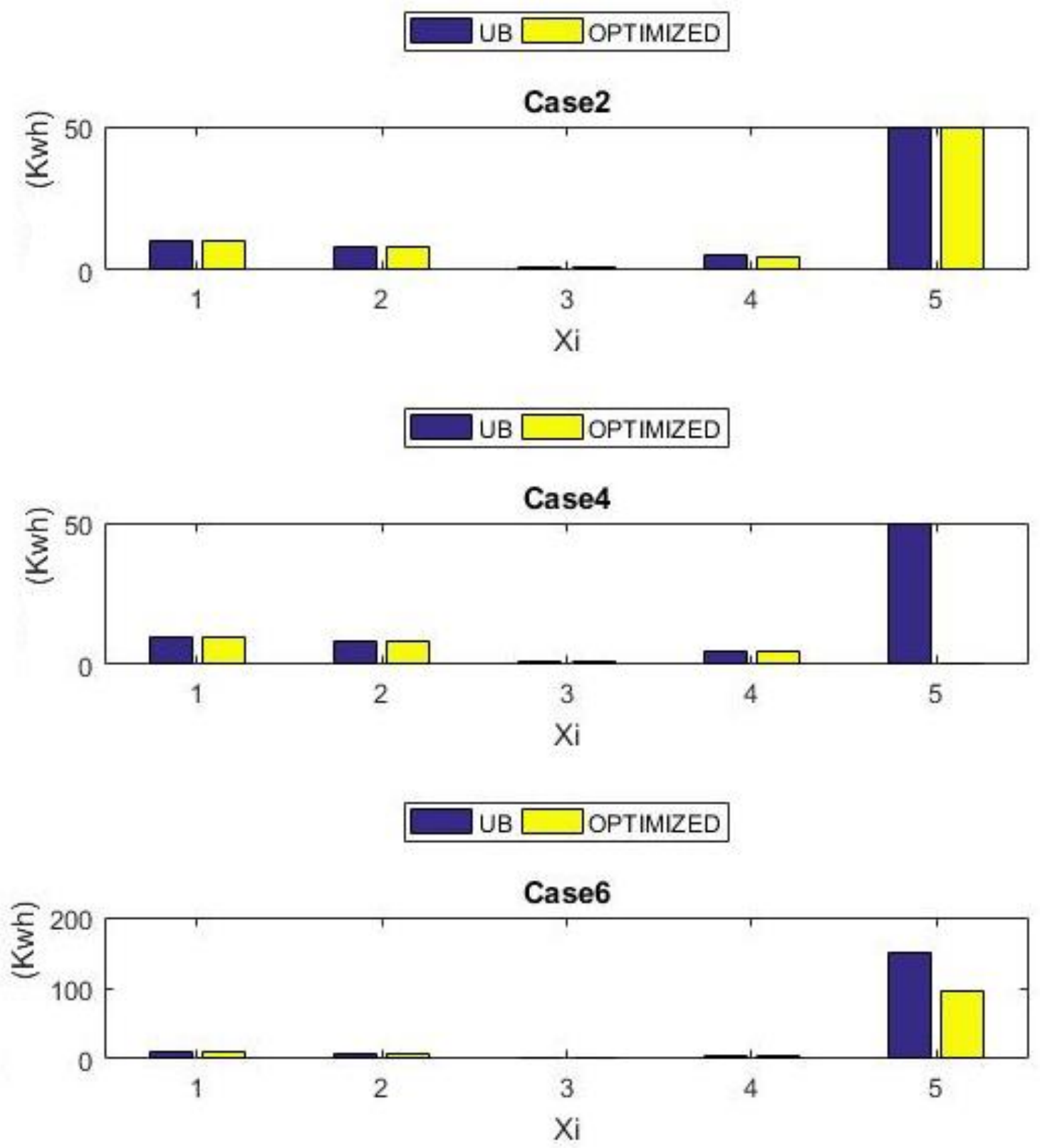

Fig. 6.16: Comparative overview of the second simulation using SA method for cases 2, 4 and 6 
Considering the available results in the literature [35], the results from additional simulations under different circumstances and the fact that the target population for optimization at household level is not typically high to cause uncapped exponential time increase in GA method, GA is the preferred method for utilization in LMC and this work.

To conclude, it should be mentioned that this work used user preferences as the basis for determination of weighting matrix. User preference is a combination of various factors including weather condition, availability of alternative sources at the moment, the price for each source, etc. In order to improve the intelligence level of the proposed optimization scheme, weighting matrix could be determined using different algorithms. There are some well-known quantifiers in the literature that can be used for this purpose. Fuzzy logic based Ordered Weighted averaging Aggregation operator (OWA) is an ideal method to determine the weighting coefficients $\alpha_{i}$. 


\section{CHAPTER 7}

\section{COMMUNITY LEVEL OPTIMIZATION}

\subsection{INTRODUCTION}

Electricity market is different from other markets since in an electricity market the policies are governed by various constraints and huge competitions. Competition plays an important role in this market since active participation of players can significantly enhance efficiency and reduce prices [36, 37]. In such a competitive market, establishment of an equilibrium point for demandsupply and a proper mechanism for pricing is essential (market clearing). The equilibrium point in an electricity market is the point where the market price has been established through a competition [38]. This chapter focuses on the concept of competitive equilibrium in an electricity market. An electricity market is a system enabling purchases through bids to buy and sales through offers to sell. Bids and offers use supply and demand principles to determine the price. For a market transaction to occur, it is essential to get to an equilibrium price where the market demand will be cleared. Thus competitive equilibrium is an important computational approach to clear the electricity market.

The electricity industry, globally, is undergoing significant restructuring to accommodate Smart Grid concept and to gear up towards deregulation and competition. In this new market, generation of electricity becomes an unbundled, deregulated activity in which decisions are no longer administrative and centralized, rather they are dependent on suppliers and consumers' 
interaction (supply-demand-price). In this scenario, the generation rate and the revenue for each individual generation unit depend on the ability of its managers to sell its product (electricity) and the decision of the community level buyers to get the demand at a low (preferred) price [39]. Therefore, it is very important for both the seller and the buyer to analyze the market and to model their decisions so that they meet their need. The traditional total cost minimization scheme will no longer benefit players in the market, rather what matters is the interaction between the profit maximizing utility provider and the cost minimizing community level buyers. The provider or the grid should try to maximize its production surplus (market revenues minus operation costs). On the other end, the neighborhood buyer should aim to minimize its cost and lower its bid in the energy market. Market equilibrium will be reached at the point of convergence of the market, provided that each participant tries to maximize its own profits.

This work introduces a Game Theoretic Optimization approach to calculate the competitive equilibrium price for electricity trade between the utility provider and community level buyer considering the following two key objectives: 1- maximizing the benefit for the supplier, and 2fulfilling the demand requested by the buyer.

\subsection{BACKGROUND}

During the past few years as the electricity market complexity has grown, researchers have turned towards Game Theory to answer demand-supply dilemma. GT has already proved its performance as a strong market tool where players in the Game (market) are rational decision makers. Therefore, application of such tool to electricity market has inspired many works in recent years. 
Kirschen et al. [36] studied the competitive electricity market from economic point of view. In the conventional electricity market, a monopoly system was prevalent among the utility providers and the customers. There was no control over the price of electricity as it depended on the utility provider supplying it. However, in the SG-enabled electricity market, where reduced price and increased quality are vital to selling the commodity, economists came up with the idea of competition among various sellers which will automatically reduce the market price and increase the quality of delivered power.

Bompard et al. [37] gave a broad overview of the market clearing models that use GT approach. The market clearance is an important factor that determines functionality and feasibility of the market and involves both players (seller and buyer) at the same time.

Wang et al. [38] introduced an innovative approach towards remodelling the market structure coupled with the advancements in the SG. The work presents a general economic equilibrium model that refines standard economic models by including dynamics, uncertainty in supply and demand, and transmission constraints. The main observation of the researchers is that the dynamic characteristics of the efficient equilibria can be highly undesirable for consumers, suppliers, or both.

Hobbs et al. [40] offer an overview of how a wholesale electricity market is organized. They provide a picture of a production cost model and using a case study to demonstrate the implementation approach the aut hors show how equilibrium constraints are incorporated into the model. 
Baldick [41] studied the supply functions of equilibrium models mainly in bid based markets. The work dealt with variable computation using the constrained and unconstrained transmissions. The impacts of the parameterised supply function model have also been studied in the work.

Smith et al. [42] mainly focused on the competitive market and electricity demand. They introduced two different auction strategies for finding competitive equilibrium: double auction and the sealed bid offer. The authors concluded that the double auction method gave significantly better results.

Other works on the techno-economics aspects of energy market using GT tools are available in the literature. This work will use a Game Theoretic, Double Auction method at its proposed community level to match demand and supply at an equilibrium market clearing price.

\subsection{PROBLEM FORMULATION}

In our pictured energy market, the two players are the community(s) or neighbourhood(s) as the buyer(s) and the utility provider(s) or grid(s) as the seller(s). The players compete to maximize their profit in the energy market. Thus, the seller asks for its preferred selling price while the buyer bids for the amount of energy it requires at its preferred buying price. Here, the goal is to obtain an equilibrium price at which both sides are willing to trade; this is where the concept of Competitive Equilibrium in Game Theory comes into the picture. The absence of such equilibrium point implies that either side of the market could unilaterally manipulate the prices to its own advantage. 


\subsubsection{MATHEMATICAL REPRESENTATION}

Let's mathematically express the market scenario using the following defined parameters:

$M$ : the number of communities

$P_{h}$ : the per unit trading price for the $h^{\text {th }}$ time slot

$d_{h}$ : the community demand for the $h^{\text {th }}$ time slot

$E_{h}$ : the amount the grid can supply during the $h^{\text {th }}$ time slot

$C_{h}$ : the per unit cost of electricity generation for the $h^{\text {th }}$ time slot

From community point of view, the objective is to fulfill the required demand at lowest possible price. This can be represented by Eq. 7.1 hereinafter referred to as the Cost Function.

$\operatorname{Min} C=\sum_{h=1}^{M} P_{h} \times d_{h}$

The constraints to Eq. 7.1 are shown in Eq. 7.2.

$$
\begin{aligned}
& \sum_{h=1}^{M} d_{h}=E_{h} \\
& d_{h}^{\text {min }}<d_{h}<d_{h}^{\text {max }}
\end{aligned}
$$

The first constraint states that the total demand of neighbourhoods in a time slot could not go beyond the maximum supply capacity of the grid for that time slot. It should be noted that considering the scenario laid out in chapter 6 , the neighbourhood demand in this case could be either the deficit energy needed after counting the DER capacity or the total energy that the neighbourhood needs regardless of other available sources of energy.

The second constraint in Eq. 7.2 simply specifies the lower and upper bounds for the neighbourhood demand in its respective time slot. 
From the grid point of view, the seller's goal is to maximize the profit by selling all its generated power and at higher prices. This can be translated to maximization of the Utility Function as shown in Eq. 7.3.

$\operatorname{Max} U=\sum_{h=1}^{M}\left[P_{h} \times d_{h}-C_{h} \times d_{h}\right]$

Since $C_{h}$ is more or less a constant value for the utility provider, the expression in Eq. 7.3 could be approximated as Eq. 7.4 for optimization purpose:

$\operatorname{Max} U_{a p p}=\sum_{h=1}^{M} P_{h} \times d_{h}$

Where the constraint associated with $U_{a p p}$ is shown in Eq. 7.5.

$E_{h}^{\min }<d_{h}<E_{h}^{\max }$

\subsubsection{THE GAME}

The players of the game in the laid out scenario are the neighbourhood and the Grid. The action pertinent to the game on the neighbourhood side is to select its demand while keeping the market price in mind to minimize the community cost. On the grid side, the action is to determine the supply amount considering the sale price to maximize utility function. Payoffs are the cost function and the utility function.

The competition begins when both players want to "win" the market. One approach in tackling such a competition is application of Competitive Equilibrium model. From an economist's perspective, it is desired to find a competitive equilibrium; a situation in which the supply equals the demand in any market scenario. Competitive equilibrium, also known as Walrasian equilibrium, is the traditional concept of economic equilibrium designed for the analysis of commodity markets with flexible prices and multiple traders. This approach is based on the 
assumption of a competitive environment where each trader decides upon a small quantity compared to the total quantity traded in the market, therefore, the individual transactions have no influence on the prices.

Using competitive equilibrium approach, we divide each day into time slots with specified durations. The duration of slots is flexible and could be adjusted based on the requirements without affecting the introduced approach. An auction will be held to determine the equilibrium price (trading price) for each time slot. In order to maintain the stability of the distribution system and the grid and to avoid instantaneous changes in demand and supply, the auctions will take place one slot prior to the slot that the trade will take place in, i.e., the price for $x^{\text {th }}$ slot will be determined by the auction held at the $(x-1)^{\text {th }}$ slot. The game procedure is as follows:

Let the grid sets the price $P_{1}$ for $Q_{1}$ units of supplied electricity during the next time slot. The neighbourhood will then request a demand of $d_{l}$ for the price $P_{l}$ for that same time slot. If $d_{l}$ is not equal to $Q_{1}$ or the price is not acceptable for the buyer, the transaction cannot occur and the grid will proceed to set another price $P_{2}$ for $Q_{2}$ units of energy. The change in the proposed quantity is due to the fact that utility should either idle or start generators to meet the new demand. The price would also vary as the grid has to change the number of working generators. These steps will be repeated until an equilibrium price of $P^{*}$ and equilibrium quantity of $Q^{*}$ are reached between the utility provider and the community.

To build the game, Toronto's ToU prices for winter and summer have been used as the pricing basis for the utility provider. The times were then expanded into one-hour slots to serve our simulation need. The rates and times are available to public at Toronto Hydro portal. It should be 
noted that the proposed approach is independent of rates and times and is applicable to any other pricing scheme. Table 7.1 shows the time versus price for summer and winter in Toronto, Ontario, Canada.

\begin{tabular}{|c|c|c|c|}
\hline From & To & Summer Rate (May - Oct) & Winter Rate (Nov - Apr) \\
\hline 7:00 AM & 8:00 AM & \multirow{4}{*}{$\begin{array}{l}\text { mid-peak rate } \\
13.2 \text { cents } / \mathrm{kWh}\end{array}$} & \multirow{4}{*}{$\begin{array}{c}\text { on-peak rate } \\
18 \text { cents } / \mathrm{kWh}\end{array}$} \\
\hline 8:00 AM & 9:00 AM & & \\
\hline 9:00 AM & 10:00 AM & & \\
\hline 10:00 AM & 11:00 AM & & \\
\hline $11: 00 \mathrm{AM}$ & 12:00 PM & \multirow{6}{*}{$\begin{array}{l}\text { on-peak rate } \\
18 \text { cents } / \mathrm{kWh}\end{array}$} & \multirow{6}{*}{$\begin{array}{l}\text { mid-peak rate } \\
13.2 \text { cents } / \mathrm{kWh}\end{array}$} \\
\hline 12:00 PM & 1:00 PM & & \\
\hline 1:00 PM & 2:00 PM & & \\
\hline 2:00 PM & 3:00 PM & & \\
\hline 3:00 PM & 4:00 PM & & \\
\hline 4:00 PM & 5:00 PM & & \\
\hline 5:00 PM & 6:00 PM & \multirow{2}{*}{$\begin{array}{l}\text { mid-peak rate } \\
13.2 \text { cents } / \mathrm{kWh}\end{array}$} & \multirow{2}{*}{$\begin{array}{l}\text { on-peak rate } \\
18 \text { cents/kWh }\end{array}$} \\
\hline 6:00 PM & 7:00 PM & & \\
\hline 7:00 PM & 8:00 PM & \multirow{6}{*}{$\begin{array}{l}\text { off-peak rate } \\
8.7 \text { cents } / \mathrm{kWh}\end{array}$} & \multirow{6}{*}{$\begin{array}{l}\text { off-peak rate } \\
8.7 \text { cents } / \mathrm{kWh}\end{array}$} \\
\hline 8:00 PM & 9:00 PM & & \\
\hline 9:00 PM & 10:00 PM & & \\
\hline 10:00 PM & 11:00 PM & & \\
\hline 11:00 PM & Midnight & & \\
\hline Midnight & 1:00 AM & & \\
\hline
\end{tabular}




\begin{tabular}{|c|c|c|c|}
\hline $1: 00 \mathrm{AM}$ & $2: 00 \mathrm{AM}$ & \multirow{5}{*}{} & \\
\hline $2: 00 \mathrm{AM}$ & $3: 00 \mathrm{AM}$ & & \\
\hline $3: 00 \mathrm{AM}$ & $4: 00 \mathrm{AM}$ & & \\
\hline $4: 00 \mathrm{AM}$ & $5: 00 \mathrm{AM}$ & & \\
\hline $5: 00 \mathrm{AM}$ & $6: 00 \mathrm{AM}$ & & \\
\hline $6: 00 \mathrm{AM}$ & 7:00 AM & & \\
\hline
\end{tabular}

Table 7.1: Hourly demand rates based on Toronto's ToU pricing for summer and winter

\subsection{SIMULATION CASES AND RESULTS}

Double Auction method is used in this work to find the competitive equilibrium price and quantity. Auction approach has been one of the widely used solutions for determining market equilibrium. Auctions are transactions with specific rules detailing resource allocation according to participants' bids. They are categorized as games with incomplete information because in the vast majority of auctions, one party possesses information related to the transaction that the other party does not. Auctions may have different forms, but they have a common basis that makes them applicable to different markets and to sell or buy any item. In many cases, the outcome of the auction is independent of the identity of the bidders. A Double Auction is a process of buying and selling goods where potential buyers and sellers submit their bids and asked prices simultaneously to an auctioneer. The auctioneer then chooses the price $P$ that clears the market; all sellers who have asked for prices less than $P$ should sell and all buyers who have bid for more than $P$ will buy at the price $P$.

To be able to apply this method, and based on the problem formulation provided in section 7.3, eight cases have been built for on-, mid- and off-peak times for residential communities in 
summer and winter. In each case, quantities for the demand and supply are generated based on known patterns while prices are arranged in ascending order and the highest rate corresponds to the actual ToU price stipulated in Table 7.1. The lowest price, however, has been selected to be in reasonable proximity of the actual ToU rate. These cases could be used as a test bench for verification of other approaches as well. The unit for supply and demand is $\mathrm{KWh}$ while price is in Cent; the approach is independent of the units.

Case 1: Residential community- 7am-11am (mid-peak) - summer time

\begin{tabular}{|c|c|c|}
\hline Demand (KWh) & Supply (KWh) & Price (c) \\
\hline 16.92 & 16.53 & 10.2 \\
\hline 16.71 & 17.00 & 11.2 \\
\hline 16.13 & 16.98 & 12.2 \\
\hline 15.83 & 17.32 & 13.2 \\
\hline
\end{tabular}

Table 7.2: Demand-supply-price for case 1

Rationale: The neighbourhood initiates the game by requesting a demand of 16.92 units of electricity $(\mathrm{KWh})$ while the grid responds by offering a supply of $16.53 \mathrm{KWh}$ at the market price of $\phi 10.2$. Since the buyer's demand is not satisfied, the buyer proceeds by requesting the new demand of 16.71 units. The grid needs to bring idle generators on line or assign more resources to be able to answer the demand. The grid's new offer would be $17.00 \mathrm{KWh}$ at $₫ 11.2$. It's obvious that the price would increase as new resources are utilized. At this stage the buyer decreases its demand to 16.13 units to compensate for the increase in the price while the seller decides to supply $16.98 \mathrm{KWh}$ at $\not 12.2$ to compensate for its lost profit. This is where the competitive game emerges: the seller wants to sell a larger volume at a greater price although the 
demand is low. This interaction continues until equilibrium is reached which denotes a win-win situation for both the seller and buyer.

Using the graphical double auction approach, the equilibrium point could be calculated at 16.8 KWh at $\phi 10.78$ for the time period 7 am to $11 \mathrm{am}$. Figure 7.1 illustrates the double auction approach for this case.

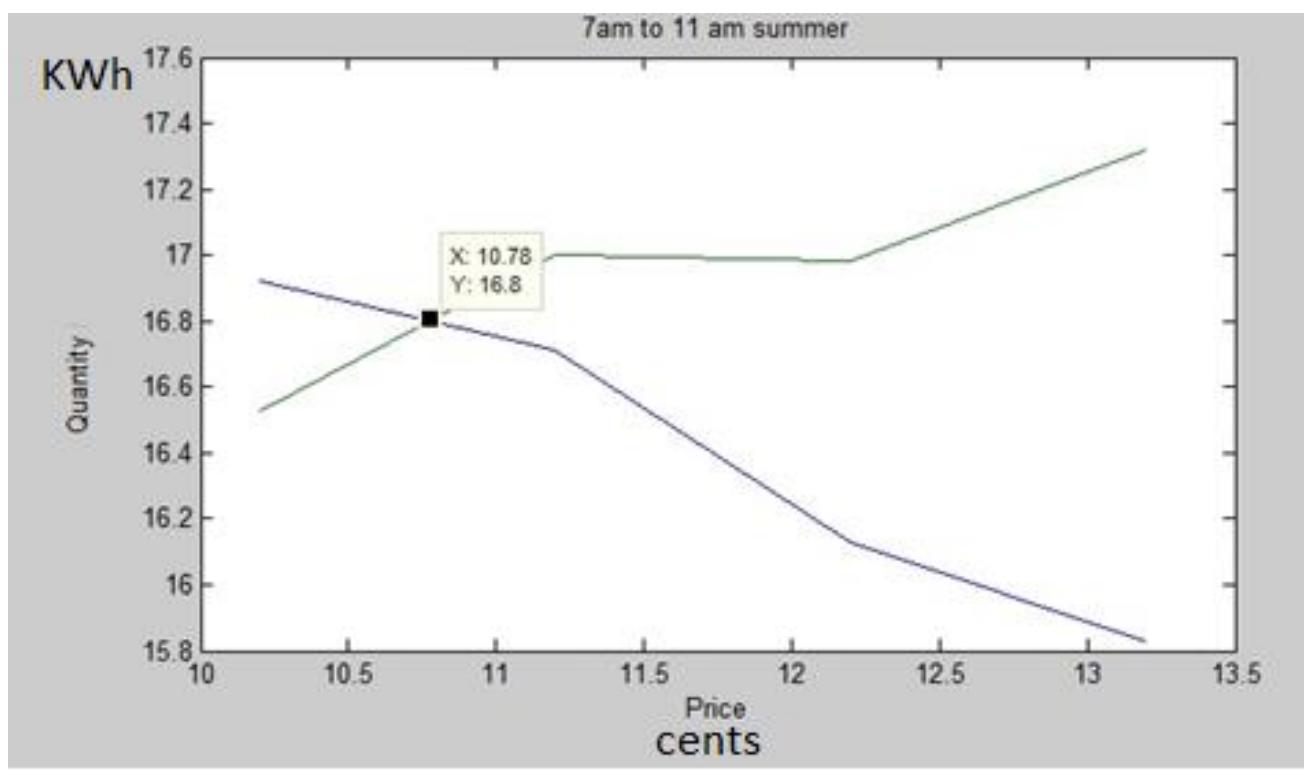

Fig. 7.1: Equilibrium points for case 1

Case 2: Residential community - 11am-5pm (on-peak) - summer time

\begin{tabular}{|c|c|c|}
\hline Demand (KWh) & Supply (KWh) & Price ( $\boldsymbol{\phi})$ \\
\hline 17.51 & 17.21 & 14 \\
\hline 17.40 & 17.35 & 15 \\
\hline 17.25 & 17.9 & 16 \\
\hline 17.16 & 17.8 & 17 \\
\hline 17.05 & 18.2 & 18 \\
\hline 16.87 & 18.4 & 19 \\
\hline
\end{tabular}

Table 7.3: Demand-supply-price for case 2 
Similar to the process presented for Case 1, the equilibrium points for Case 2 are calculated to be at $17.39 \mathrm{KWh}$ and $\phi 15.08$.

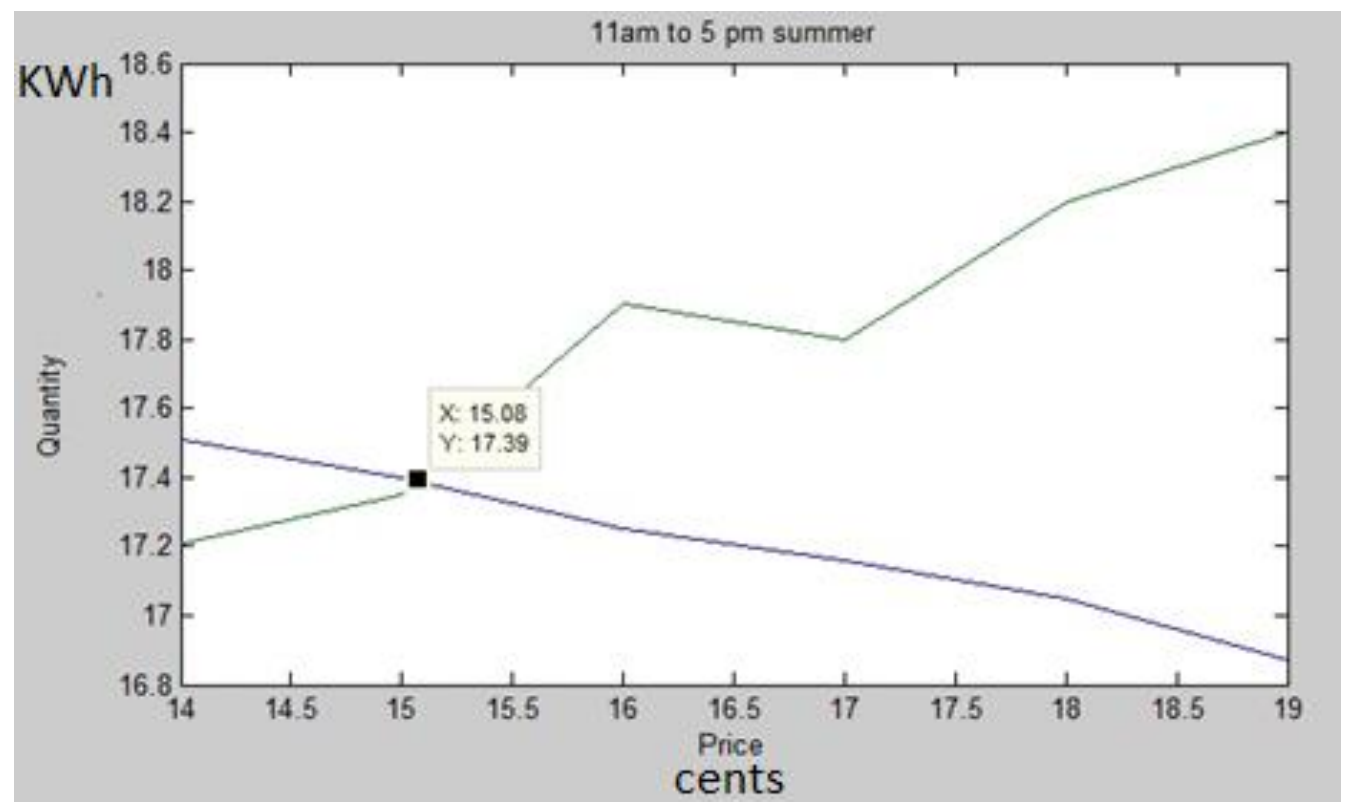

Fig. 7.2: Equilibrium points for case 2

Case 3: Residential community - 5pm-7pm (mid peak) - summer time

\begin{tabular}{|c|c|c|}
\hline Demand (KWh) & Supply $(\mathbf{K W h})$ & Price $(\boldsymbol{\phi})$ \\
\hline 16.53 & 16.92 & 12.2 \\
\hline 17.00 & 16.71 & 13.2 \\
\hline
\end{tabular}

Table 7.4: Demand-supply-price for case 3

The equilibrium points for Case 3 are calculated to be at $16.8 \mathrm{KWh}$ and $\phi 12.78$ as shown in Figure 7.3. 


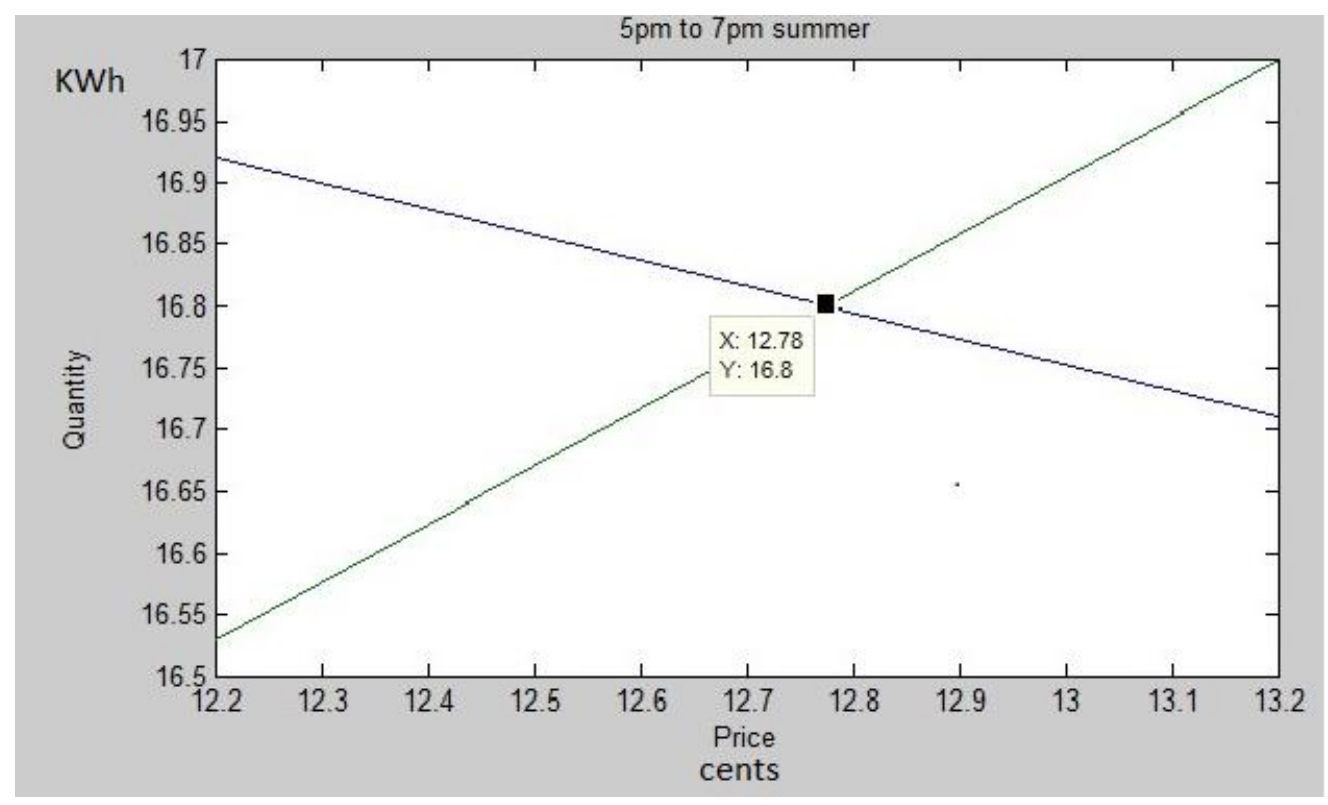

Fig. 7.3: Equilibrium points for case 3

Case 4: Residential community - 7pm-7am (off-peak) - summer time

\begin{tabular}{|c|c|c|}
\hline Demand (KWh) & Supply (KWh) & Price (ф) \\
\hline 17.05 & 16.53 & 8.3 \\
\hline 16.96 & 16.6 & 8.4 \\
\hline 15.99 & 16.4 & 8.5 \\
\hline 14.52 & 15.5 & 8.6 \\
\hline 13.38 & 15 & 8.7 \\
\hline 13.46 & 14.2 & 8.8 \\
\hline 12.90 & 13.6 & 8.9 \\
\hline 12.65 & 13 & 9 \\
\hline 12.55 & 12.9 & 9.2 \\
\hline 12.77 & 14 & \\
\hline
\end{tabular}




\begin{tabular}{|c|c|c|}
\hline 13.77 & 14.1 & 9.3 \\
\hline 13.8 & 14.3 & 9.4 \\
\hline
\end{tabular}

Table 7.5: Demand-supply-price for case 4

Unlike previous cases and during off-peak periods, the demand and supply decrease as time passes as well as at higher price rates. This is due to the fact that during off-peak periods, the activities of the neighbourhood decrease which results in less demand. From the seller's point of view, an increase in generation is not the proper approach for compensating the reduction in utility function since during such time there will be lower demand at any rates.

The equilibrium points for Case 4 are calculated to be $16.51 \mathrm{KWh}$ at $₫ 8.44$.

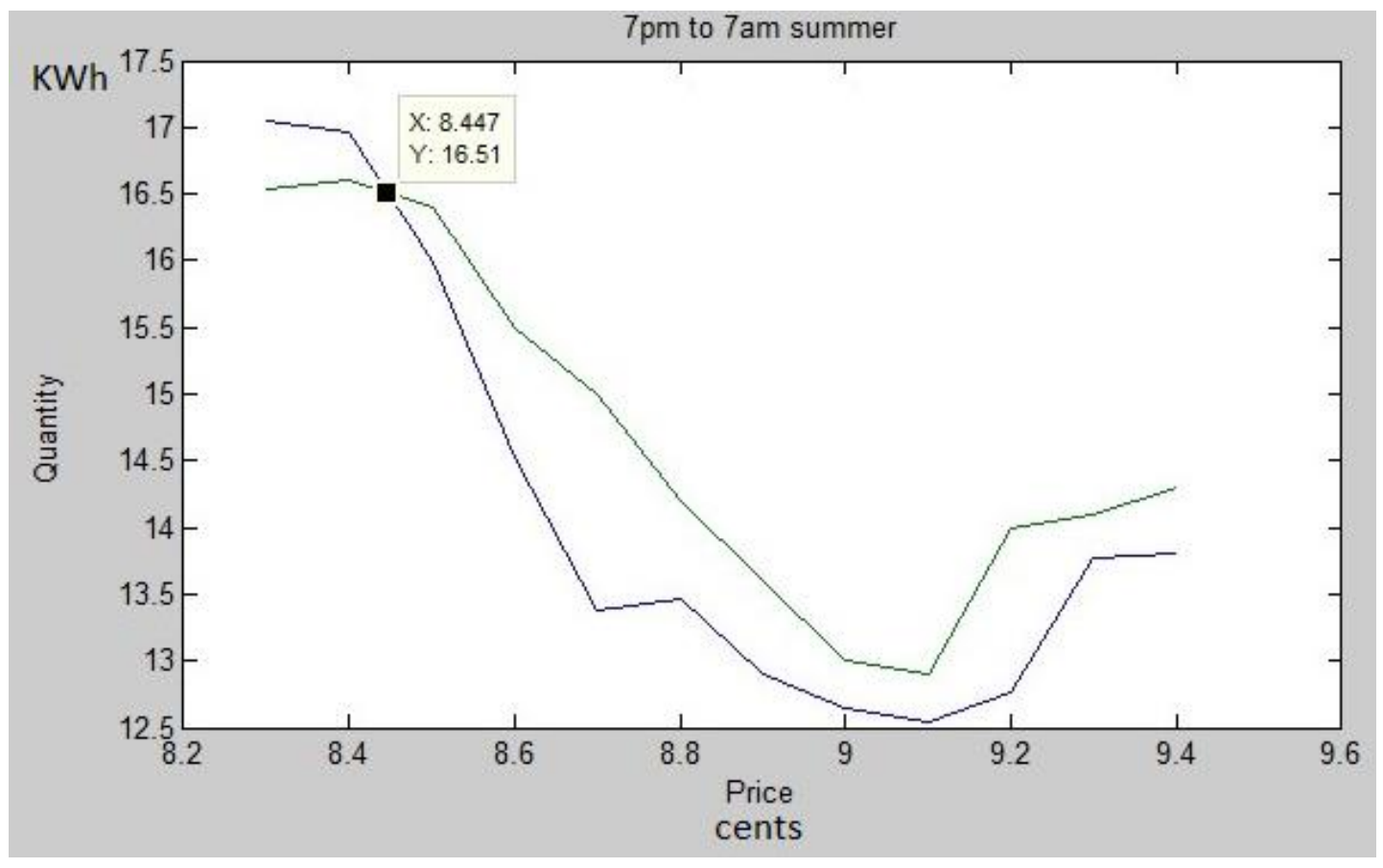

Fig. 7.4: Equilibrium points for case 4 
Case 5: Residential community - 7am-11am (on-peak) - winter time

\begin{tabular}{|c|c|c|}
\hline Demand (KWh) & Supply (KWh) & Price (ф) \\
\hline 28.54 & 19.2 & 17 \\
\hline 25 & 20.2 & 17.5 \\
\hline 19 & 20.8 & 18 \\
\hline 18.3 & 21.8 & 18.5 \\
\hline
\end{tabular}

Table 7.6: Demand-supply-price for case 5

The equilibrium points for on-peak period in a residential community in winter are calculated at 20.64 KWh and $\varnothing 17.87$.

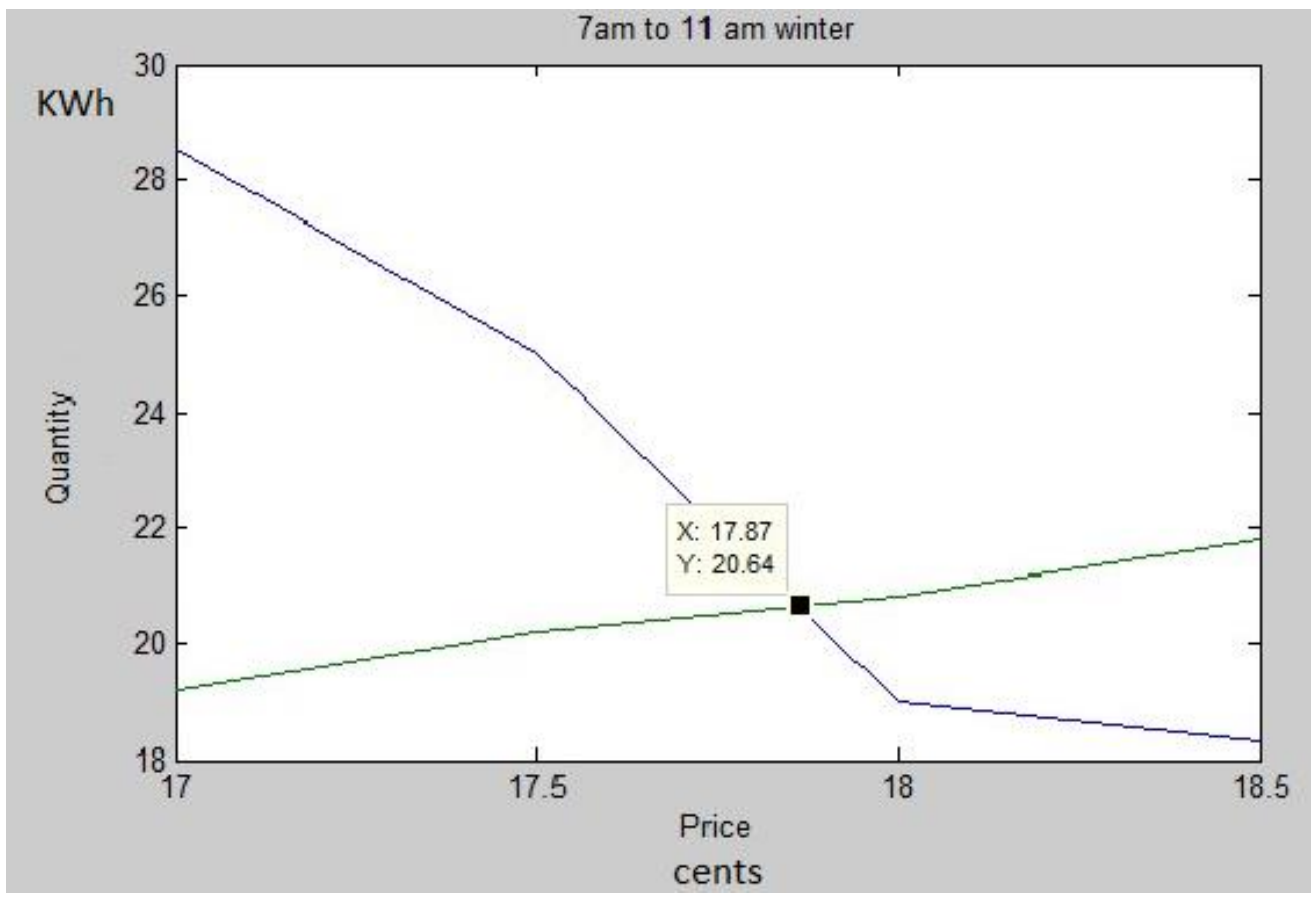

Fig. 7.5: Equilibrium points for case 5 
Case 6: Residential community - 11am-5pm (mid-peak) - winter time

\begin{tabular}{|c|c|c|}
\hline Demand (KWh) & Supply (KWh) & Price (c) \\
\hline 28.93 & 19.9 & 12.9 \\
\hline 25.3 & 20 & 13 \\
\hline 22.1 & 20.2 & 13.1 \\
\hline 19.3 & 20.6 & 13.2 \\
\hline 17.1 & 20.8 & 13.3 \\
\hline 14.5 & 21 & 13.4 \\
\hline 11.8 & 21.9 & 13.5 \\
\hline
\end{tabular}

Table 7.7: Demand-supply-price for case 6

The equilibrium points for Case 6 are calculated to be $20.45 \mathrm{KWh}$ and $₫ 13.16$.

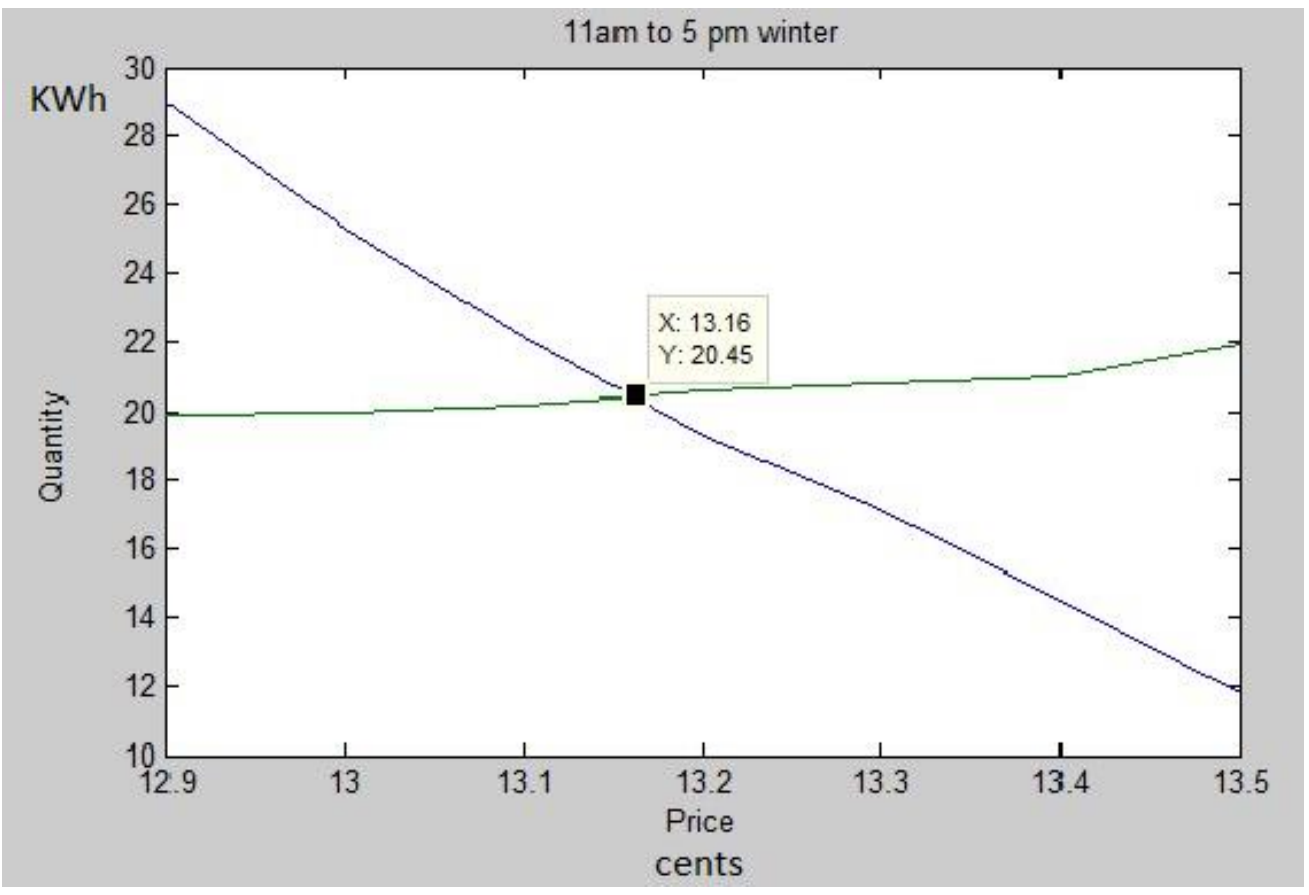

Fig. 7.6: Equilibrium points for case 6 
Case 7: Residential community - 5pm-7pm (on-peak) - winter time

\begin{tabular}{|c|c|c|}
\hline Demand (KWh) & Supply (KWh) & Price (ф) \\
\hline 28.54 & 20 & 18 \\
\hline 25 & 21 & 18.2 \\
\hline 19 & 22 & 18.3 \\
\hline
\end{tabular}

Table 7.8: Demand-supply-price for case 7

The equilibrium points for Case 7 are calculated to be $21.58 \mathrm{KWh}$ and $ф 18.26$.

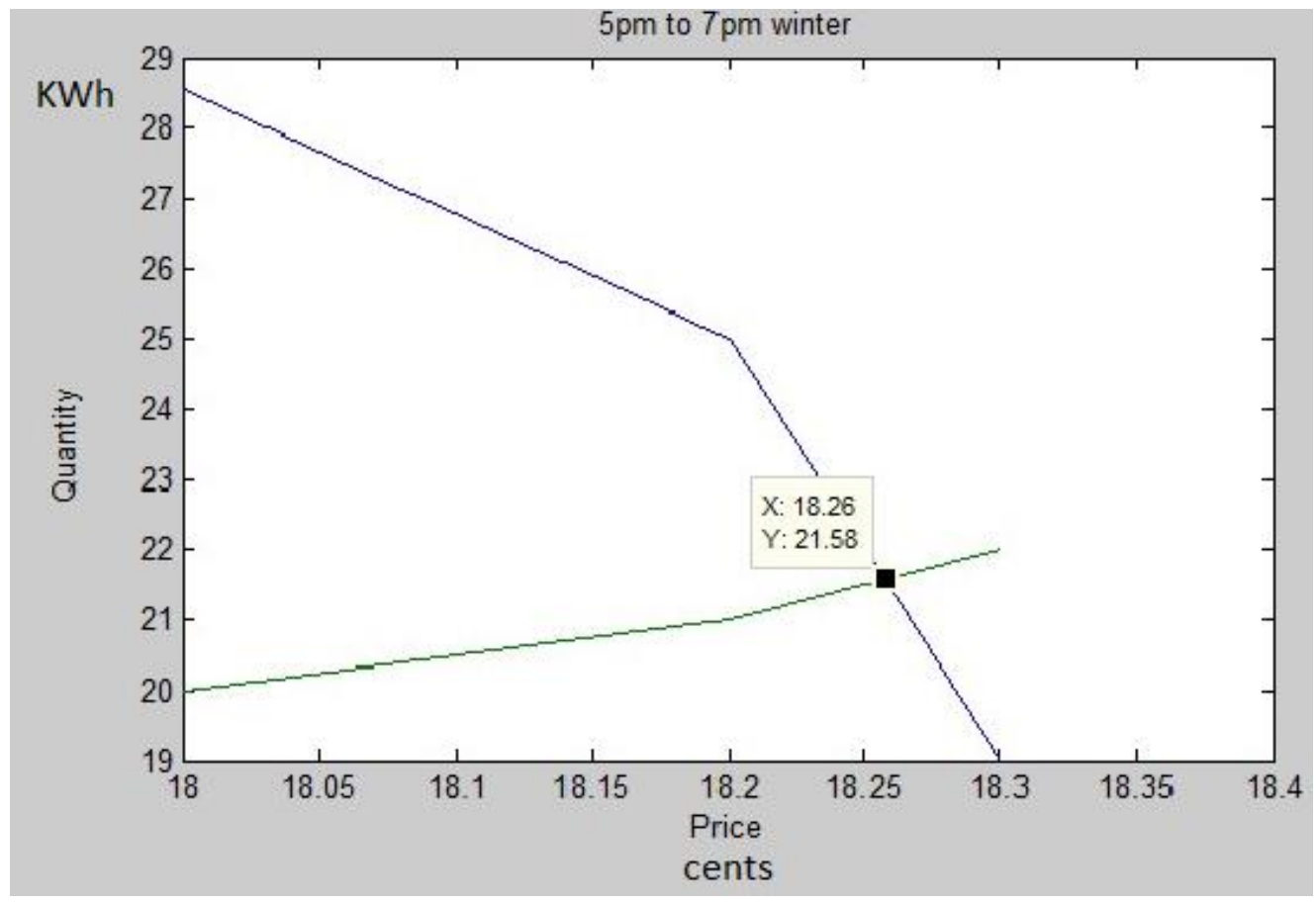

Fig. 7.7: Equilibrium points for case 7

Case 8: Residential community - 7pm-7am (off-peak) - winter time

\begin{tabular}{|c|c|c|}
\hline Demand (KWh) & Supply (KWh) & Price (k) \\
\hline 19.05 & 18.53 & 8.3 \\
\hline 18.96 & 18.6 & 8.4 \\
\hline 17.99 & 18.4 & 8.5 \\
\hline
\end{tabular}


Ryerson University $\quad$ Chapter 7: COMMUNITY LEVEL OPTIMIZATION 2017

\begin{tabular}{|c|c|c|}
\hline 16.52 & 17.5 & 8.6 \\
\hline 15.38 & 17 & 8.7 \\
\hline 15.46 & 16.2 & 8.8 \\
\hline 14.90 & 15.6 & 8.9 \\
\hline 14.65 & 15 & 9 \\
\hline 14.55 & 15.9 & 9.1 \\
\hline 14.77 & 16 & 9.2 \\
\hline 15.77 & 16.1 & 9.3 \\
\hline 16 & 16.3 & 9.4 \\
\hline
\end{tabular}

Table 7.9: Demand-supply-price for case 8

The equilibrium points for Case 8 are calculated to be $18.5 \mathrm{KWh}$ and $\notin 8.451$.

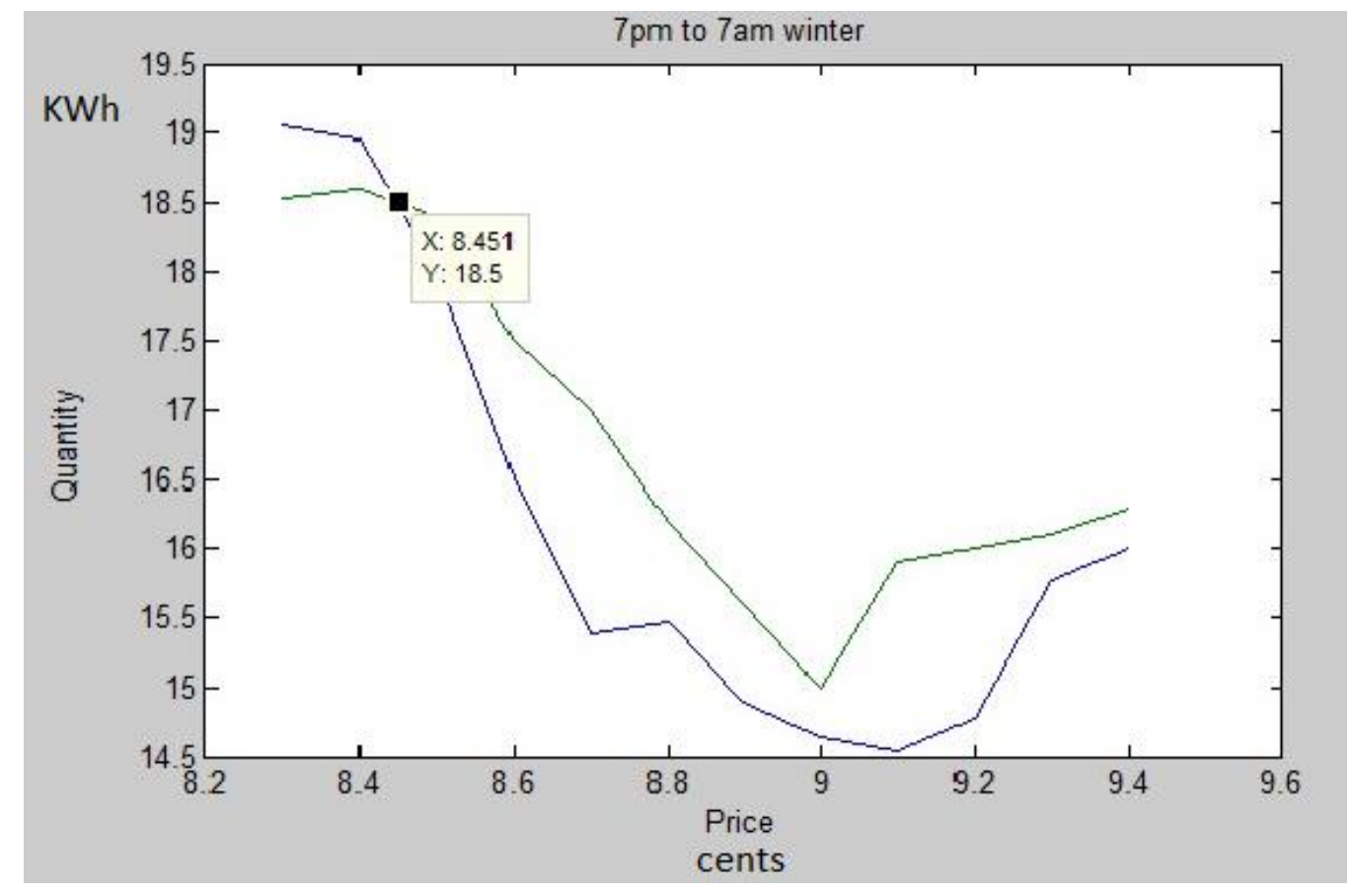

Fig. 7.8: Equilibrium points for case 8

Comparison of the summer and winter results using the proposed game theoretic approach to calculate competitive equilibrium by means of double auction technique has been illustrated in 
Figures 7.9 and 7.10 for a residential community in Toronto, Ontario, Canada as per cases presented in this section.

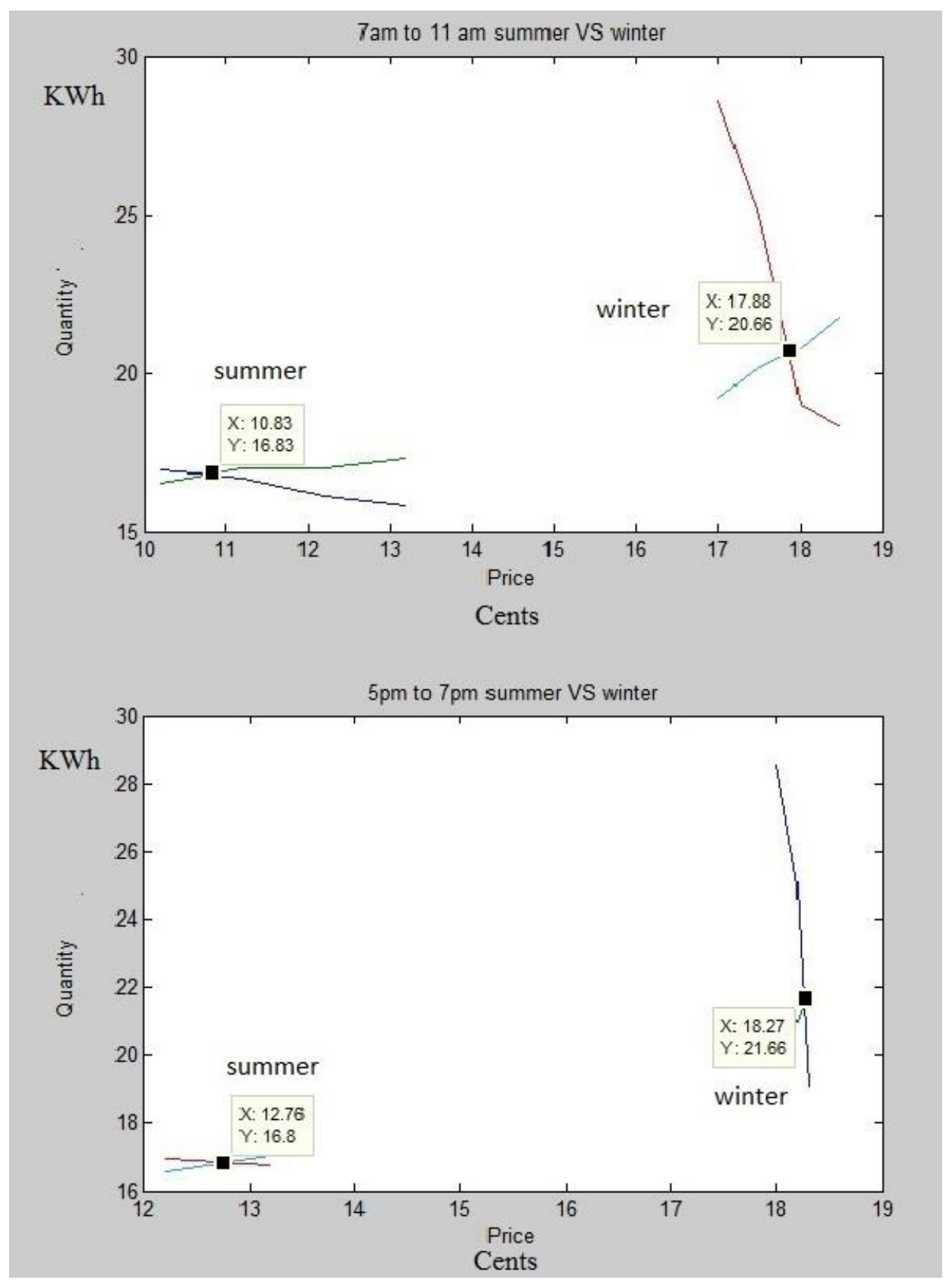

Fig. 7.9: Summer vs. winter results (1) 


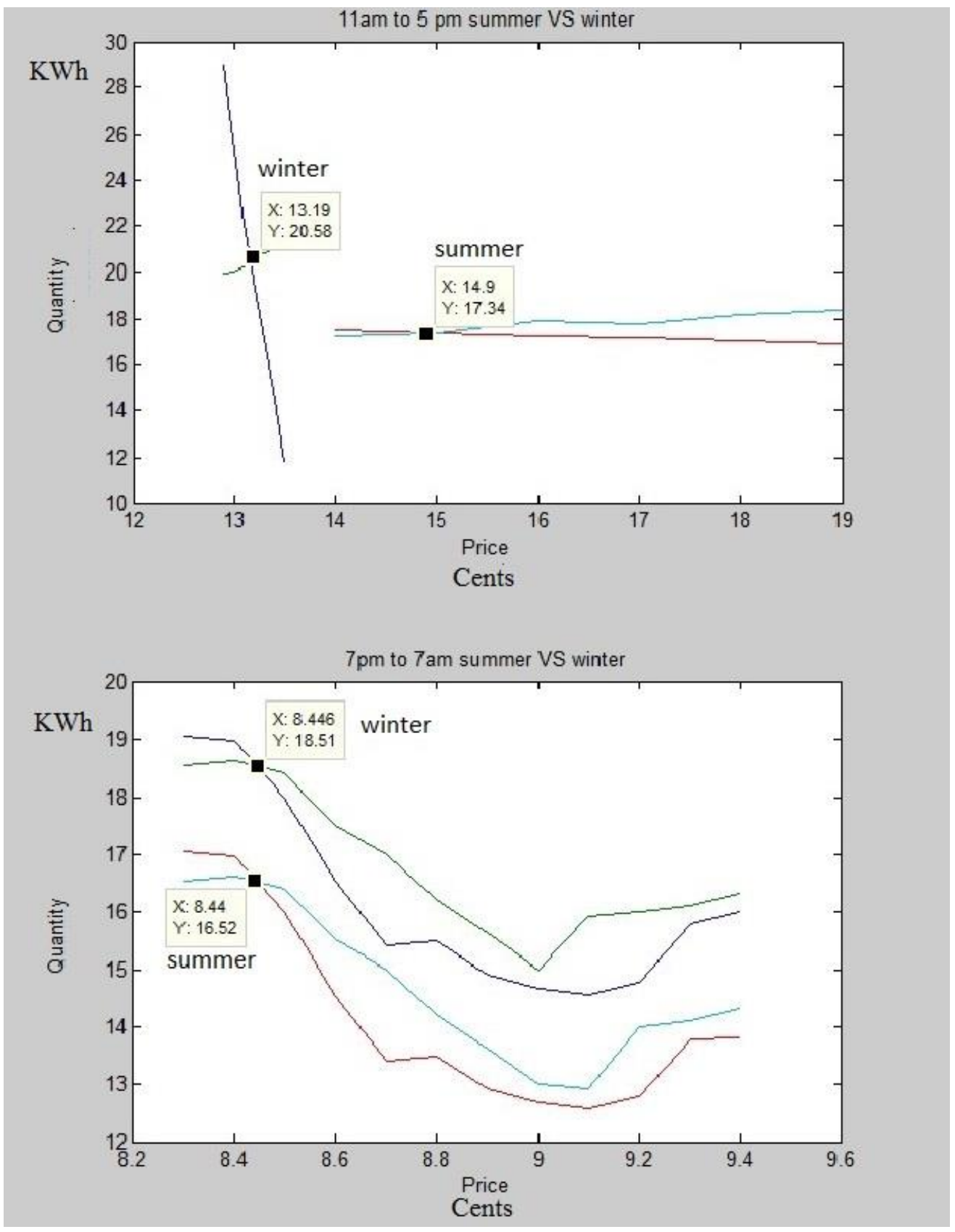

Fig. 7.10: Summer vs. winter results (2) 
The comparison shows fairly higher consumption and equilibrium prices for winter season which yields to greater Cost (Utility) Function as explained in Eq. 7.1 and 7.4. This finding is in line with real-world consumption patterns where seasonal pattern affects the consumption rates in residential, commercial and industrial sectors. Residential communities have highest seasonal variations among the three sectors due to the nature of their consumption. Winter time generally boosts the electricity utilization in residential units due to temperature and humidity condition as well as lighting needs.

\subsection{ANALYSIS OF THE RESULTS}

GT can be broken down into two distinct categories: Non-Cooperative and Cooperative. NonCooperative games allow players to optimize their objective functions independently; there is no coordination of strategic choices and all players want to maximize their individual goals. Cooperative games however, allow players to work as groups with full communication to maximize their goals. The communication layer in the SG allows for both non-cooperative and cooperative scenarios.

Another key aspect of GT is the equilibrium solution. In most GT scenarios, the Nash Equilibrium is the primary optimum result. The Nash equilibrium is a solution concept of a noncooperative game which means that the player has the optimal choice considering whatever choice the other party picks. A game may have multiple Nash equilibria or none at all.

Perfect Competition is another concept in GT. It describes a market structure which is entirely controlled by market forces. In such a market, all participants sell identical products or services, they cannot control dominant market prices, the share or contribution of each participant in 
overall market is small, participants have perfect knowledge about the industry and there is no limitation in entry to or exit from the market. If any of these conditions are not met, then the market is not perfectly competitive. Perfect Competition is an abstract concept but not in the real world. For such imperfect competition which also suits our market scenario quite extensively, such equilibrium is known as Nash equilibrium point [43].

Based on the definitions provided, our case constitutes a non-cooperative game, imperfect competition and the answers are potentially Nash Equilibrium.

The majority of the works on auction strategy are similar with double auction as the most widely used approach. [44] uses a non-cooperative game and double auction for decision making processes in a case that a number of plug-in hybrid electric vehicle groups seeking to sell part of their stored energy in a power market. The work mainly deals with the stored energy rather than the overall demand and therefore, is different in essence with our proposed approach. On the residential end of the energy market, [45] provided an image of a transactive market. The work utilized distributed controllers and a centralized auction mechanism to create an interactive system which can limit demand at key times on a distribution system thus decreasing congestion. The proposed approach in this dissertation is different from [45] as we sliced each day into several time intervals of flexible duration and calculated the optimal values for each slot. [46] is the most similar work to our proposed solution which gives a double auction mechanism for the allocation and pricing of energy resources that especially take the specific requirements of energy producers and consumers into account. While this work has the same approach as our solution in considering the price and source-load allocation as points of focus, the differentiator 
of our work is in the vertical arrangement of the two levels of optimization. [46] is also more focused on decentralized micro grids and their integration into the larger power grids; however, we have offered extensive use of decentralized DER as local sources rather than incorporation of them into the grid.

\subsection{CONCLUSION}

This chapter presented a Game Theoretic Optimization approach that uses Double Auction Technique to calculate a market clearance price. The particularity of this price is that it is a competitive equilibrium point determined by both the seller and the buyer. This price constitutes a win-win situation as both sides of the deal could optimize their objective function at this point. This is unlike the traditional market pricing strategies where one side of the deal was left out. Table 7.10 shows the maximum, minimum and optimum values of the objective function for each of the eight cases.

\begin{tabular}{|c|c|c|c|c|c|c|c|c|c|}
\hline \multicolumn{2}{|c|}{} & \multicolumn{5}{|c|}{ SUMMER } & \multicolumn{4}{c|}{ WINTER } \\
\hline Function & Case & $\mathbf{1}$ & $\mathbf{2}$ & $\mathbf{3}$ & $\mathbf{4}$ & $\mathbf{5}$ & $\mathbf{6}$ & $\mathbf{7}$ & $\mathbf{8}$ \\
\hline \multirow{3}{*}{ Utility } & Min. & 168.6 & 240.94 & 206.42 & 134.42 & 326.4 & 256.71 & 360 & 153.22 \\
\cline { 2 - 10 } & Max. & 228.62 & 349.6 & 220.57 & 137.19 & 403.3 & 295.65 & 402.6 & 153.79 \\
\hline \multirow{3}{*}{ Cost } & Min. & 172.58 & 245.14 & 201.66 & 129.72 & 338.55 & 159.3 & 347.7 & 150.4 \\
\cline { 2 - 10 } & Max. & 208.95 & 320.53 & 224.4 & 141.51 & 485.18 & 373.19 & 513.72 & 158.11 \\
\hline $\begin{array}{l}\text { Competitive } \\
\text { Equilibrium }\end{array}$ & 181.1 & 262.24 & 214.7 & 139.45 & 368.83 & 269.12 & 394.05 & 156.34 \\
\hline
\end{tabular}

Table 7.10: Minimum, maximum and optimum values of the objective function per case 
It is evident that the optimum value falls between the maximum amount which is desired by the utility provider (seller) and the minimum which is desired by the community (buyer). This value ensures that both sides have their needs met:

- The seller has optimized the amount he is selling by adjusting its offered price to a level that satisfies the buyer. Higher prices mean lower traded amount as the buyer should minimize its cost function. Excessive cost reduction, on the other hand, may cause a drastic cut in the Utility Function of the seller and result in revenue loss due to higher production costs.

- The buyer has optimized its cost while fulfilling its balanced demand. Unlike in conventional cases, here the seller is not the sole player in determining the market price. The buyer has the advantage of participating in the price scheduling process and in return adjusting its demand to meet generation constraints of the seller.

Another notable point is that the optimized objective function value for case 4 and 8 , which denote the off-peak periods in summer and winter seasons respectively, are higher than the maximum amount of objective function for utility (Utility Function). This translates into higher benefit (revenue) for the seller as the objective function goes beyond its expected value. This is due to the fact that the intension of this optimization process, as explained in chapter 6 for household level optimization, is to maximize utilization of grid during off-peak periods to supply non-critical loads and storages in a household that are kept off-line in mid- or on-peak periods. The response time for this proposed approach should also be taken into account as well. The response time is one of the key performance indices for every approach. It is the time required to reach (calculate) the equilibrium point where the market clearance occurs. For a system to be efficient, the time required to calculate this point should be much shorter than the duration of the 
time slot. In the presented cases, the average computation time to reach the equilibrium point was $95 \mu$ s which is satisfactory. However, further investigation is needed to determine response time where more than one community is involved in the process. The calculated time is exclusive of the required time to transmit the data to both ends (utility and occupants) and receive the optimized values. Therefore, the total time required by the system to successfully calculate optimized values is comprised of processing time, i.e. $95 \mu \mathrm{s}$, plus the transmission time. This total time should be small enough compared to the time slot duration to give utility provider ample time to plan and deploy required actions. The response time for this level of optimization is more important compared to residential level since at community level, the target population for optimization is much bigger. At community level, distribution automation networks are the link between the utility provider and the optimization scheme residing in the substation thus, compatibility of the proposed scheme with the time requirements of industrial networks is also critical. Different bus structure protocols such as Modbus, Control Area Network (CAN), Asynchronous Serial Interface (ASI), Profibus and Foundation Field bus are used in recent SGs; these technologies can sustain data transmission rates of $1 \mathrm{Mb} / \mathrm{s}$ and above with some considerations in terms of number of supported nodes and length. It is likely that based on the characteristics of the automation network used at substation level, and the number of connected users, the processing time of the proposed optimization scheme needs improvement. 


\section{CHAPTER 8}

\section{LEVEL INTEGRATION}

\subsection{OVERVIEW}

This chapter discusses the integration of the two separate optimization processes at household and community levels described in chapters 6 and 7, respectively. The term "Integration" is sometimes misused instead of similar concepts in the literature such as aggregation, combination or fusion. The intention, in this chapter, is to combine the two levels of residential and community optimization to create a uniform system where the grid and end user have direct interaction: the buyer participates in the process of determining a fair price while helping the grid in adjusting its demand based on the current state of production at the utility end. The grid will also participate in the game by sharing its decision making authority on the price and will benefit from the users that effectively implement DSM by maximizing their DER utilization, therefor, relieving the pressure on the grid to supply the requested demand under all circumstances. Although according to the presented simulation results each of the proposed optimization schemes works properly as a stand-alone solution, the added benefit of combining the two levels would be a continuous process where each level will be fed by an optimized value as an input from the other level. Figure 8.1 depicts this relation. The link between the two levels insures that the processes of determining an equilibrium price at community level and adjusting demand 


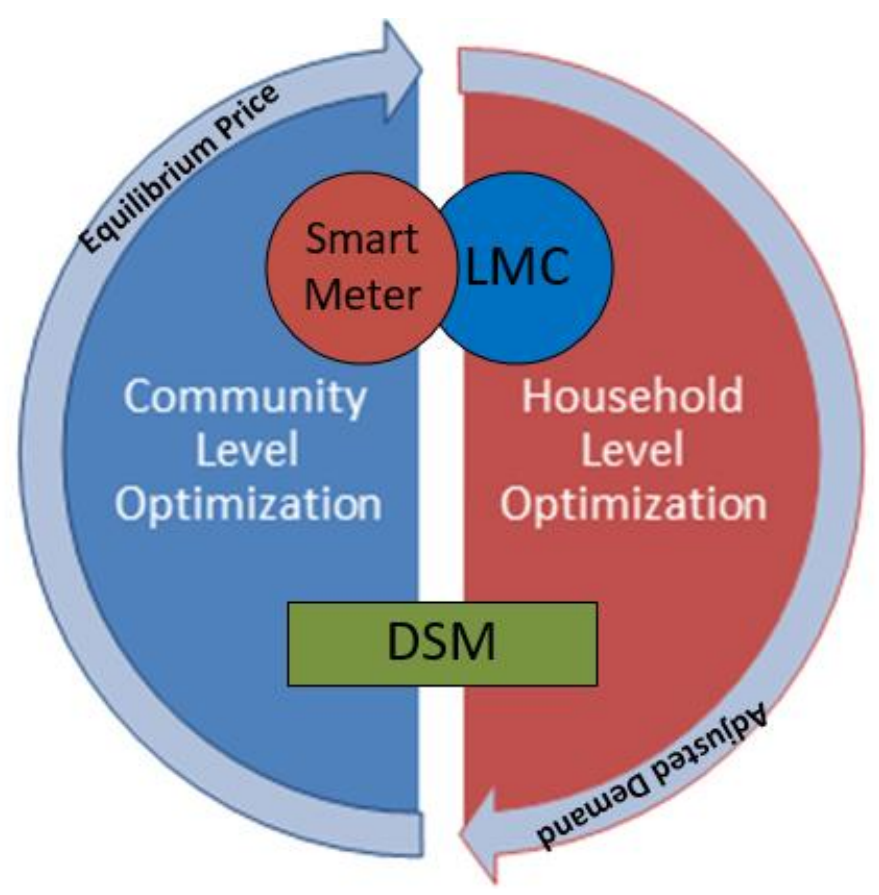

Fig. 8.1: Interaction between the two levels of optimization

based on grid generation status at household level are forged together rather than being in two different domains. Thus changes in one side trigger the reiteration of the optimization process on the other side to keep the optimal values valid for every given instant. The levels only take the values (outputs) from another level as an input to their process; no alteration or manipulation of values will be done in the linked system.

Three methods of integration have been explained in the literature, namely vertical, horizontal and star; with the vertical and horizontal ones have been more in the forefront. Vertical integration denotes integration based on the functionality of subsystems where the subsystems are not at the same stage or level in that specific process; however, they come together to realize a common goal. This is in contrast with horizontal integration where the subsystems are at the 
same level. In horizontal integration the objective is to improve the overall process by expanding functionalities of subsystems at the same level. Based on the provided explanation, the integration used in this work is closer in meaning to vertical integration.

The following section explains the assumptions made in combining the two levels, the method of integration and the simulation results for the overall system.

\subsection{INTEGRATION RESULTS}

In integration of the two optimization systems, all the assumptions and cases built and explained in chapters 6 and 7 are still valid. GA is selected as the method of choice for household level optimization and winter as the season. Tables 7.6 to 7.9 were used in the simulations. The program initiates by community level optimization module fetching information from the grid side and coming up with the initial offered price. This price will then be transferred to a "basket." Household level optimization module will be triggered at this point and will update its table of values, i.e., DER upper and lower bounds and status, active loads and required demand through LMC as well as picking up the initial offered price from the basket. The program then calculates the optimized values using GA method and transfers its balanced requested demand to another "basket" for utilization by community optimization module. The community module will pick this value from the basket and reiterates the process to come up with a counter offer for the price and supply. This process continues until a competitive equilibrium is achieved. It should be noted that the calculations will be done at the beginning of each time slot to determine the price, and demand and supply values for the next time slot. 
In order to have a better understanding of the performance of the combined system, new upper bounds for DER as well as the Grid have been used in this simulation:

- DER1: $\quad 5 \mathrm{KWh}$

- DER2: $4 \mathrm{KWh}$

- DER3: $2 \mathrm{KWh}$

- DER4: $1 \mathrm{KWh}$

- GRID: $\quad 30 \mathrm{KWh}$

Similar to the previous cases, the optimization process is independent of the units. The storage is considered to have a maximum capacity of $100 \mathrm{KWh}$ and its minimum should be kept at $20 \mathrm{KWh}$ (20\%) at all times. The initial storage value is assumed to be $20 \mathrm{KWh}$. Table 8.1 shows the calculated values using the integrated optimization scheme.

In our simulation scenario, the maximum DER generation capacity is $12 \mathrm{KWh}$. This is a dynamic value which changes with the situation, i.e., the time of the day, the weather, user preferences, the working capability of the DER, etc. The program is capable of updating this value without any interruption in the optimization process. The update takes place at the beginning of each iteration when household level module fetches information to update its table of values.

\begin{tabular}{|c|c|c|c|c|c|c|c|c|}
\hline $\begin{array}{c}\text { Demand } \\
(\mathbf{K W h})\end{array}$ & $\begin{array}{c}\text { Equilibrium } \\
\text { Market Price } \\
\left(\boldsymbol{P}_{\boldsymbol{e}}\right) \text { per KWh } \\
(\boldsymbol{c})\end{array}$ & $\begin{array}{c}\text { Preferred } \\
\text { Price }\left(\boldsymbol{P}_{\boldsymbol{p}}\right) \\
\text { per KWh } \\
(\boldsymbol{c})\end{array}$ & $\begin{array}{c}\text { DER1 } \\
(\mathbf{K W h})\end{array}$ & $\begin{array}{c}\text { DER2 } \\
(\mathbf{K W h})\end{array}$ & $\begin{array}{c}\text { DER3 } \\
(\mathbf{K W h})\end{array}$ & $\begin{array}{c}\text { DER4 } \\
(\mathbf{K W h})\end{array}$ & $\begin{array}{c}\text { GRID } \\
(\mathbf{K W h})\end{array}$ & $\begin{array}{c}\text { Storage } \\
(\mathbf{K W h})\end{array}$ \\
\hline 16.92 & 10.2 & 10.77 & 5.0000 & 4.0000 & 2.0000 & 1.0000 & 30.0000 & 45.0800 \\
\hline 16.71 & 11.2 & 10.77 & 5.0000 & 4.0000 & 2.0000 & 1.0000 & - & 40.3700 \\
\hline 16.13 & 12.2 & 10.77 & 5.0000 & 4.0000 & 2.0000 & 1.0000 & - & 36.2400 \\
\hline 15.83 & 13.2 & 10.77 & 5.0000 & 4.0000 & 2.0000 & 1.0000 & - & 32.4100 \\
\hline
\end{tabular}




\begin{tabular}{|c|c|c|c|c|c|c|c|c|}
\hline 17.51 & 14 & 15.08 & 5.0000 & 4.0000 & 2.0000 & 1.0000 & 30.0000 & 56.9000 \\
\hline 17.40 & 15 & 15.08 & 5.0000 & 4.0000 & 2.0000 & 1.0000 & 30.0000 & 81.5000 \\
\hline 17.25 & 16 & 15.08 & 5.0000 & 4.0000 & 2.0000 & 1.0000 & - & 76.2500 \\
\hline 17.16 & 17 & 15.08 & 5.0000 & 4.0000 & 2.0000 & 1.0000 & - & 71.0900 \\
\hline 17.05 & 18 & 15.08 & 5.0000 & 4.0000 & 2.0000 & 1.0000 & - & 66.0400 \\
\hline 16.87 & 19 & 15.08 & 5.0000 & 4.0000 & 2.0000 & 1.0000 & - & 61.1700 \\
\hline 16.92 & 16.5 & 16.8 & 5.0000 & 4.0000 & 2.0000 & 1.0000 & 30.0000 & 86.2500 \\
\hline 16.71 & 17 & 16.8 & 5.0000 & 4.0000 & 2.0000 & 1.0000 & - & 86.2500 \\
\hline 17.05 & 8.3 & 8.445 & 4.9979 & 3.9937 & 1.9985 & 0.9981 & 23.5216 & 100 \\
\hline 16.96 & 8.4 & 8.445 & 5.0000 & 4.0000 & 2.0000 & 1.0000 & - & 95.0400 \\
\hline 15.99 & 8.5 & 8.445 & 5.0000 & 4.0000 & 2.0000 & 1.0000 & - & 91.0500 \\
\hline 14.52 & 8.6 & 8.445 & 5.0000 & 4.0000 & 2.0000 & 1.0000 & - & 88.5300 \\
\hline 13.38 & 8.7 & 8.445 & 5.0000 & 4.0000 & 2.0000 & 1.0000 & - & 87.1500 \\
\hline 13.46 & 8.8 & 8.445 & 5.0000 & 4.0000 & 2.0000 & 1.0000 & - & 85.6900 \\
\hline 12.90 & 8.9 & 8.445 & 5.0000 & 4.0000 & 2.0000 & 1.0000 & - & 84.7900 \\
\hline 12.65 & 9 & 8.445 & 5.0000 & 4.0000 & 2.0000 & 1.0000 & - & 83.5900 \\
\hline 12.55 & 9.1 & 8.445 & 5.0000 & 4.0000 & 2.0000 & 1.0000 & - & 82.8200 \\
\hline 12.77 & 9.2 & 8.445 & 5.0000 & 4.0000 & 2.0000 & 1.0000 & - & 81.0500 \\
\hline 13.77 & 9.3 & 8.445 & 5.0000 & 4.0000 & 2.0000 & 1.0000 & - & 81.0500 \\
\hline 13.8 & 9.4 & 8.445 & 5.0000 & 4.0000 & 2.0000 & 1.0000 & - & 76.5000 \\
\hline
\end{tabular}

Table 8.1: Simulation results of the integrated optimization approach case 1

LMC is responsible to keep the table up-to-date. The advantage of this approach is that each change in the DER's status will be immediately reflected in the calculations and the demandsupply-price set will be kept up-to-date for the next time slot. The optimization logic is as follows:

- If $P_{p}>P_{e}$, then the neighbourhood is willing to fulfill the deficit of the demand as well as fully charging the storage for future use. Non critical loads within the household could be supplied at this stage. 
- If $P_{p}<P_{e}$, the grid should be avoided as much as possible. If the DER generation is less than that of the demand, then the storage will kick in. If the storage level is over its defined minimum (i.e., 20\%), the storage will be utilized to supply the deficit. Grid will be used when the storage capacity is not enough to answer the deficit or it is below the minimum level.

In Table 8.1, the first row shows that the demand is $16.92 \mathrm{KWh}$, equilibrium price is $\phi 10.2$ and the preferred price is $\phi 10.77$. In this case, logically, the buyer should maximize its purchase from the grid. It is clear that in this case maximum DER capacity is $4.92 \mathrm{KWh}$ short from the total demand, and the storage is at $20 \mathrm{KWh}$. Therefore, the buyer will purchase $30 \mathrm{KWh}$ (maximum availability) from the grid. Here, the $4.92 \mathrm{KWh}$ deficit in demand will be compensated from the purchased $30 \mathrm{KWh}$ and the remaining $25.08 \mathrm{KWh}$ is used to charge the storage to $45.08 \mathrm{KWh}$.

The second row of Table 8.1 shows that the price has increased; therefore, the equilibrium price is now higher than the preferred price. In this case the user is not willing to buy unless demand exceeds the DER maximum generation capacity and the storage level is not high enough to supply the deficit. As the demand $(16.71 \mathrm{KWh})$ is less than the maximum DER capacity $(12 \mathrm{KWh})$ plus the storage level $(45.08 \mathrm{KWh}$ at the end of previous time slot), the grid is not used at this time slot. The same logic has been implemented throughout the 24-hour duration of a typical winter day, divided into 24 one-hour time slots and the results are shown in Table 8.1.

Table 8.1 presents the results for a tailored scenario where the grid alone has a generation capacity greatly higher than the maximum demand from the community (30KWh generation vs. $17.51 \mathrm{KWh}$ maximum demand) and total maximum generation capacity of DER (12KWh) is fairly close to the maximum demand of neighbourhood as well. In this case, the grid has been 
used during off-peak times or when the equilibrium price is lower than the expected price of the buyers mainly to charge the storage to its maximum capacity for utilization in future. These conclusions are evident in Table 8.1 where grid utilization has been limited to 5 time slots and the storage level stayed at $76.5 \mathrm{KWh}$ at the end of the day compared to its $20 \mathrm{KWh}$ at the beginning of the day. This could be a normal scenario during the days that weather condition allows for considerable power generation from RE sources and there is no need for excessive cooling or heating inside the houses, resulting in reduced demand and availability of unused capacity at utility provider end. To further examine the performance of a combined system, an opposite scenario has been simulated where the DER and Grid generation capacities are low compared to the maximum demand and storage level is at its minimum. The upper bounds of sources have been changed as follows to echo the situation:

- DER1: $\quad 3(\mathrm{KWh})$

- DER2: $1 \mathrm{KWh}$

- DER3: $5 \mathrm{KWh}$

- DER4: OKWh

- GRID: $\quad 10 \mathrm{KWh}$

All other assumptions remain the same as the previous case. Table 8.2 presents the results.

\begin{tabular}{|c|c|c|c|c|c|c|c|c|}
\hline $\begin{array}{c}\text { Demand } \\
(\mathbf{M W})\end{array}$ & $\begin{array}{c}\text { Equilibrium } \\
\text { Market Price } \\
\left(\boldsymbol{P}_{\boldsymbol{e}}\right) \text { per KWh } \\
(\boldsymbol{k})\end{array}$ & $\begin{array}{c}\text { Preferred } \\
\text { Price }\left(\boldsymbol{P}_{\boldsymbol{p}}\right) \\
\mathbf{p e r} \mathbf{K W h} \\
(\boldsymbol{c})\end{array}$ & $\begin{array}{c}\text { DER1 } \\
(\mathbf{K W h})\end{array}$ & $\begin{array}{c}\text { DER2 } \\
(\mathbf{K W h})\end{array}$ & $\begin{array}{c}\text { DER3 } \\
(\mathbf{K W h})\end{array}$ & $\begin{array}{c}\text { DER4 } \\
(\mathbf{K W h})\end{array}$ & $\begin{array}{c}\text { GRID } \\
(\mathbf{K W h})\end{array}$ & $\begin{array}{c}\text { Storage } \\
(\mathbf{K W h})\end{array}$ \\
\hline 16.92 & 10.2 & 10.77 & 3.0000 & 1.0000 & 5.0000 & 0 & 10.0000 & 22.0800 \\
\hline 16.71 & 11.2 & 10.77 & 3.0000 & 0.9999 & 4.9961 & 0 & 5.6338 & 20.0000 \\
\hline 16.13 & 12.2 & 10.77 & 3.0000 & 0.9990 & 4.9629 & 0 & 7.1681 & 20.0000 \\
\hline
\end{tabular}




\begin{tabular}{|l|c|c|c|c|c|c|c|c|}
\hline 15.83 & 13.2 & 10.77 & 3.0000 & 0.9998 & 4.9998 & 0 & 6.8304 & 20.0000 \\
\hline 17.51 & 14 & 15.08 & 3.0000 & 1.0000 & 5.0000 & 0 & 10.0000 & 21.4900 \\
\hline 17.40 & 15 & 15.08 & 3.0000 & 1.0000 & 5.0000 & 0 & 10.0000 & 23.0900 \\
\hline 17.25 & 16 & 15.08 & 2.9970 & 1.0000 & 4.9991 & 0 & 5.1639 & 20.0000 \\
\hline 17.16 & 17 & 15.08 & 2.9996 & 0.9994 & 4.9984 & 0 & 8.1626 & 20.0000 \\
\hline 17.05 & 18 & 15.08 & 3.0000 & 0.9988 & 4.9974 & 0 & 8.0536 & 20.0000 \\
\hline 16.87 & 19 & 15.08 & 3.0000 & 0.9980 & 5.0000 & 0 & 7.8719 & 20.0000 \\
\hline 16.92 & 16.5 & 16.8 & 3.0000 & 1.0000 & 5.0000 & 0 & 10.0000 & 22.0800 \\
\hline 16.71 & 17 & 16.8 & 3.0000 & 0.9999 & 4.9999 & 0 & 5.6302 & 20.0000 \\
\hline 17.05 & 8.3 & 8.445 & 3.0000 & 1.0000 & 5.0000 & 0 & 10.0000 & 21.9500 \\
\hline 16.96 & 8.4 & 8.445 & 3.0000 & 1.0000 & 5.0000 & 0 & 10.0000 & 23.9900 \\
\hline 15.99 & 8.5 & 8.445 & 3.0000 & 1.0000 & 4.8957 & 0 & 3.1042 & 20.0000 \\
\hline 14.52 & 8.6 & 8.445 & 3.0000 & 1.0000 & 5.0000 & 0 & 5.5200 & 20.0000 \\
\hline 13.38 & 8.7 & 8.445 & 3.0000 & 0.0998 & 4.9992 & 0 & 4.3802 & 20.0000 \\
\hline 13.46 & 8.8 & 8.445 & 3.0000 & 0.9998 & 4.9992 & 0 & 4.4610 & 20.0000 \\
\hline 12.90 & 8.9 & 8.445 & 3.0000 & 1.0000 & 4.9996 & 0 & 3.9004 & 20.0000 \\
\hline 12.65 & 9 & 8.445 & 2.9976 & 1.0000 & 4.9999 & 0 & 3.6523 & 20.0000 \\
\hline 12.55 & 9.1 & 8.445 & 3.0000 & 0.9985 & 4.9999 & 0 & 3.5516 & 20.0000 \\
\hline 12.77 & 9.2 & 8.445 & 3.0000 & 1.0000 & 4.9997 & 0 & 3.7703 & 20.0000 \\
\hline 13.77 & 9.3 & 8.445 & 3.0000 & 0.9988 & 4.9999 & 0 & 4.7713 & 20.0000 \\
\hline 13.8 & 9.4 & 8.445 & 2.9994 & 0.9999 & 4.9975 & 0 & 4.8029 & 20.0000 \\
\hline
\end{tabular}

Table 8.2: Simulation results of the integrated optimization approach case 2

The results presented in Table 8.2 show that DER utilization is still at its maximum while unlike previous scenario, the grid has been used extensively. Despite extensive use of grid, the system minimized the requested amount from the grid and its maximum capacity (10KWh) has been consumed in few time slots. This is in line with our expectation since the total maximum DER generation is significantly lower than the maximum community demand (9KWh vs. $17.51 \mathrm{KWh}$ ). 
It is also evident that due to the deficit in DER generation as well as reduced capacity of the grid, storage level remained, more or less, at its minimum during the day.

\subsection{CONCLUSION}

The outcome of the integrated optimization approach, based on the defined scenarios, presented in Tables 8.1 and 8.2 shows that:

- The absolute maximum capacity of the DER has been utilized in the time slots

- Grid utilization has been limited to minimum based on the availability of RE generation capacity, storage level and actual demand from the consumer

- The minimum storage level maintained at $32.4 \%$ and $20 \%$ for each case respectively after the optimization

These findings are in line with the expectations and prove that the combination of the adopted GA optimization at household level and GTO method based on double auction approach at community level can provide the required output.

In the process of combining the two optimization methods no further feature or capability has been added to the procedure and each level performs its operation independently. The advantage of combining the two levels is in obtaining a continuous, consistent and interconnected optimization process. Such interconnection allows for the transfer of values from one level (output) to the other (input) in real-time and guarantees reflecting the changes in status of each and every player (e.g. DER, grid, consumer demand, etc.) in the optimized values by reiterating the calculations upon observation of the change. This capability would enable the Smart Grids of 
future to effectively implement DSM initiatives, extensively incorporate and utilize DER, take advantage of local storages, improve the quality of delivered power and minimize their down times due to failures in the system resulted from excessive pressure for generation during peak times. 
Ryerson University Chapter 9: CONCLUSION AND FUTURE WORKS 2017

\section{CHAPTER 9}

\section{CONCLUSION AND FUTURE WORKS}

\subsection{CONCLUSIONS}

The research presented in chapters 3 and 4 reveals that the DSM initiatives based on maximum utilization of DER at residential units have the potential to curtail the peak demand. By incorporating storage systems in the LMC, and by eliminating or minimizing the direct supply of loads inside a house through grid, the undetectability of load signatures at SM points are expected. Based on the plan laid out in chapter 2 and by introduction of LMC, two levels of optimization were designed and carried out for households and communities in chapters 6 and 7, respectively. Simulations at each level and under various conditions showed satisfactory results that match the expectation and objective of the work as suggested by case studies. Integration of the two optimization layers, presented in chapter 8 , provided a continuous optimization mechanism that enables seller-buyer interaction and keeps the optimized values up-to-date as the conditions change. The author believes that the strength of the approach proposed in this thesis has roots in three facts:

- Utilization of two independent optimization schemes at two consecutive levels. Human capability in making decisions on how to prioritize consumption or allocate sources to loads is profoundly limited. This limitation is due to the fact that there are numerous parameters involved in the process of decision making and without the help of computer aided algorithms, it is very difficult, if not impossible, to perform the required calculations and come up with the proper decision in real-time or near real-time intervals. 
- Incorporation of GTO, which is an optimization technique designed for demand and supply in different markets, will improve the precision of the optimization process at the community level.

- Utilization of DER at residential units, in other words as close to the loads as possible, will significantly reduce the technical complexity associated with them in SG. This reduced complexity will lead to increased desire from home owners to employ such systems in their households. Home owners can exploit DER technologies at lower cost at their end, partially relieving the providers from the financial burden.

It is anticipated that by maximizing the presence of RE and storages in the supply-demand chain of residential units, as per the approach presented in this thesis, the main objectives laid out in chapters 2 and 3 will be realized:

1. Effective deployment of DSM at users' end

2. Maximizing utilization of DER at residential units

3. Eliminating the risk of consumer profiling by making load signatures of the devices undetectable

4. Realization of win-win market strategy for sellers and buyers.

There are some key factors that should be considered in the design of the LMC and overall system implementation in order to have a fully functional system, successful in the market and acceptable by users. These factors could be summarized as follows:

- Interoperability of LMC: LMC's hardware and software should be able to work with other systems or products, such as BMS, without special effort from the customer. This could be achieved by adhering to published interface standards or using modules that can convert LMC interface into another product's interface on the fly

- Considering market dominant networking protocols and single bus structure for power and data transmission inside LMC 
- Improving and automating the process of calculating weighting matrix for residential level optimization

- Optimizing the time required for community level optimization process including equilibrium point calculation and data transmission time

- Considering practical constraints in power generation and transmission as well as storage systems that affect implementation of the required actions derived from the proposed decision making scheme. Examples include limitation in size of the storage system, rapid change in bringing generators on or off line, etc.

- Considering the capital costs for equipment, e.g. roof top PV systems, LMC, storage, etc. in the overall costs of implementation of the proposed solution and calculating the savings accordingly

\subsection{FUTURE WORKS}

Smart Grid and its related technologies have been at the center of attention of many researchers from different backgrounds for many years. The interdisciplinary nature of SG attracted engineers and scientists from IT, management, computer science, automation and instrumentation, power systems, economics and mathematics domains as well as strategists, policy makers and politicians. Therefore, the perspective of future works in SG looks vast and promising. Based on the approach introduced and explained in this thesis, the areas for future work include, but are not limited to, the following:

- Hardware development and fabrication of LMC for embedding the proposed optimization method in the device

- Clustering or forming "coalitions" among utility providers as sellers on one side and communities as buyers on the other side

- Incorporation of predictive models at household level

- Incorporation of Big Data and cloud computing capabilities in the LMC 


\section{REFERENCES}

[1] Mohassel RR, Fung A, Mohammadi F, Raahemifar K. A survey on advanced metering infrastructure. International Journal of Electrical Power \& Energy Systems. 2014 Dec 31; 63:473-84.

[2] Momoh JA. Smart grid design for efficient and flexible power networks operation and control. In Power Systems Conference and Exposition, 2009. PSCE'09. IEEE/PES 2009 Mar 15, pp. 1-8.

[3] The History of Electrification: The Birth of our Power Grid, Edison Tech Center. [online] Available at: http://edisontechcenter.org/ HistElectPowTrans.html, accessed November, 2013.

[4] http://www.sensorsuite.com/blog/, accessed September 2014.

[5] Navigant Consulting Ltd. for EnerCare Connections Inc. Evaluation of the Impact of Sub-Metering on Multi residential Electricity Consumption and the Potential Economic and Environmental Impact on Ontario, 2012.

[6] National Science and Technology Council Committee on Technology. Submetering of Building Energy and Water Usage, 2011.

[7] Balijepalli VM, Pradhan V, Khaparde SA, Shereef RM. Review of demand response under smart grid paradigm. In Innovative Smart Grid Technologies-India (ISGT India), 2011 IEEE PES, 2011 Dec 1, pp. 236-243.

[8] National Institute of Standard and Technology (NIST). Guidelines for Smart Grid Cyber Security, in Privacy and the smart grid, Vol. 2, 2010.

[9] National Energy Technology Laboratory for the U.S. Department of Energy. Advanced Metering Infrastructure, NETL Modern Grid Strategy, 2008.

[10] SAIC Smart Grid Team for The Energy Policy Initiatives Center, University of San Diego School of Law, "San Diego Smart Grid Study Final Report,” 2006.

[11] Mohassel RR, Fung AS, Mohammadi F, Raahemifar K. A survey on advanced metering infrastructure and its application in Smart Grids. In Electrical and Computer Engineering (CCECE), 2014 IEEE 27th Canadian Conference on 2014 May 4, pp. 1-8. 
[12] Electric Power Research Institute (EPRI). Advanced Metering Infrastructure (AMI), 2007.

[13] Mohassel RR, Fung A, Mohammadi F, Raahemifar K. Application of Advanced Metering Infrastructure in Smart Grids. In Control and Automation (MED), 2014 22nd Mediterranean Conference of 2014 Jun 16, pp. 822-828.

[14] Depuru SS, Wang L, Devabhaktuni V. Smart meters for power grid: Challenges, issues, advantages and status. Renewable and sustainable energy reviews. 2011 Aug 31;15(6):2736-42.

[15] Deign J. and Salazar C.M. Data Management and Analytics for Utilities, FC Business Intelligence Ltd., 2013.

[16] Anderson D, Zhao C, Hauser C, Venkatasubramanian V, Bakken D, Bose A. Intelligent Design" Real-Time Simulation for Smart Grid Control and Communications Design. IEEE Power and Energy Magazine. 2012 Jan;10(1):49-57.

[17] Cohen R. Is cloud computing really cheaper? Forbes, August 2012, [online] Available at: http://www.forbes.com/sites/reuvencohen/2012/08/03/is-cloud-computingreally-cheaper, accessed September 2014.

[18] Erol-Kantarci M, Mouftah HT. Wireless sensor networks for cost-efficient residential energy management in the smart grid. IEEE Transactions on Smart Grid. 2011 Jun;2(2):314-25.

[19] http://www.cogeneration.net/Demand_Side_Management.htm, accessed September 2015.

[20] Sustainable Energy Regulation and Policymaking for Africa, [online] Available at: http://africa-toolkit.reeep.org/modules/Module14.pdf, accessed September 2015.

[21] Saini S. Power Position in Ontario - The growing need of Demand-Side Management, January 2004, [online] Available at: http://www.intelligentutility.com/article/04/01/power-position-ontario-growing-needdemand-side-management, accessed September 2015.

[22] The Bureau of Energy Efficiency (BEE), Ministry of Power, India [online] Available at: http://bee-dsm.in/DSMTheory_1.aspx, accessed September 2015. 
[23] International Institute for Energy Conservation (IIEC). Demand Side Management Best Practices Guidebook, July 2006.

[24] Atikol U. Energy Management \& Utilization, Chapter 5: Utility Demand-Side Management," Eastern Mediterranean University Open Courseware, [online] Available at: http://opencourses.emu.edu.tr/pluginfile.php/4476/mod_resource/content/1/ME547UA-CH5-DSM-2013.pdf, accessed September 2015.

[25] Delgado RM, Stitt JR, Chamberlin JH, Flory J. Load Management-How Will Operators Want to Use it. IEEE Transactions on Power Apparatus and Systems. 1983 Jun;102(6).

[26] Gonen T. Electric Power Distribution System Engineering, McGraw Hill, 1986

[27] Embracing The Internet of Everything, Cisco and/or its affiliates 2013, [online] Available at: http://www.cisco.com/web/about/ac79/docs/innov/IoE_Economy.pdf, Accessed January 2014.

[28] Ogwumike C, Short M, Abugchem F. Heuristic optimization of consumer electricity costs using a generic cost model. Energies. 2015 Dec 23;9(1):6.

[29] MathWorks Documentation [online] Available at: http://in.mathworks.com/help/gads/performing-a-genetic-algorithm-optimization.html

[30] Lim TY. Structured population genetic algorithms: a literature survey. Artificial Intelligence Review. 2014 Mar 1;41(3):385-99.

[31] Van Laarhoven PJ, Aarts EH. Simulated annealing. In Simulated Annealing: Theory and Applications 1987 (pp. 7-15). Springer Netherlands.

[32] Bozchalui MC, Hashmi SA, Hassen H, Cañizares CA, Bhattacharya K. Optimal operation of residential energy hubs in smart grids. IEEE Transactions on Smart Grid. 2012 Dec;3(4):1755-66.

[33] Ramabhotla S, Bayne S, Giesselmann M. Operation and Maintenance Cost Optimization in the Grid Connected Mode of Microgrid. In Green Technologies Conference (GreenTech), 2016 IEEE 2016 Apr 6, pp. 56-61.

[34] Hosseini SM. Optimization of Microgrid Using Quantum Inspired Evolutionary Algorithm. International Journal of Intelligent Systems and Applications. 2014 Aug $1 ; 6(9): 47$. 
[35] Adewole AP, Otubamowo K, Egunjobi TO, Ng KM. A comparative study of simulated annealing and genetic algorithm for solving the travelling salesman problem. International Journal of Applied Information Systems (IJAIS). 2012;4(4):6-12.

[36] Kirschen DS, Strbac G. Fundamentals of power system economics. John Wiley \& Sons; 2004 Oct 22.

[37] Bompard E, Ma YC, Napoli R, Gross G, Guler T. Comparative analysis of game theory models for assessing the performances of network constrained electricity markets. IET generation, transmission \& distribution. 2010 Mar;4(3):386-99.

[38] Wang G, Kowli A, Negrete-Pincetic M, Shafieepoorfard E, Meyn S. A control theorist's perspective on dynamic competitive equilibria in electricity markets. IFAC Proceedings Volumes. 2011 Jan 31;44(1):4933-8.

[39] Ramos A, Ventosa M, Rivier M. Modeling competition in electric energy markets by equilibrium constraints. Utilities Policy. 1999 Feb 28;7(4):233-42.

[40] Hobbs BF, Metzler CB, Pang JS. Strategic gaming analysis for electric power systems: An MPEC approach. IEEE transactions on power systems. 2000 May;15(2):638-45.

[41] Baldick R. Electricity market equilibrium models: The effect of parametrization. IEEE Transactions on Power Systems. 2002 Nov;17(4):1170-6.

[42] Smith VL, Williams AW, Bratton WK, Vannoni MG. Competitive market institutions: Double auctions vs. sealed bid-offer auctions. The American Economic Review. 1982 Mar 1;72(1):58-77.

[43] Trebicka B. Imperfect Markets, Imperfect Competition and Basic Model. Mediterranean Journal of Social Sciences. 2014 Oct 11;5(16):706.

[44] Saad W, Han Z, Poor HV, Başar T. A noncooperative game for double auctionbased energy trading between PHEVs and distribution grids. In Smart Grid Communications (SmartGridComm), 2011 IEEE International Conference on 2011 Oct 17, pp. 267-272.

[45] Fuller JC, Schneider KP, Chassin D. Analysis of residential demand response and double-auction markets. In Power and Energy Society General Meeting, 2011 IEEE 2011 Jul 24, pp. 1-7. 
[46] Block C, Neumann D, Weinhardt C. A market mechanism for energy allocation in micro-chip grids. In Hawaii International Conference on System Sciences, Proceedings of the 41st Annual 2008 Jan 7, pp. 172-172. 